NIST NCSTAR 1-5B

Federal Building and Fire Safety Investigation of the World Trade Center Disaster

\title{
Experiments and Modeling of Structural Steel Elements Exposed to Fire
}

\section{(Appendices D-G)}

\author{
Anthony Hamins \\ Alexander Maranghides \\ Kevin B. McGrattan \\ Erik L. Johnsson \\ Thomas J. Ohlemiller \\ Michelle K. Donnelly \\ Jiann C. Yang \\ George W. Mulholland \\ Kuldeep R. Prasad \\ Scott R. Kukuck \\ Robert L. Anleitner \\ Therese P. McAllister
}





\section{Appendix D \\ Velocity MeAsurementS AT THE COMPARTMENT INLET AND \\ OUTLET}

This appendix presents data on the inlet and outlet velocities and the corresponding corrected temperature measurements that was not presented in Chapter 7 of this report (sec Figs. D-1 through D-42). Further information on these measurements can be found in Chapter 7.

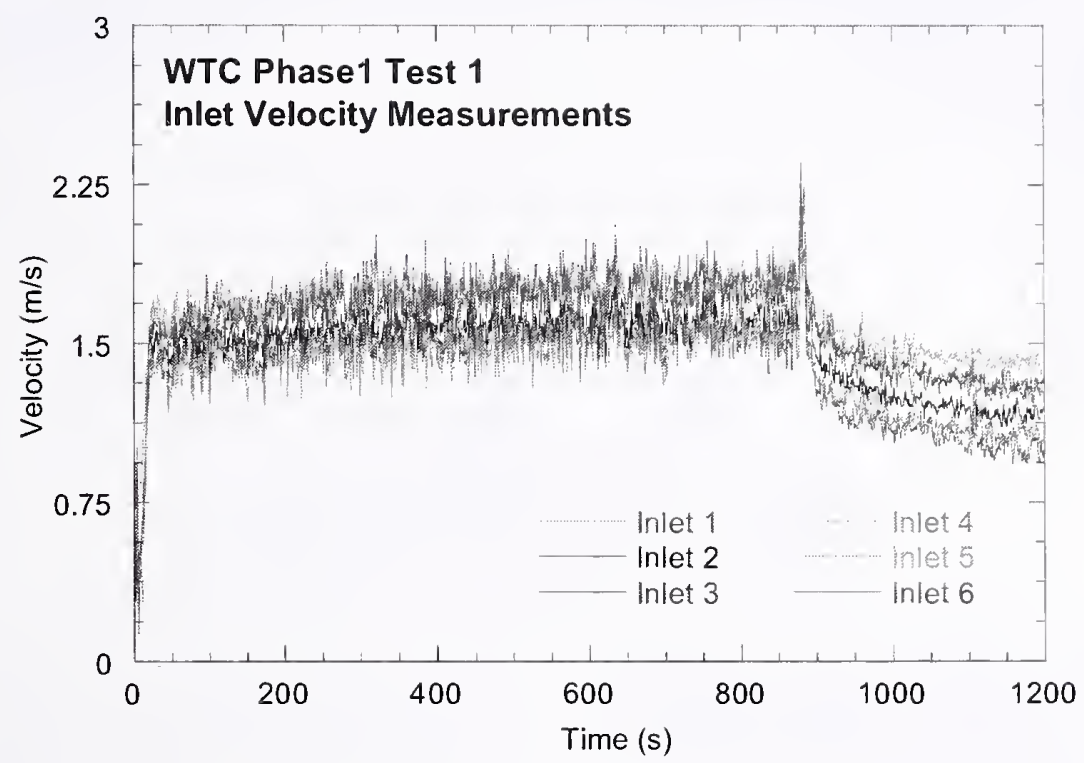

Figure D-1. Inlet velocities for Test 1.

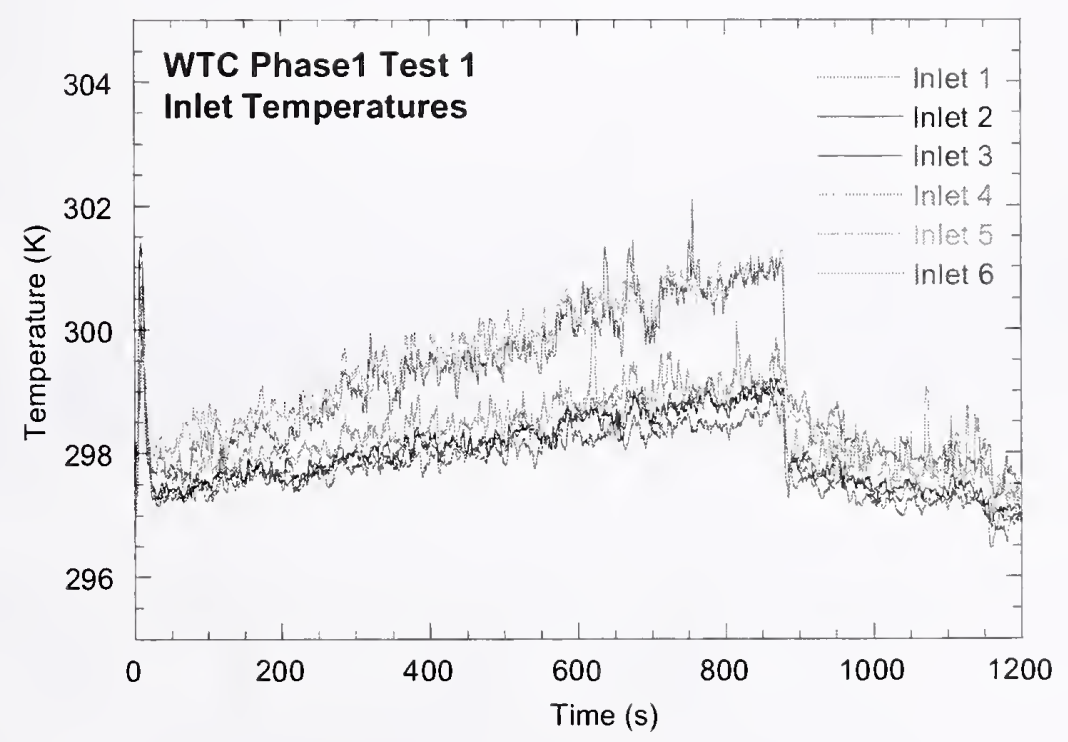

Figure D-2. Inlet temperatures for Test 1. 


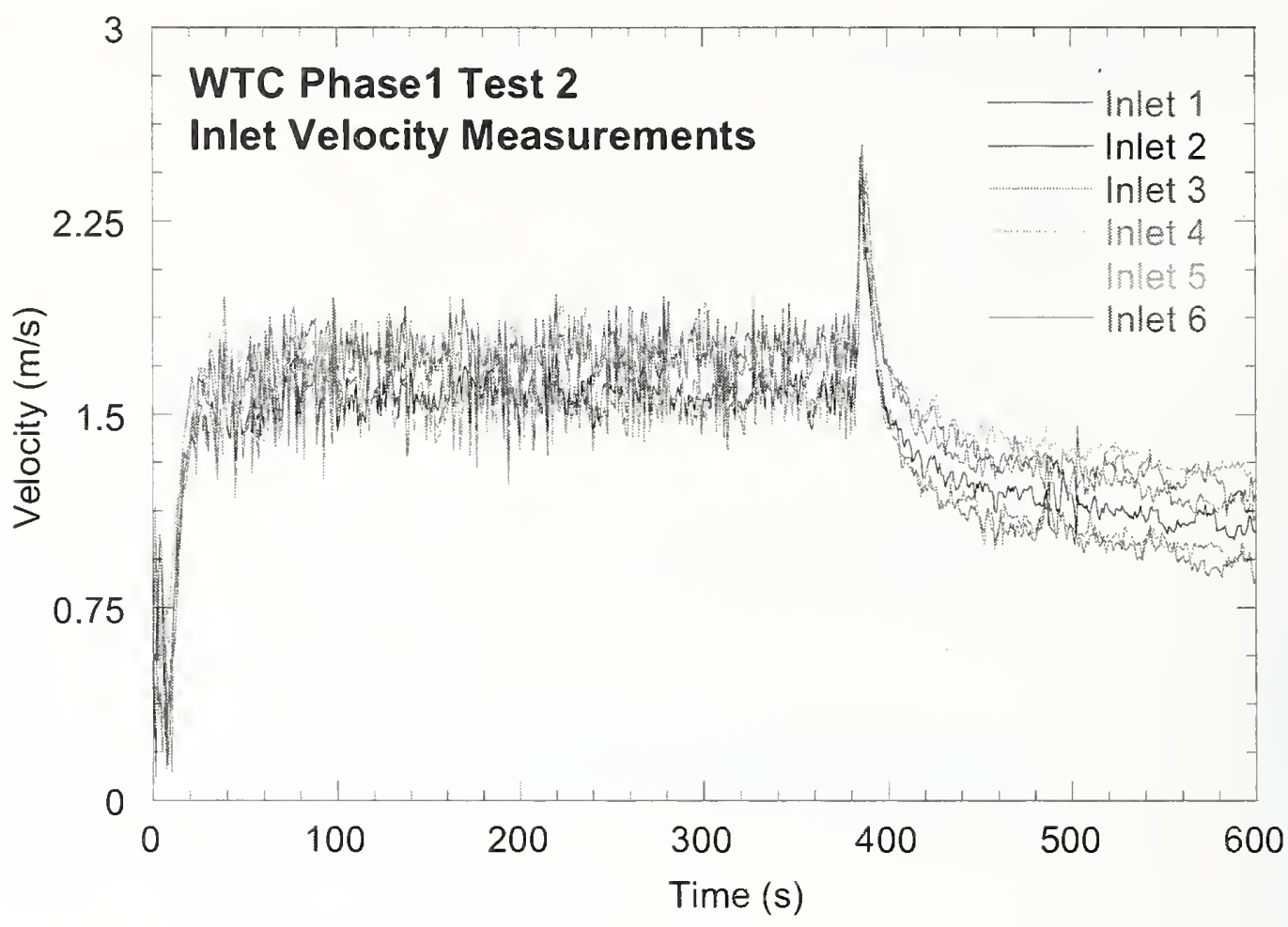

Figure D-3. Inlet velocities for Test 2.

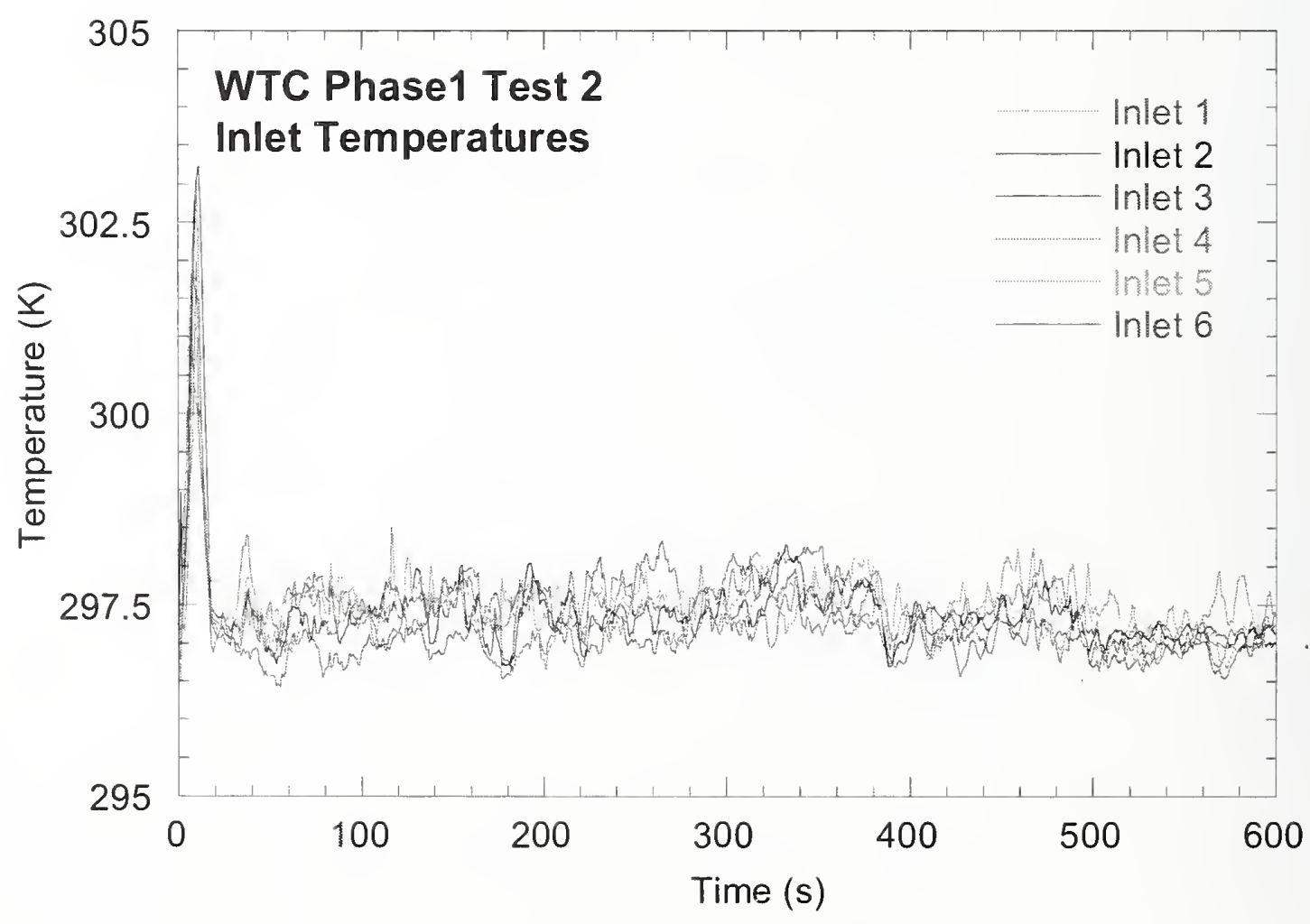

Figure D-4. Inlet temperatures for Test 2. 


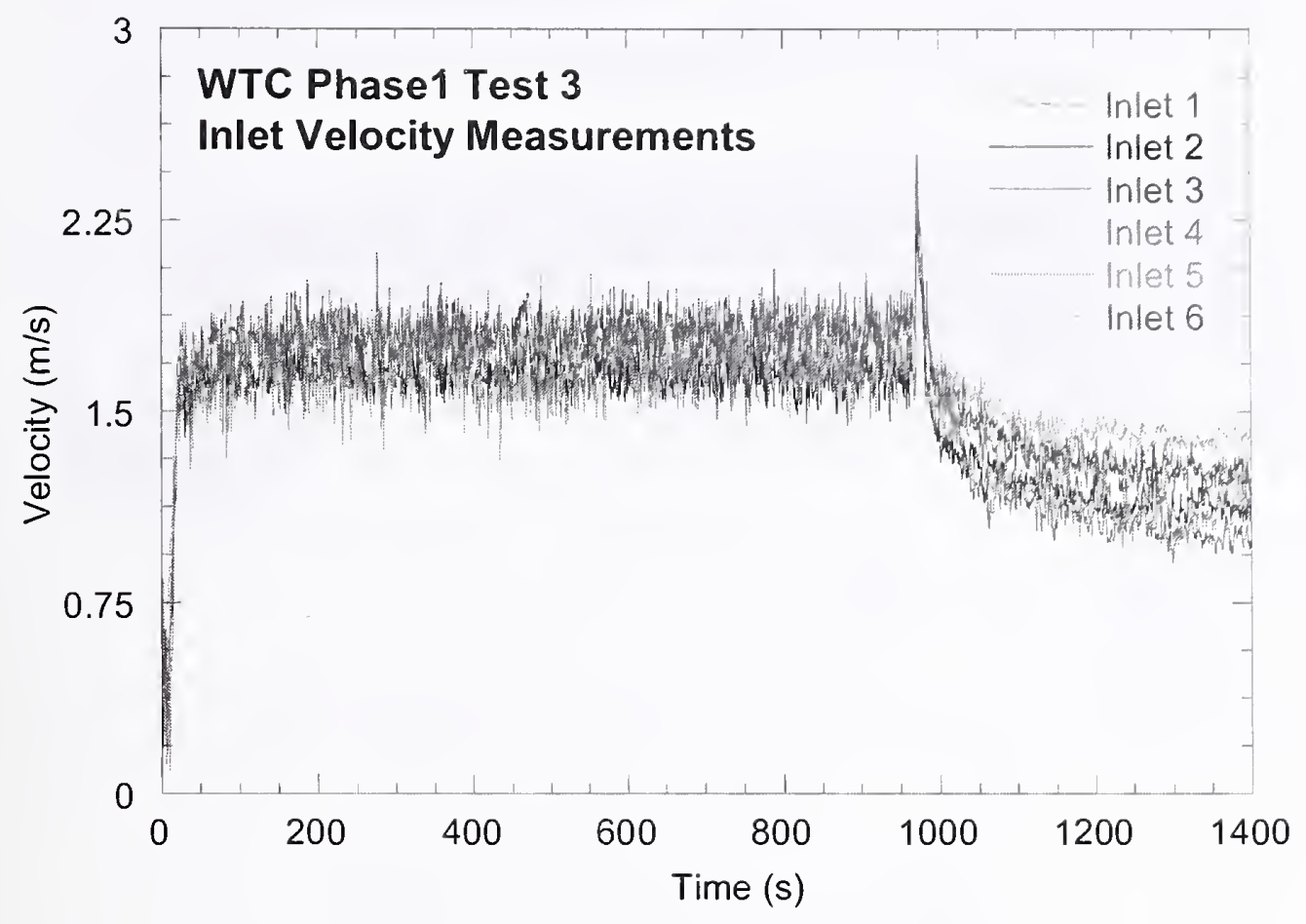

Figure D-5. Inlet velocities for Test 3.

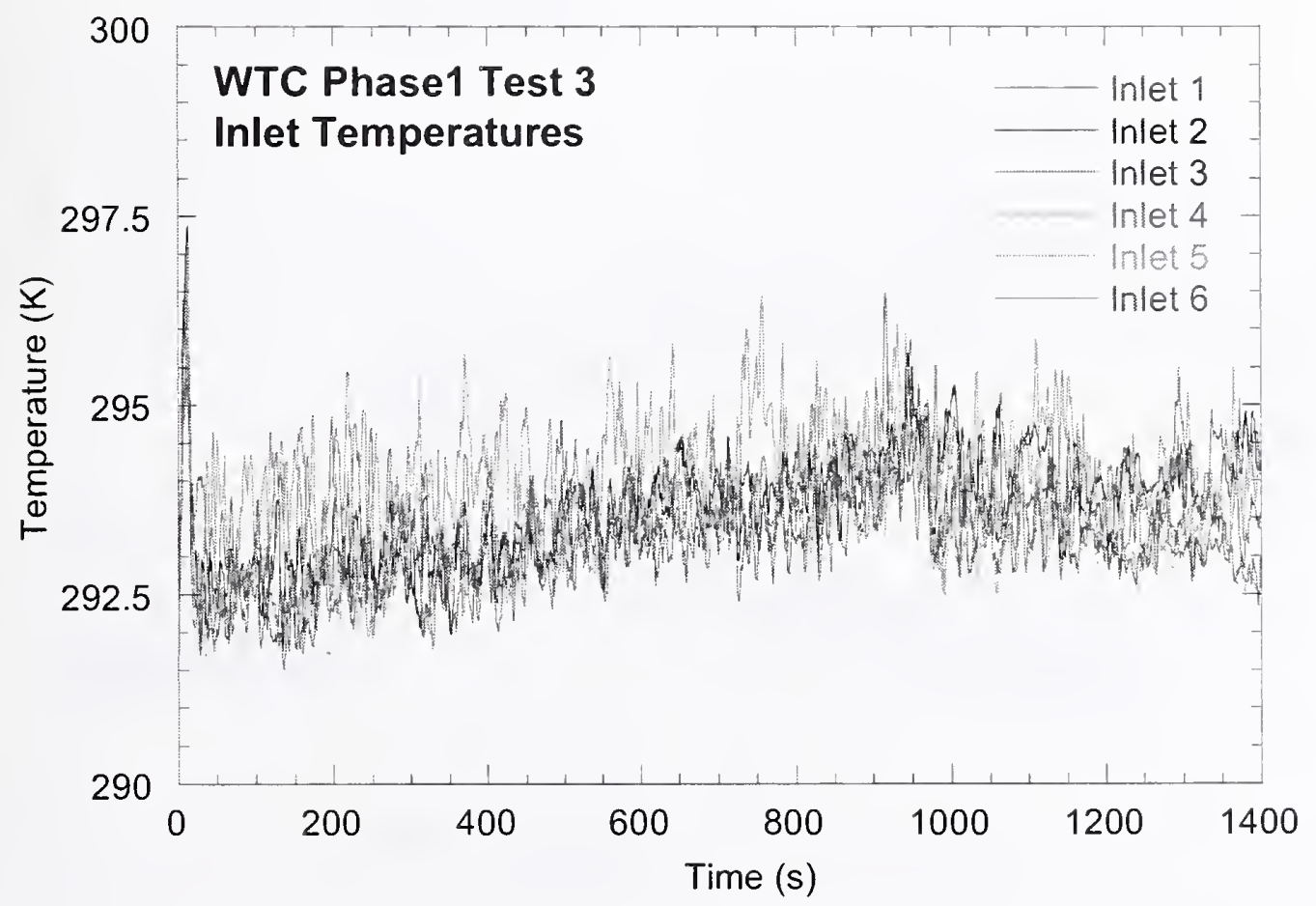

Figure D-6. Inlet temperatures for Test 3. 


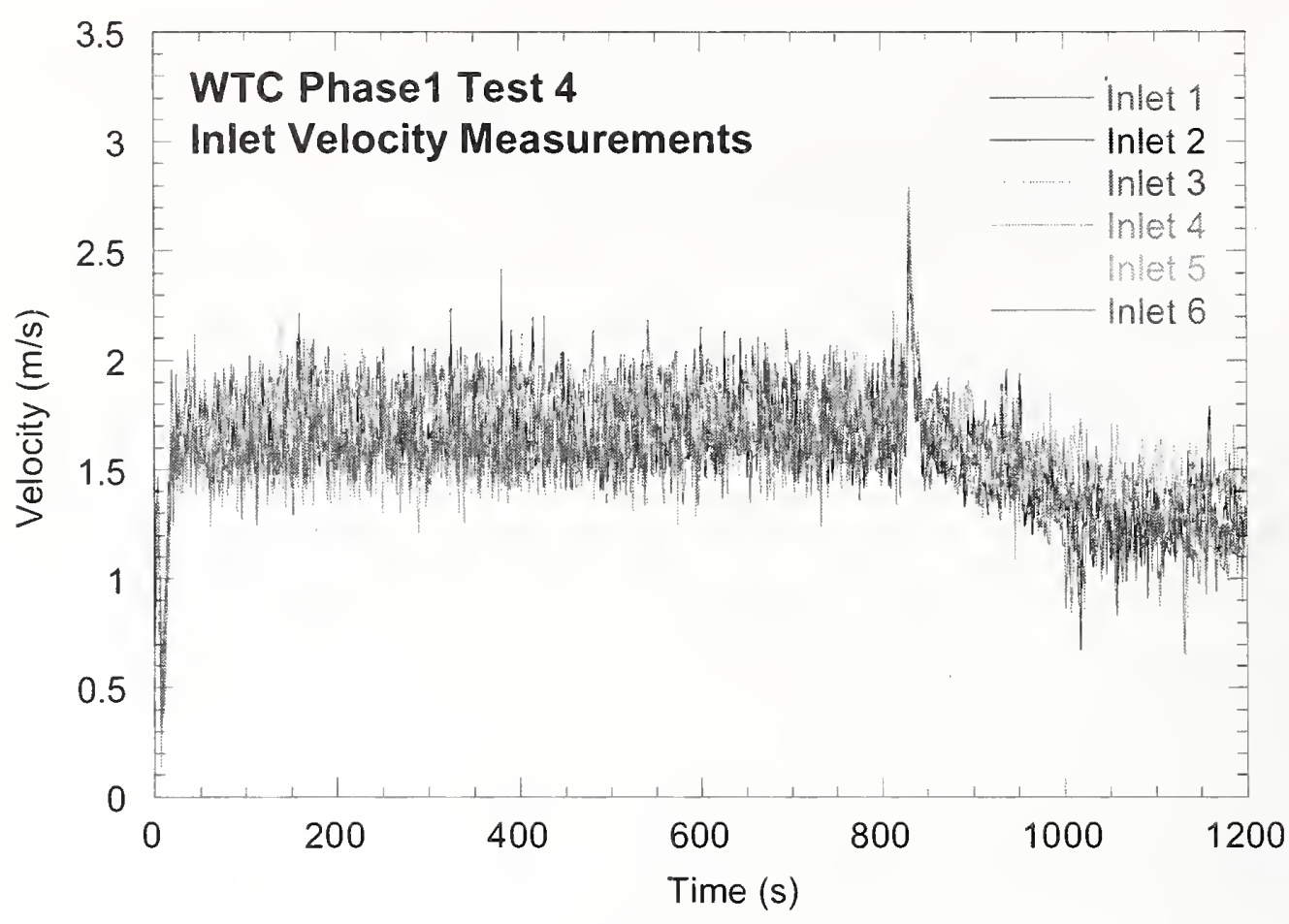

Figure D-7. Inlet velocities for Test 4.

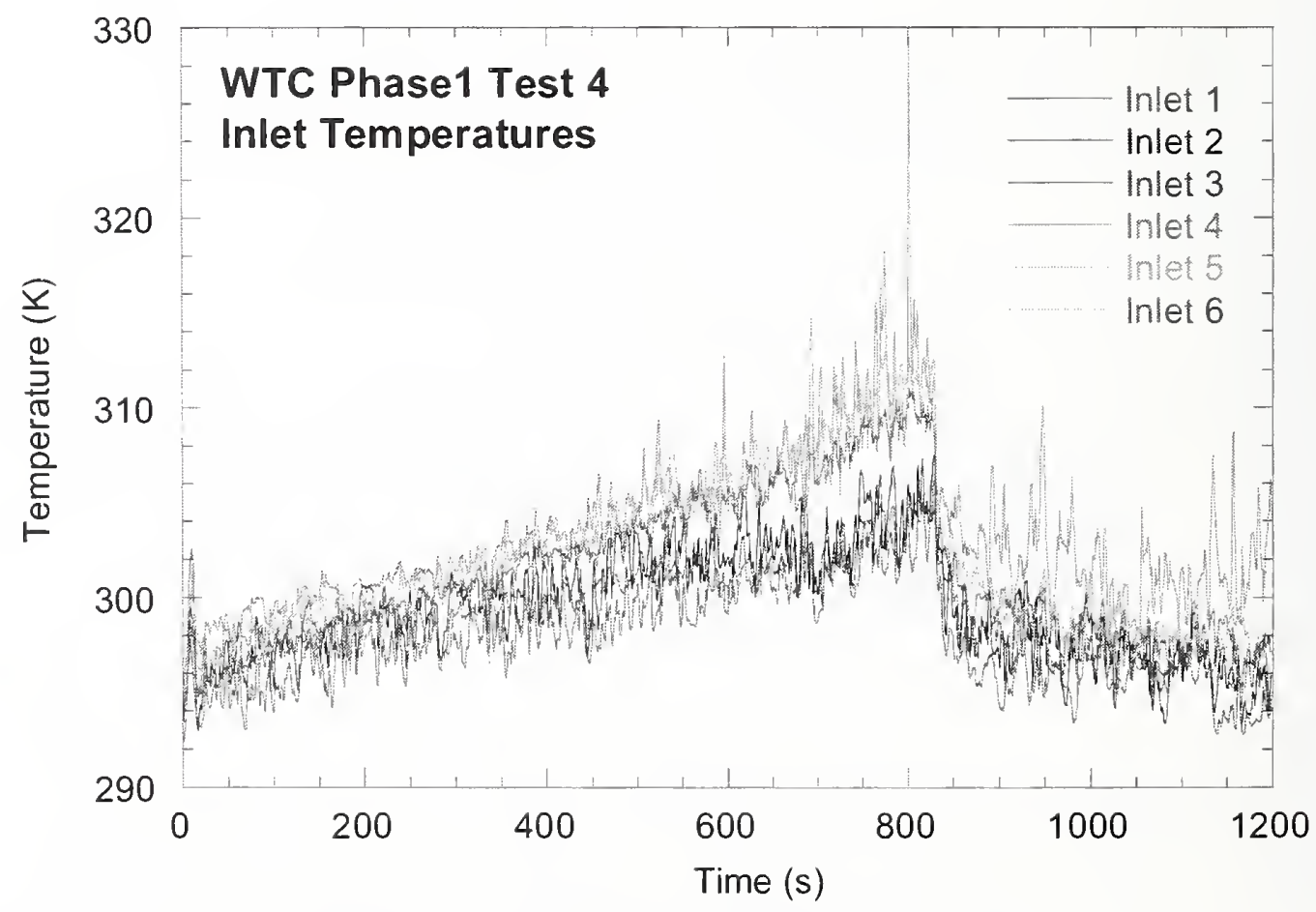

Figure D-8. Inlet temperatures for Test 4. 


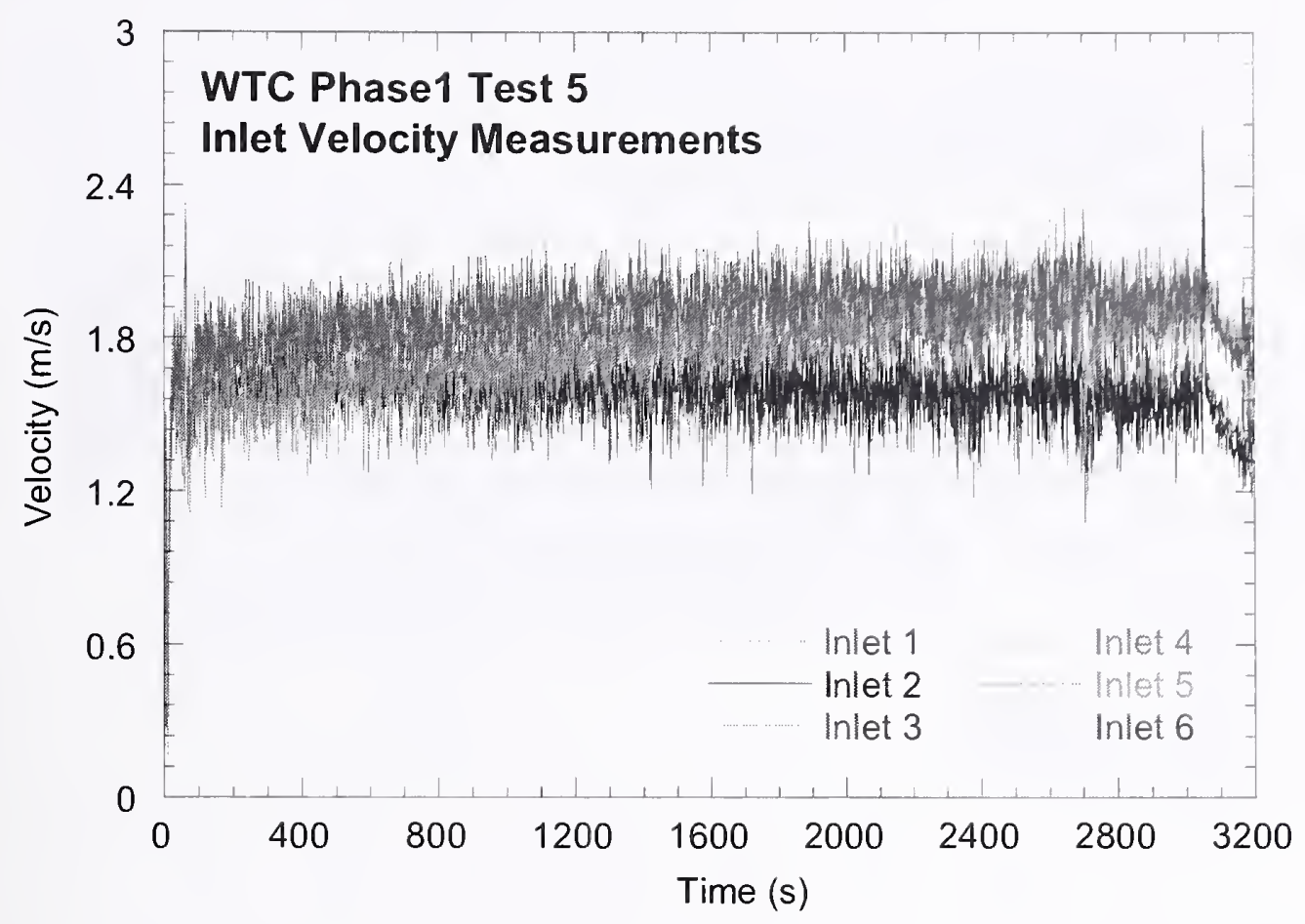

Figure D-9. Inlet velocities for Test 5.

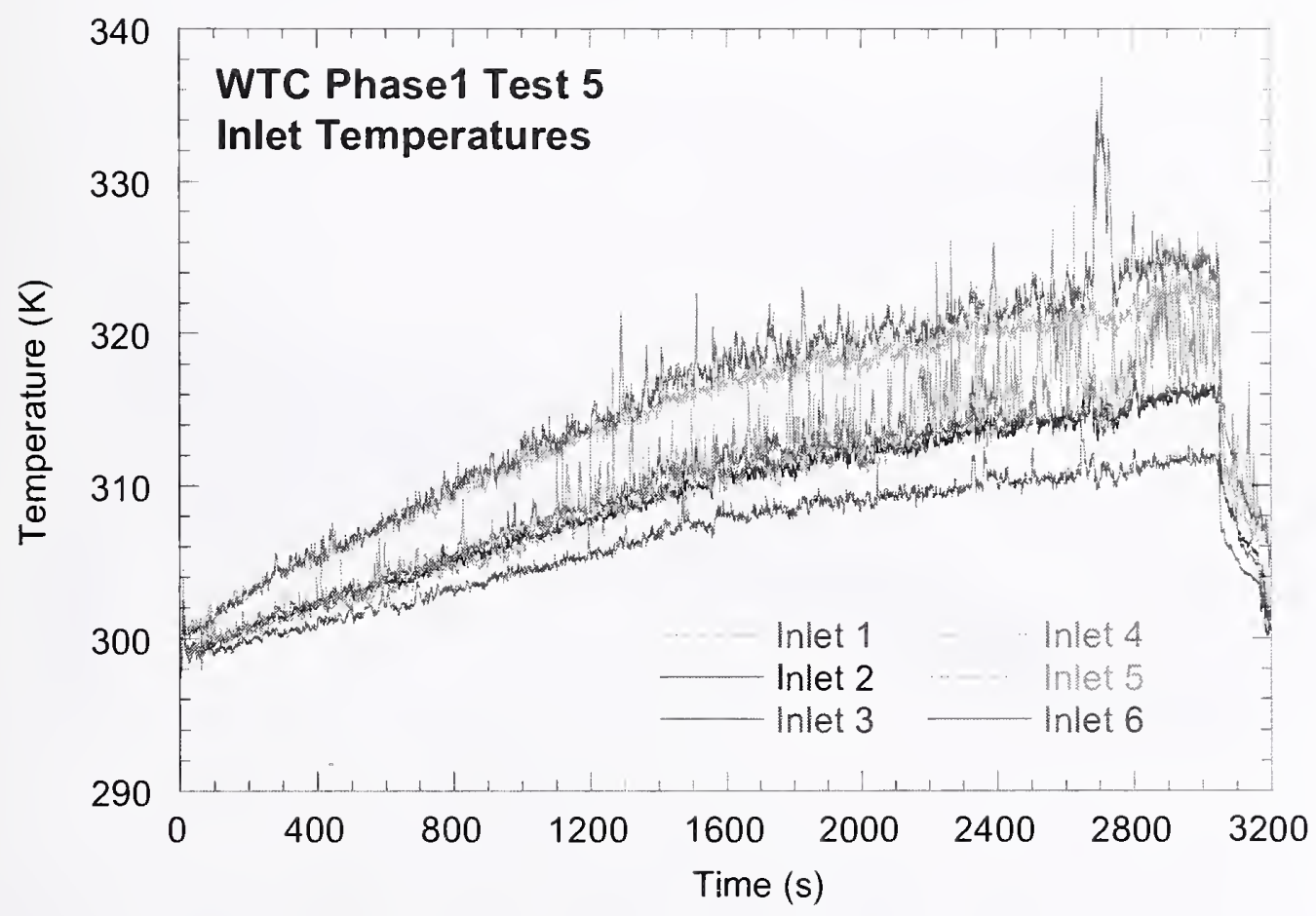

Figure D-10. Inlet temperatures for Test 5. 


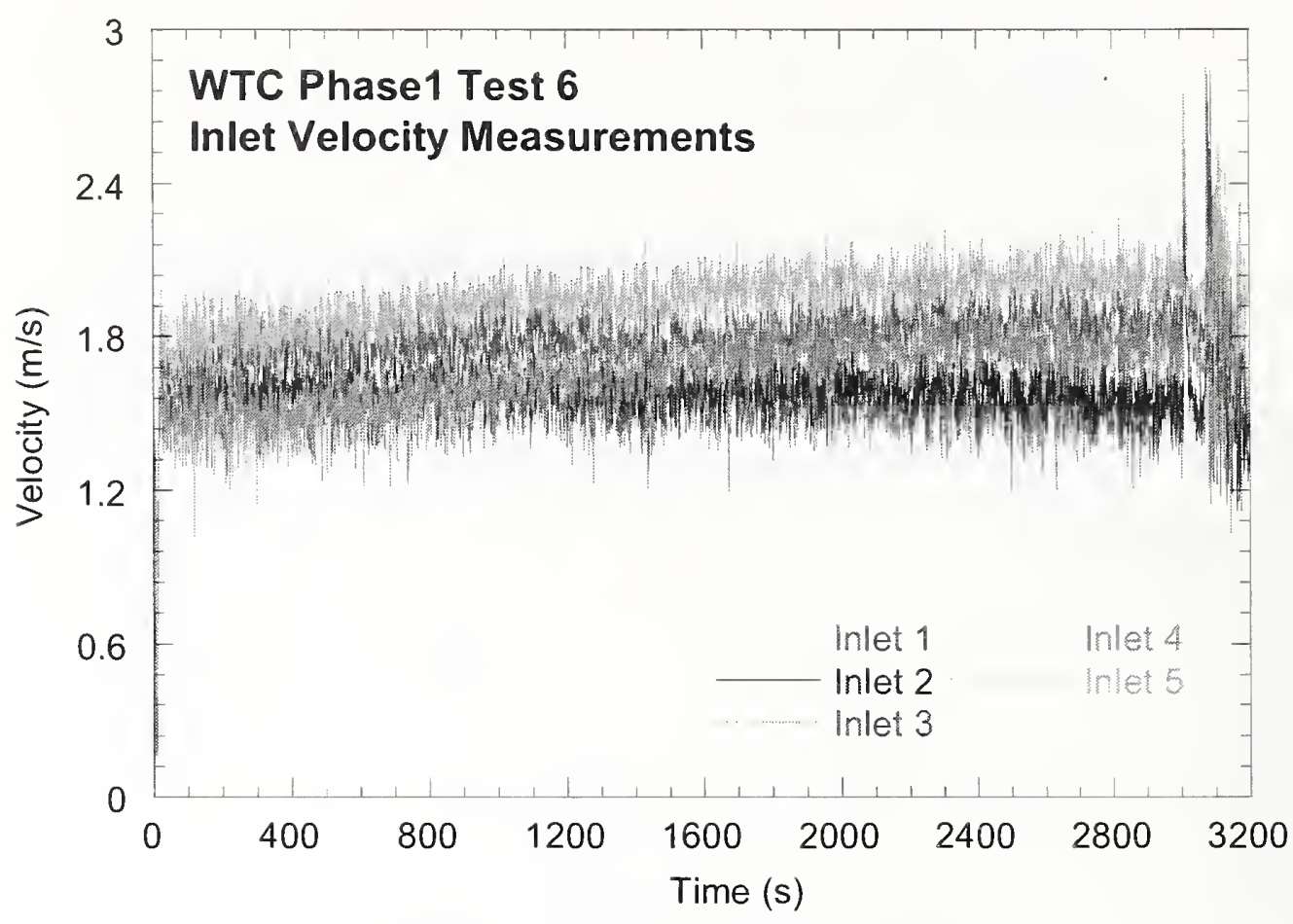

Figure D-11. Inlet velocities for Test 6.

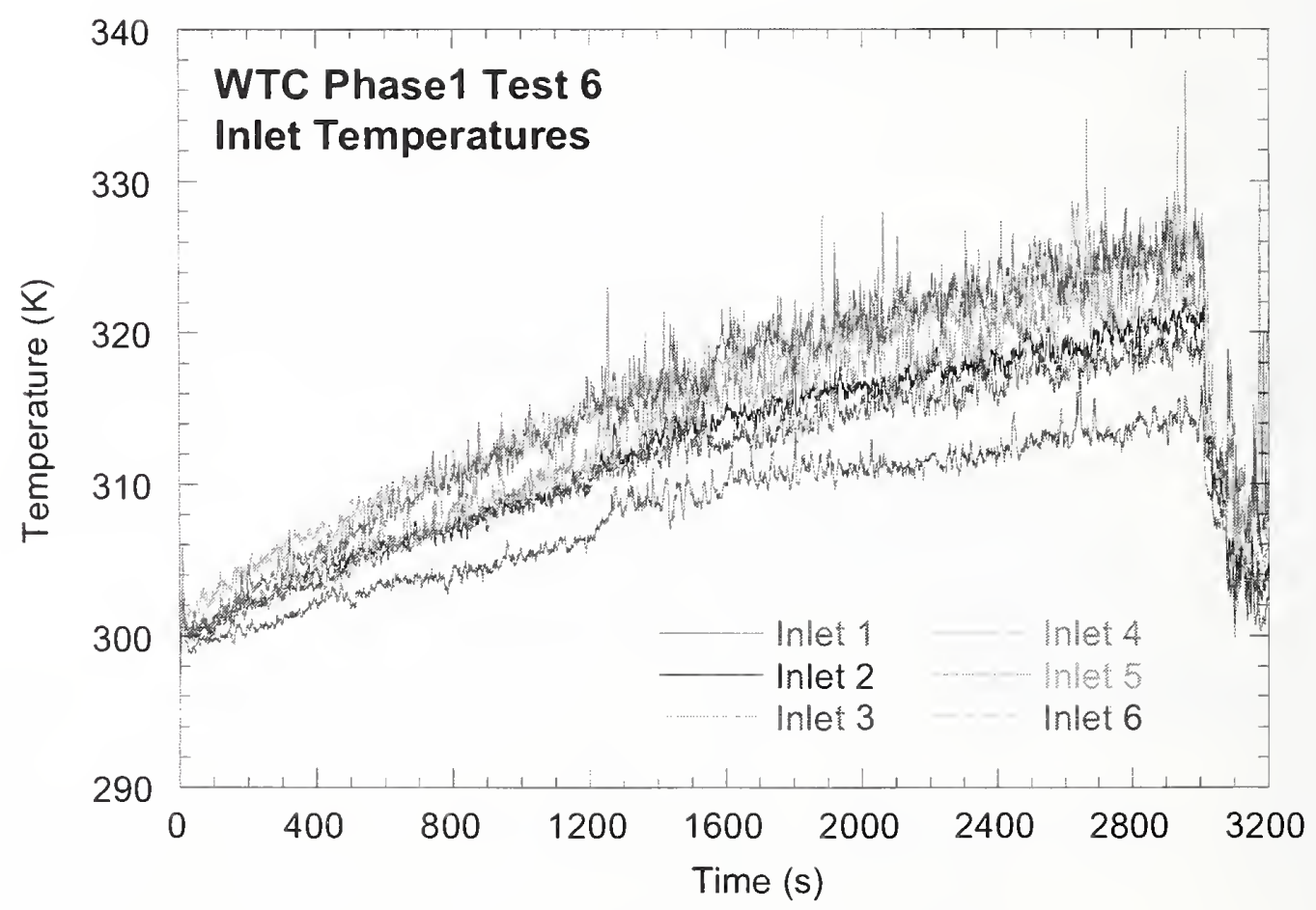

Figure D-12. Inlet temperatures for Test 6. 


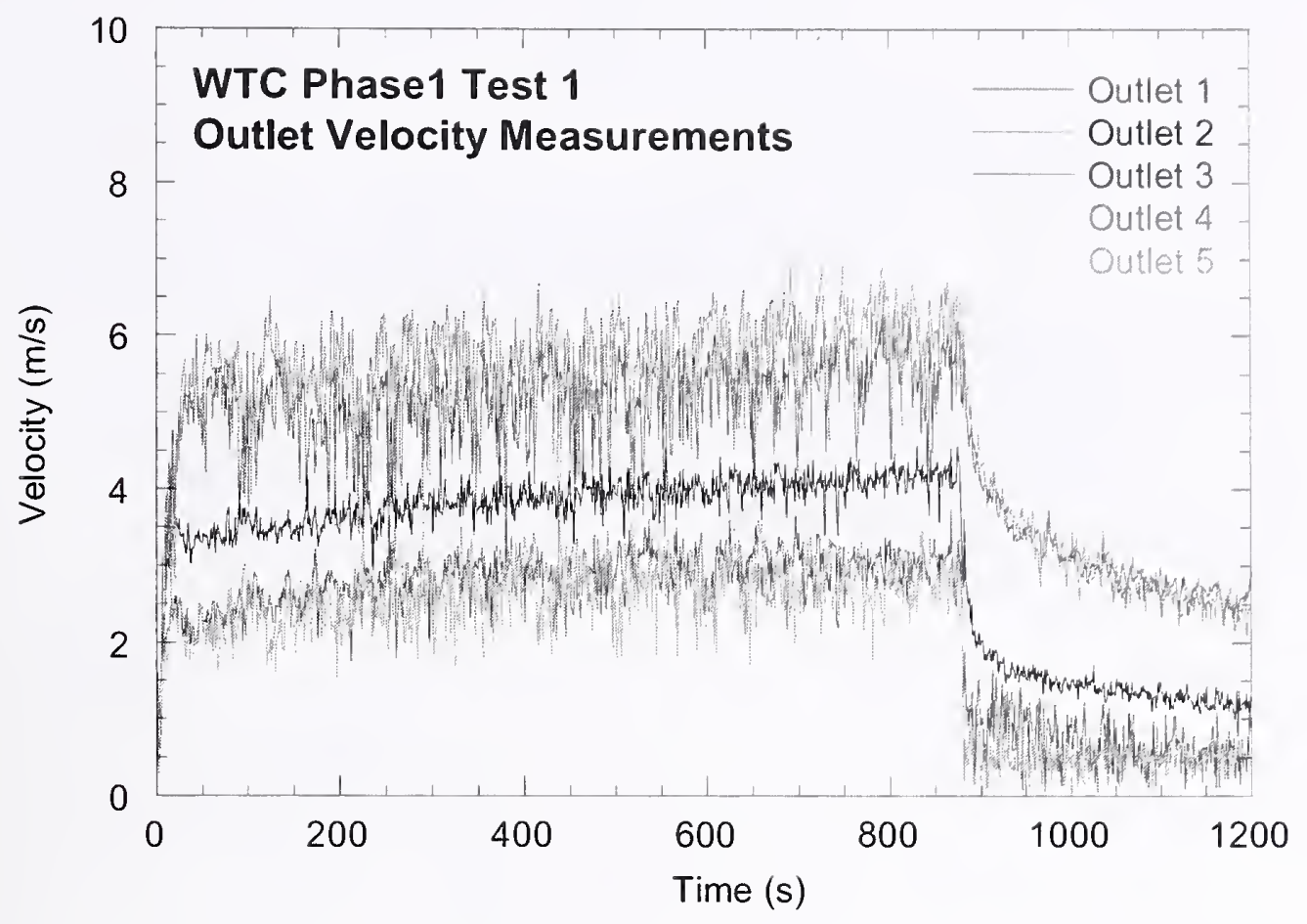

Figure D-13. Outlet velocities for Test 1, outlet locations 1, 2, 3, 4, and 5.

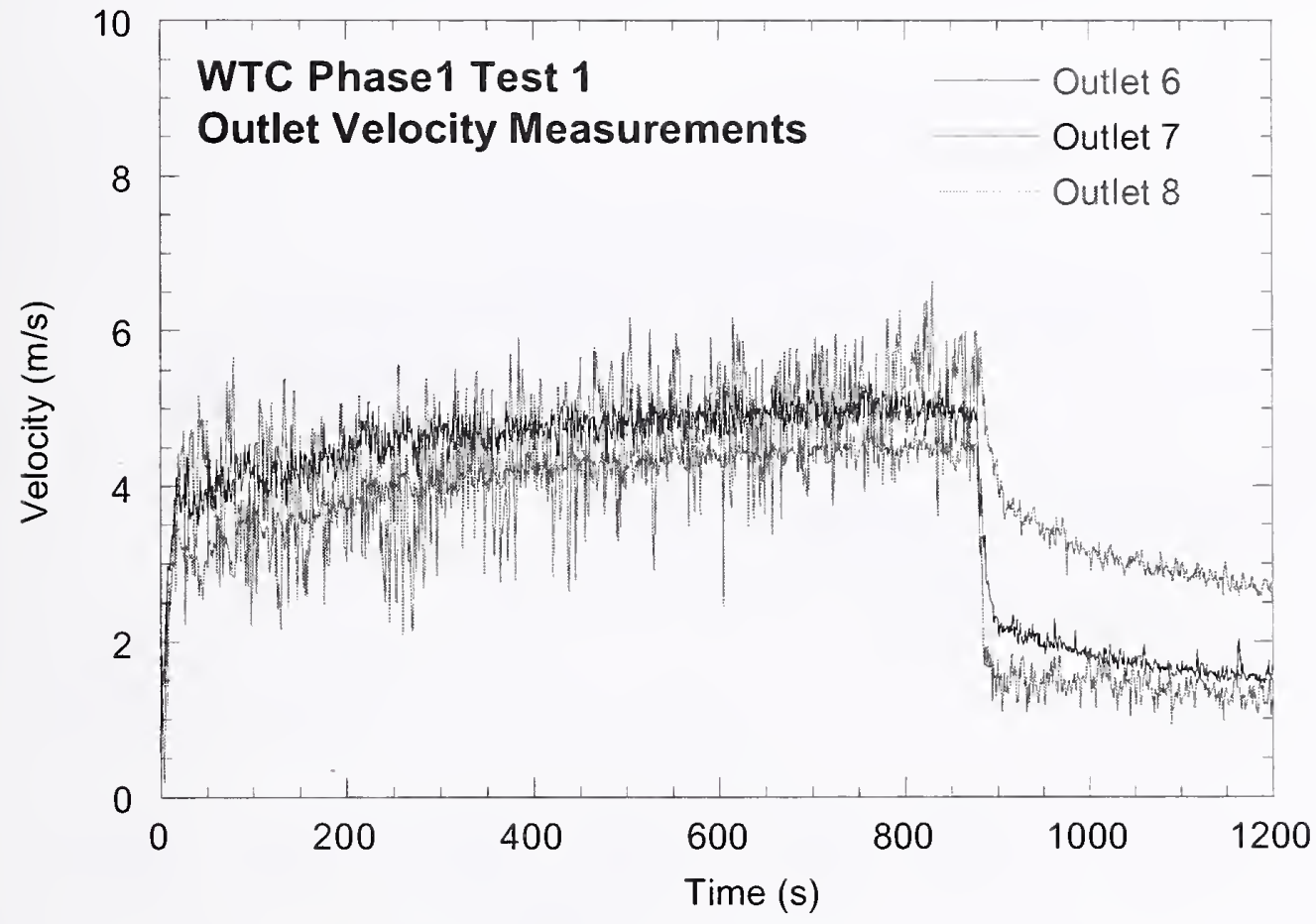

Figure D-14. Outlet velocities for Test 1, outlet locations 6, 7, and 8. 


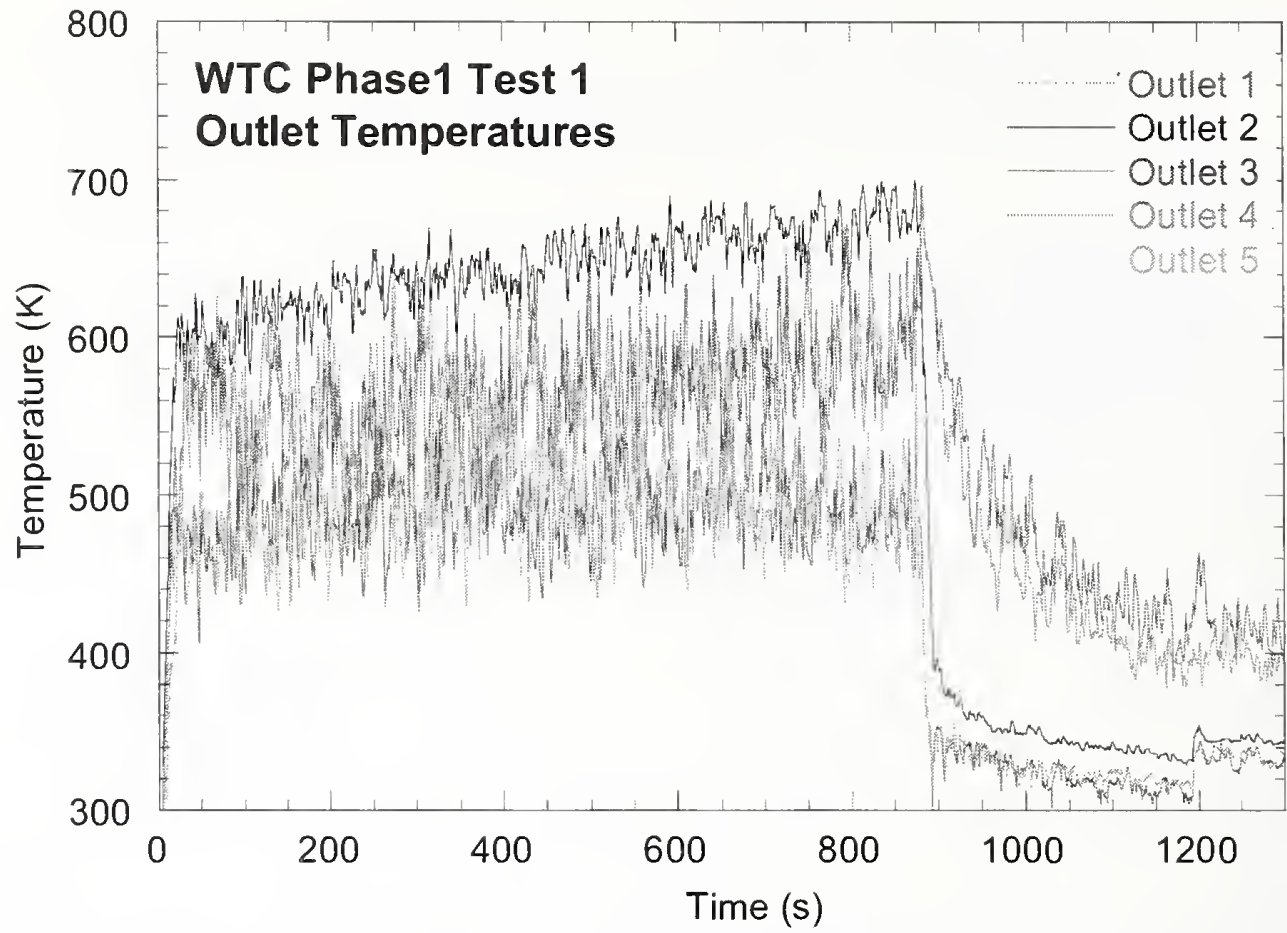

Figure D-15. Outlet temperatures for Test 1, outlet locations 1, 2, 3, 4, and 5.

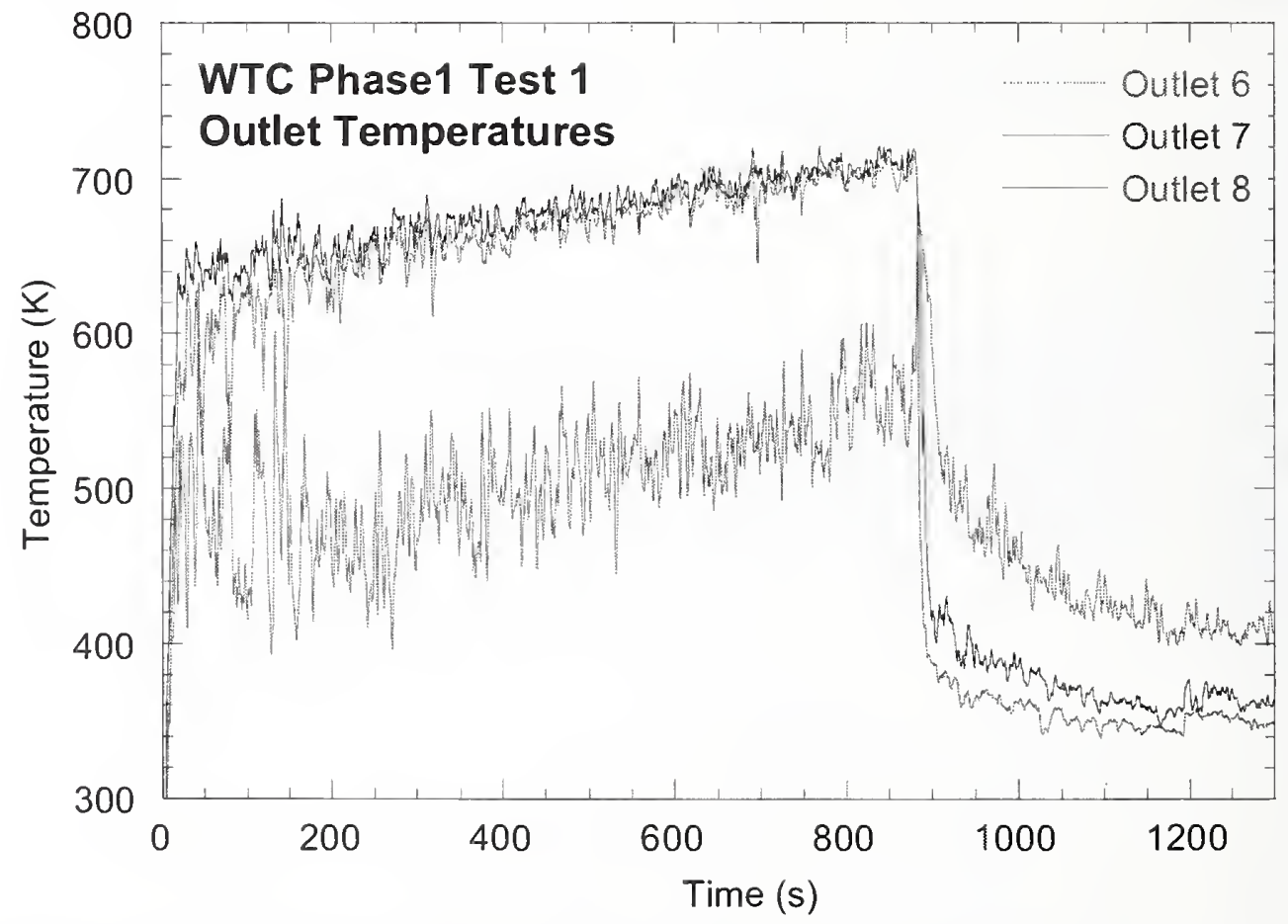

Figure D-16. Outlet temperatures for Test 1, outlet locations 6, 7, and 8. 


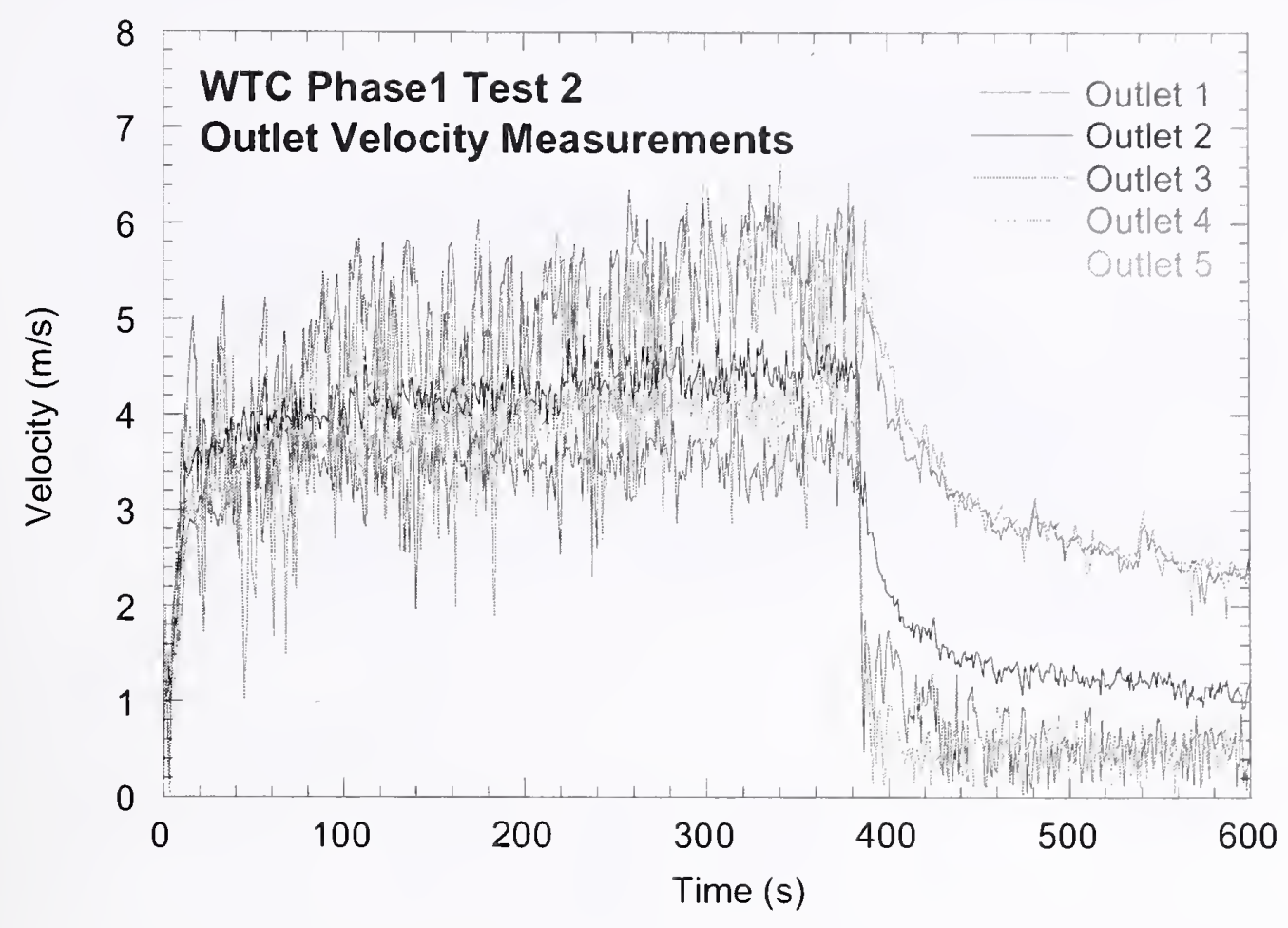

Figure D-17. Outlet velocities for Test 2, outlet locations 1, 2, 3, 4, and 5.

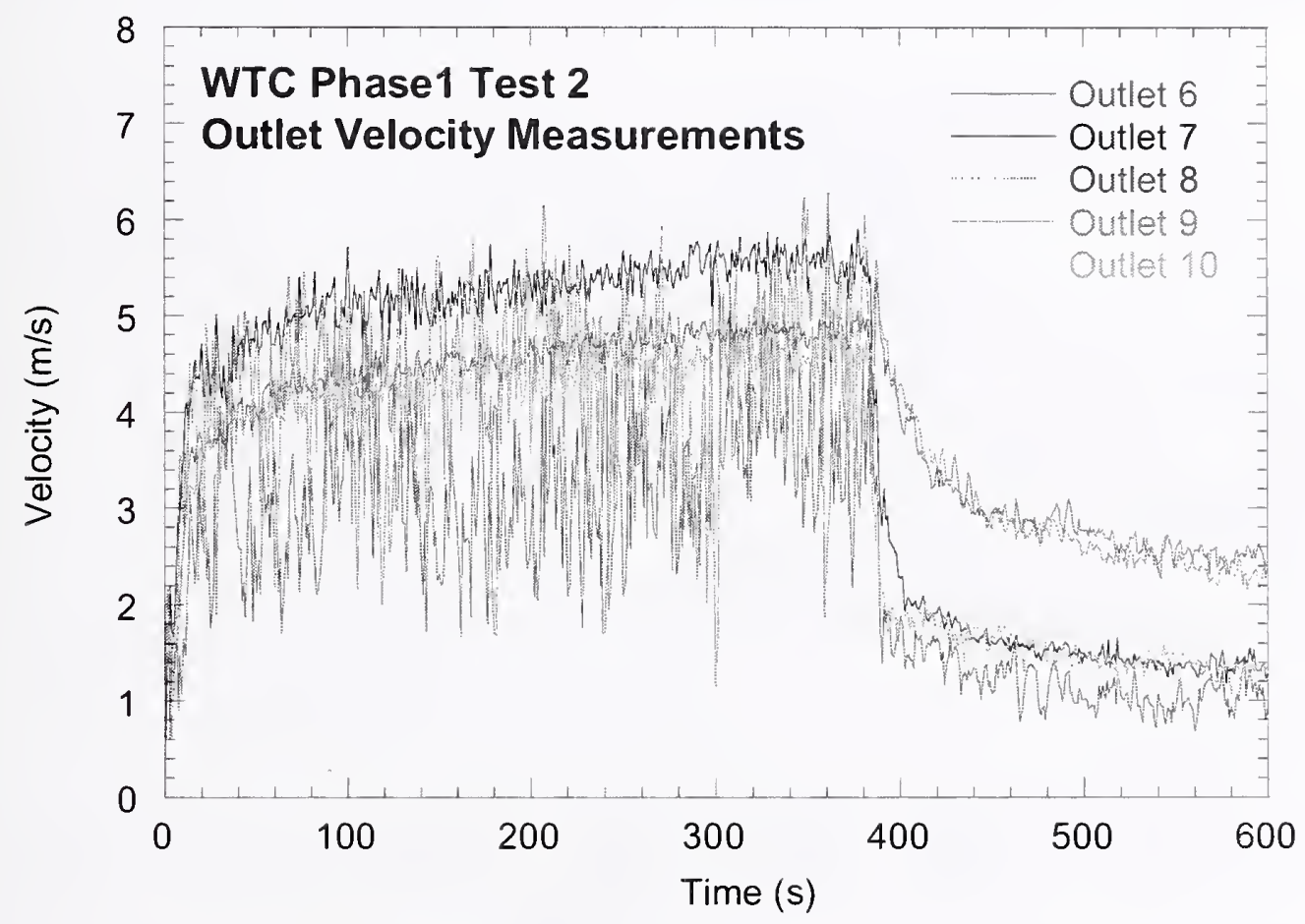

Figure D-18. Outlet velocities for Test 2, outlet locations 6, 7, 8, 9, and 10. 


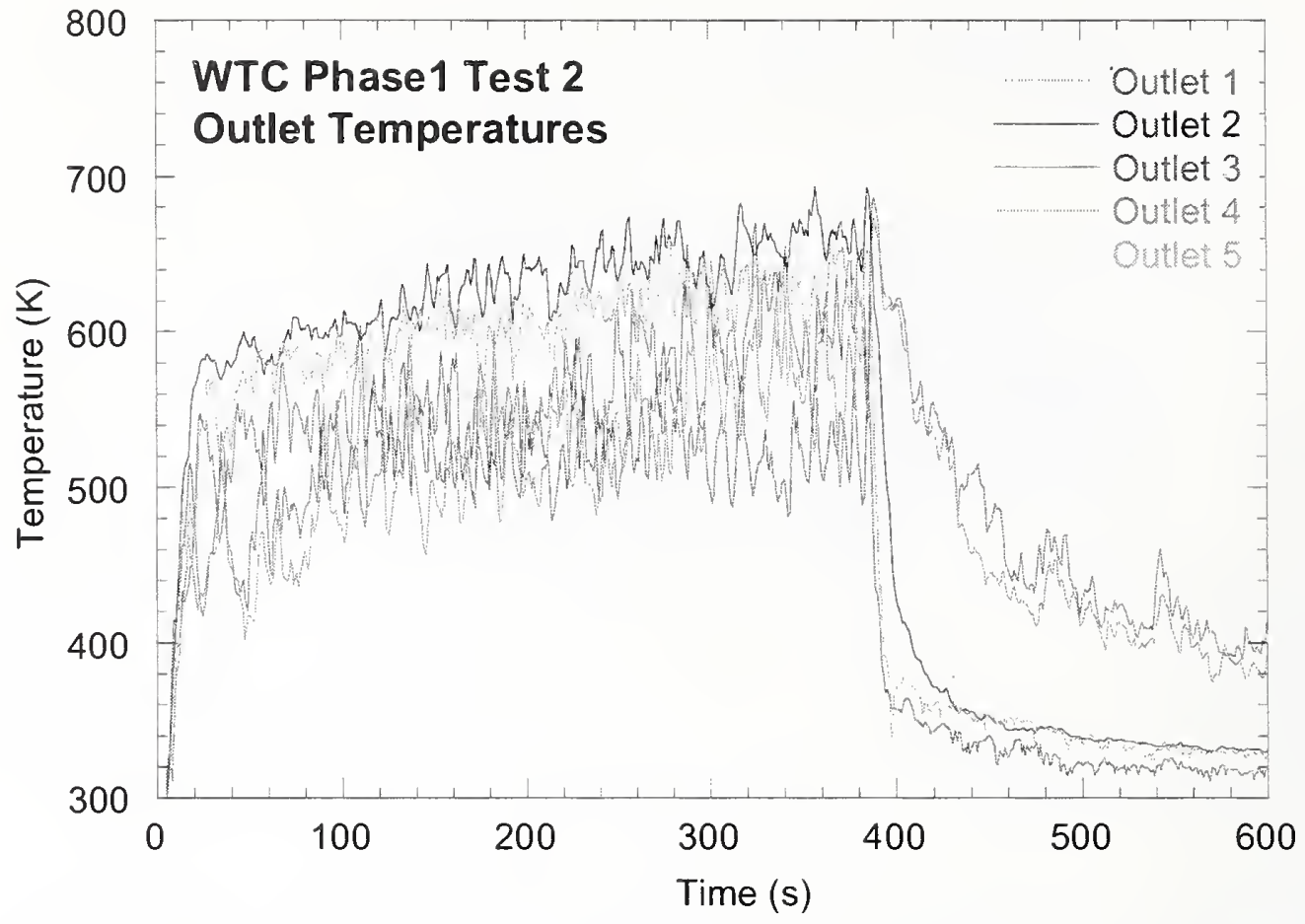

Figure D-19. Outlet temperatures for Test 2, outlet locations 1, 2, 3, 4, and 5.

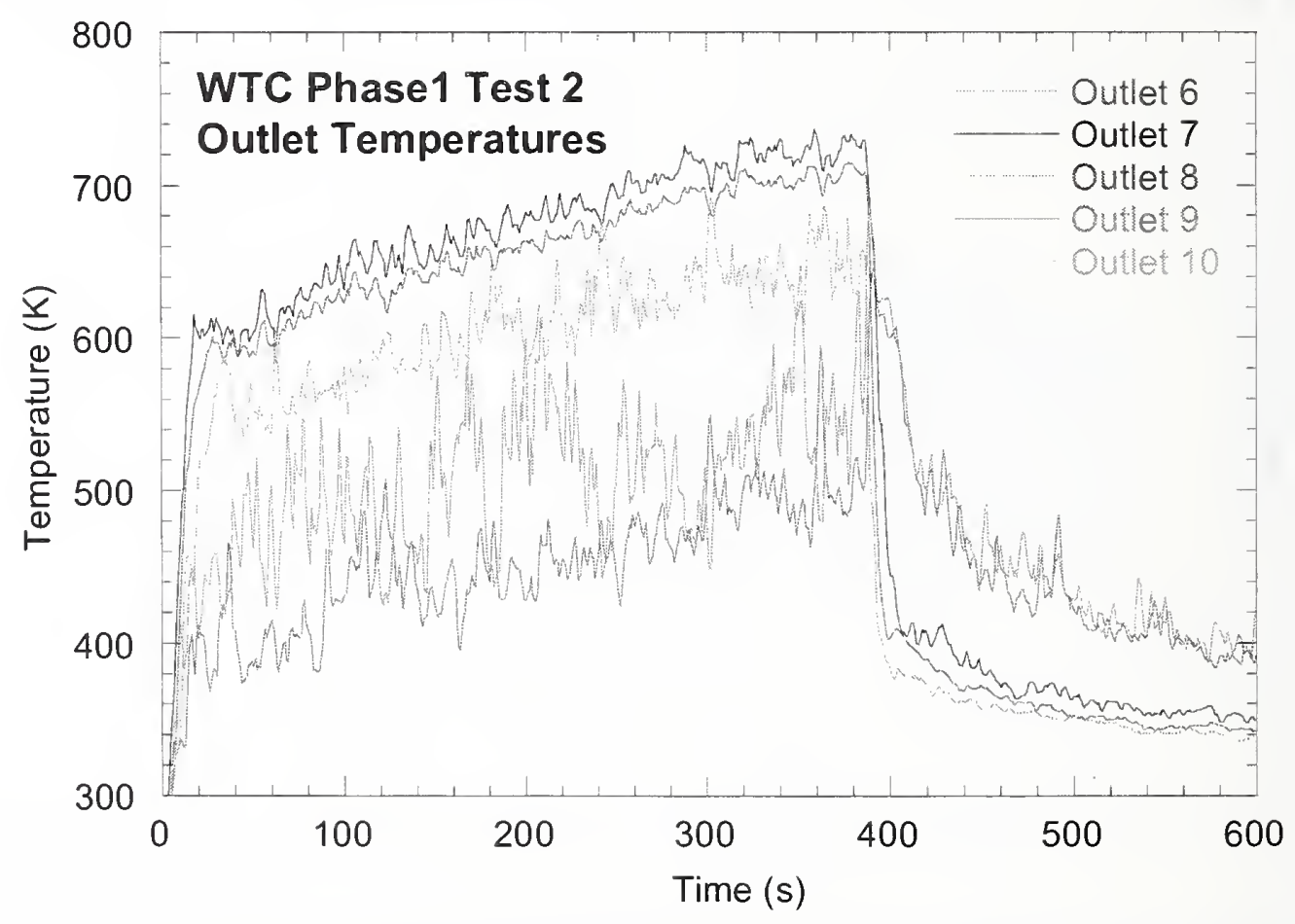

Figure D-20. Outlet temperatures for Test 2, outlet locations 6, 7, 8, 9, and 10. 


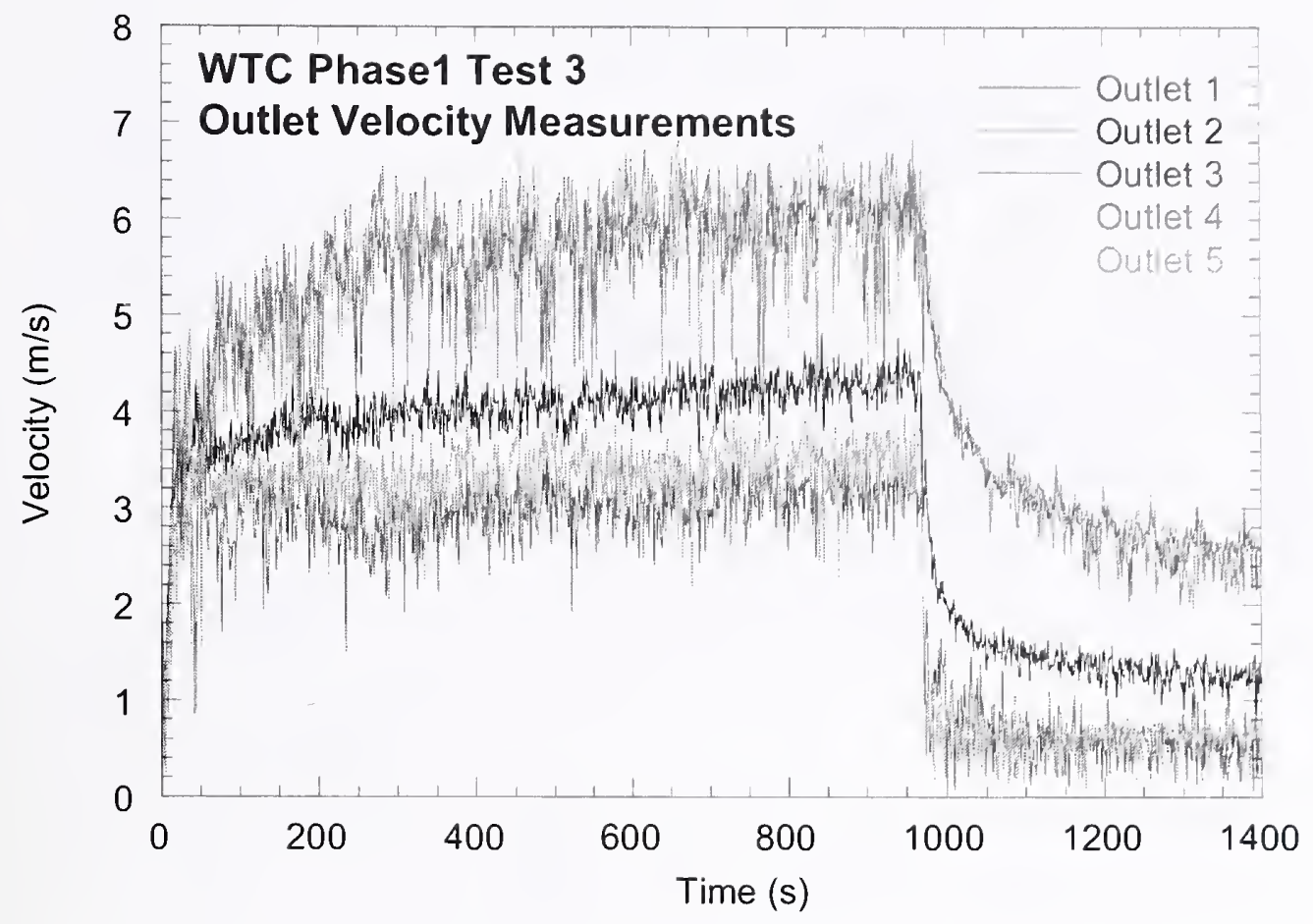

Figure D-21. Outlet velocities for Test 3, outlet locations 1, 2, 3, 4, and 5.

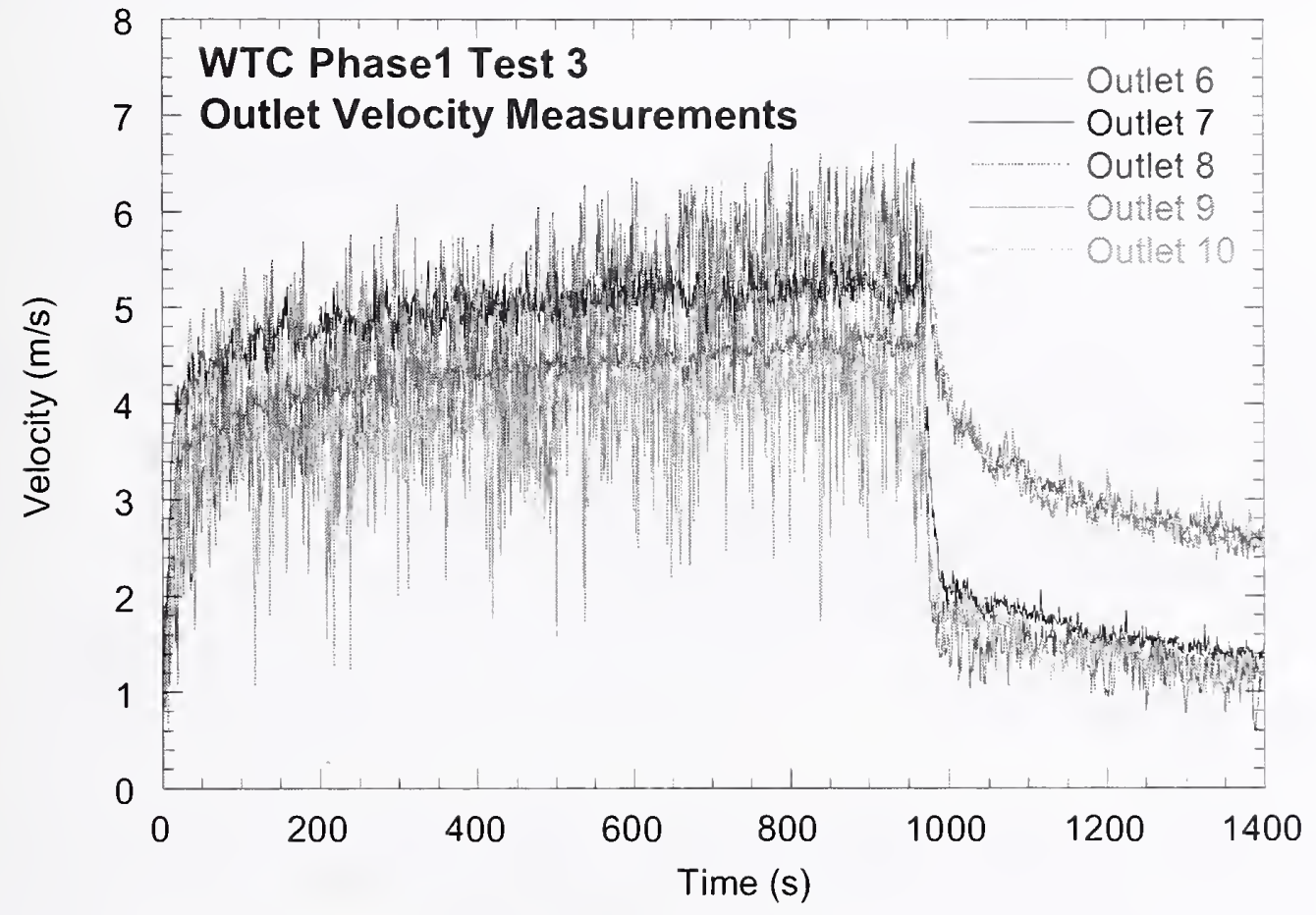

Figure D-22. Outlet velocities for Test 3, outlet locations 6, 7, 8, 9, and 10. 


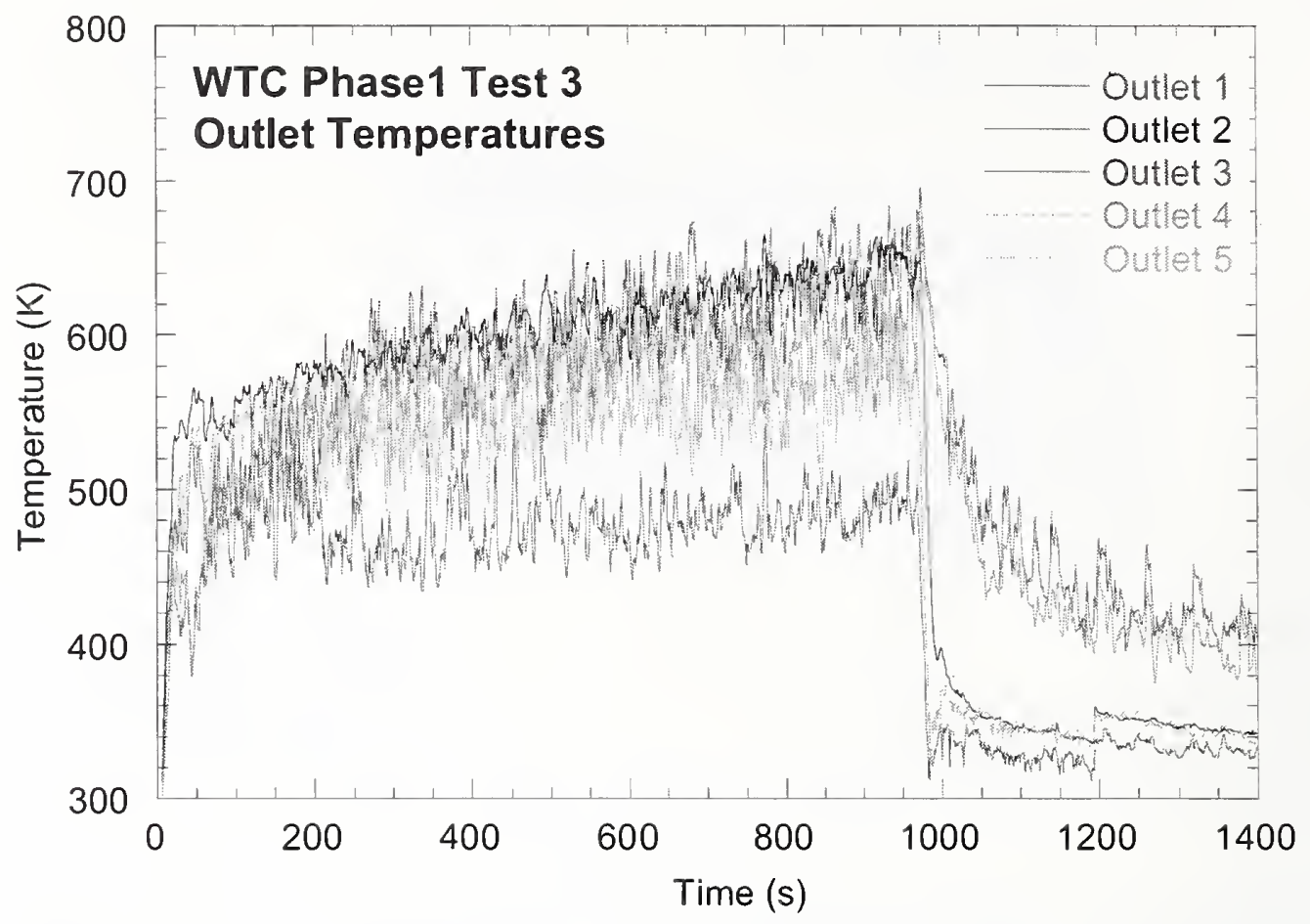

Figure D-23. Outlet temperatures for Test 3, outlet locations 1, 2, 3, 4, and 5.

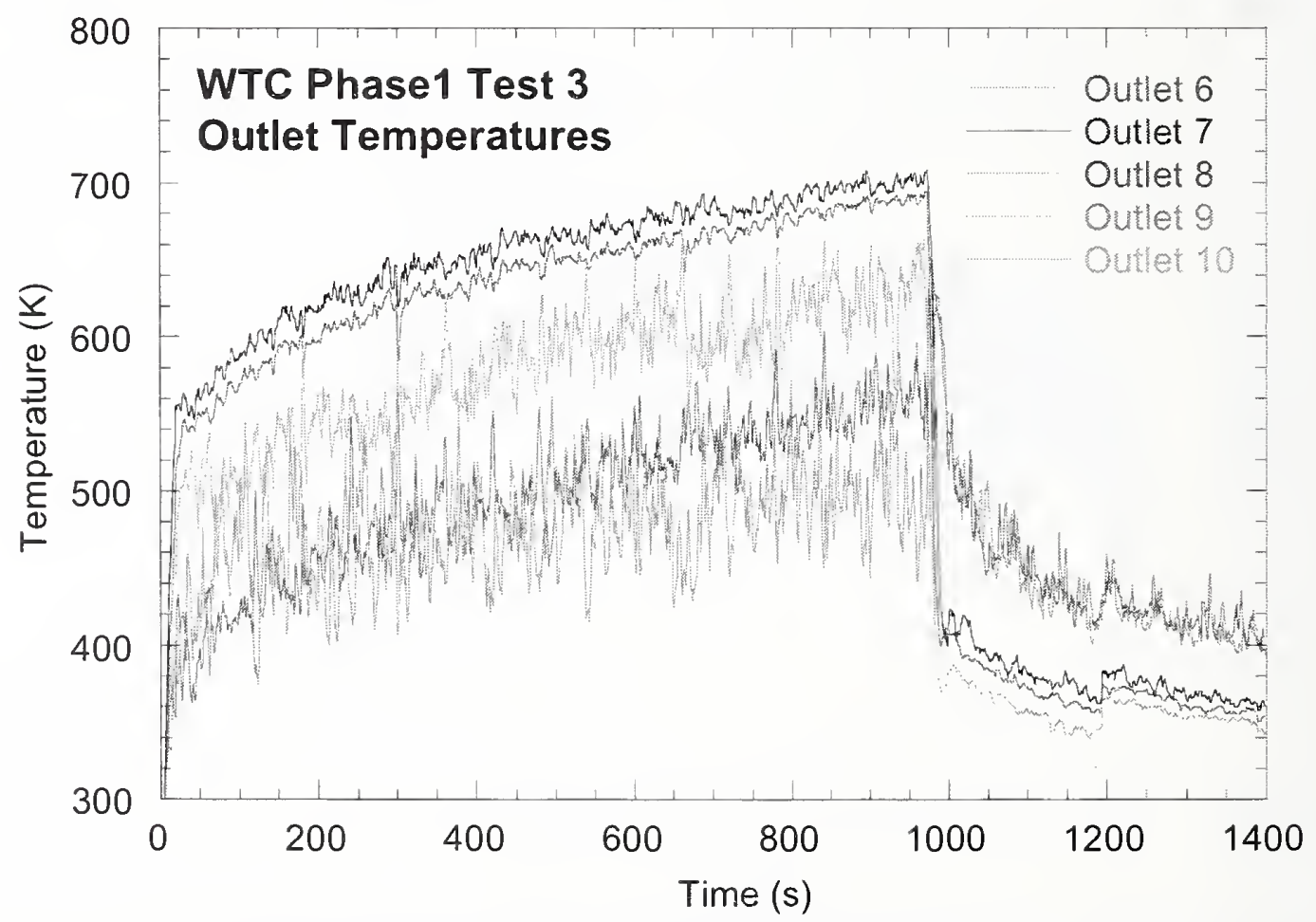

Figure D-24. Outlet temperatures for Test 3, outlet locations 6, 7, 8, 9, and 10. 


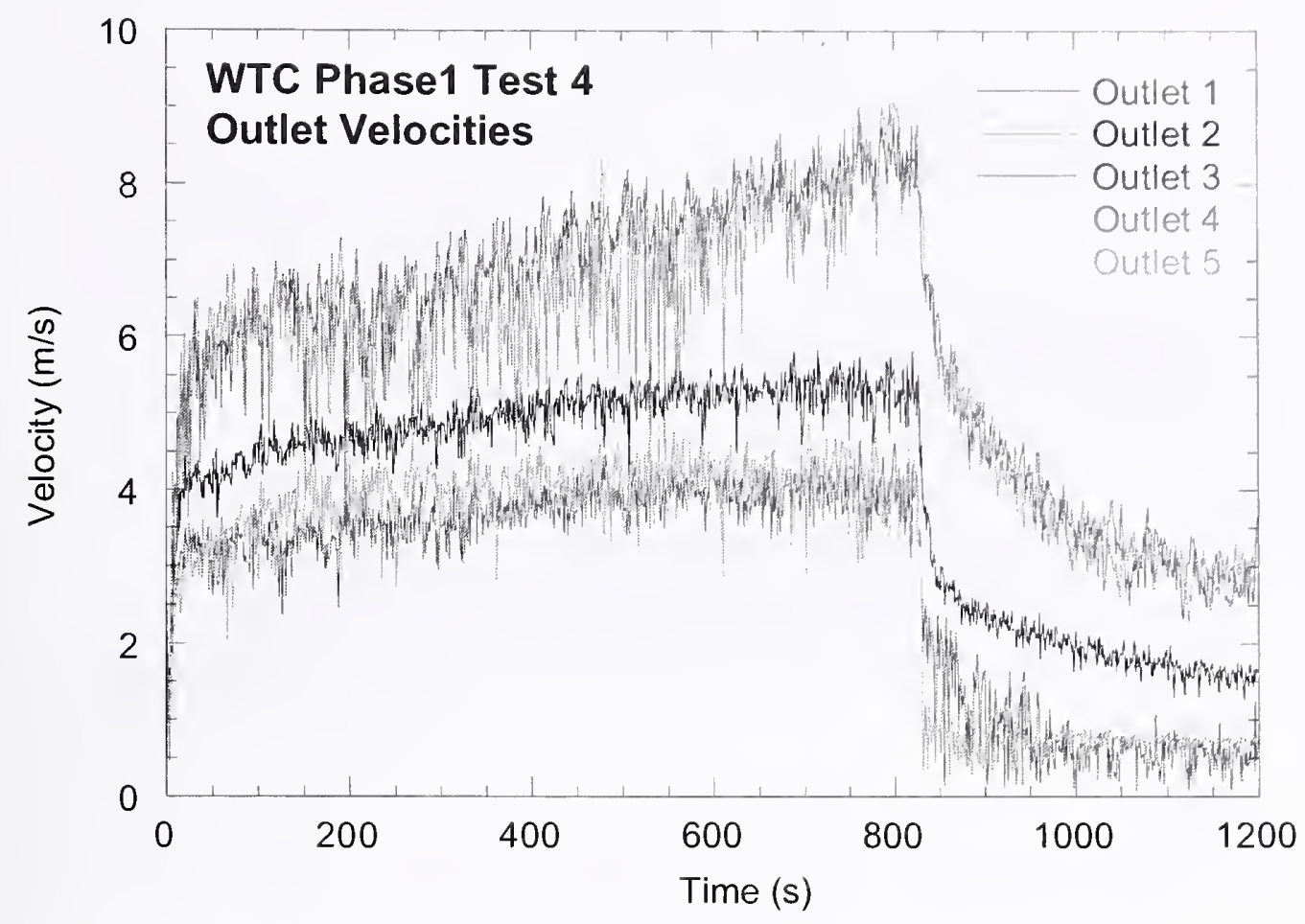

Figure D-25. Outlet velocities for Test 4, outlet locations 1, 2, 3, 4, and 5.

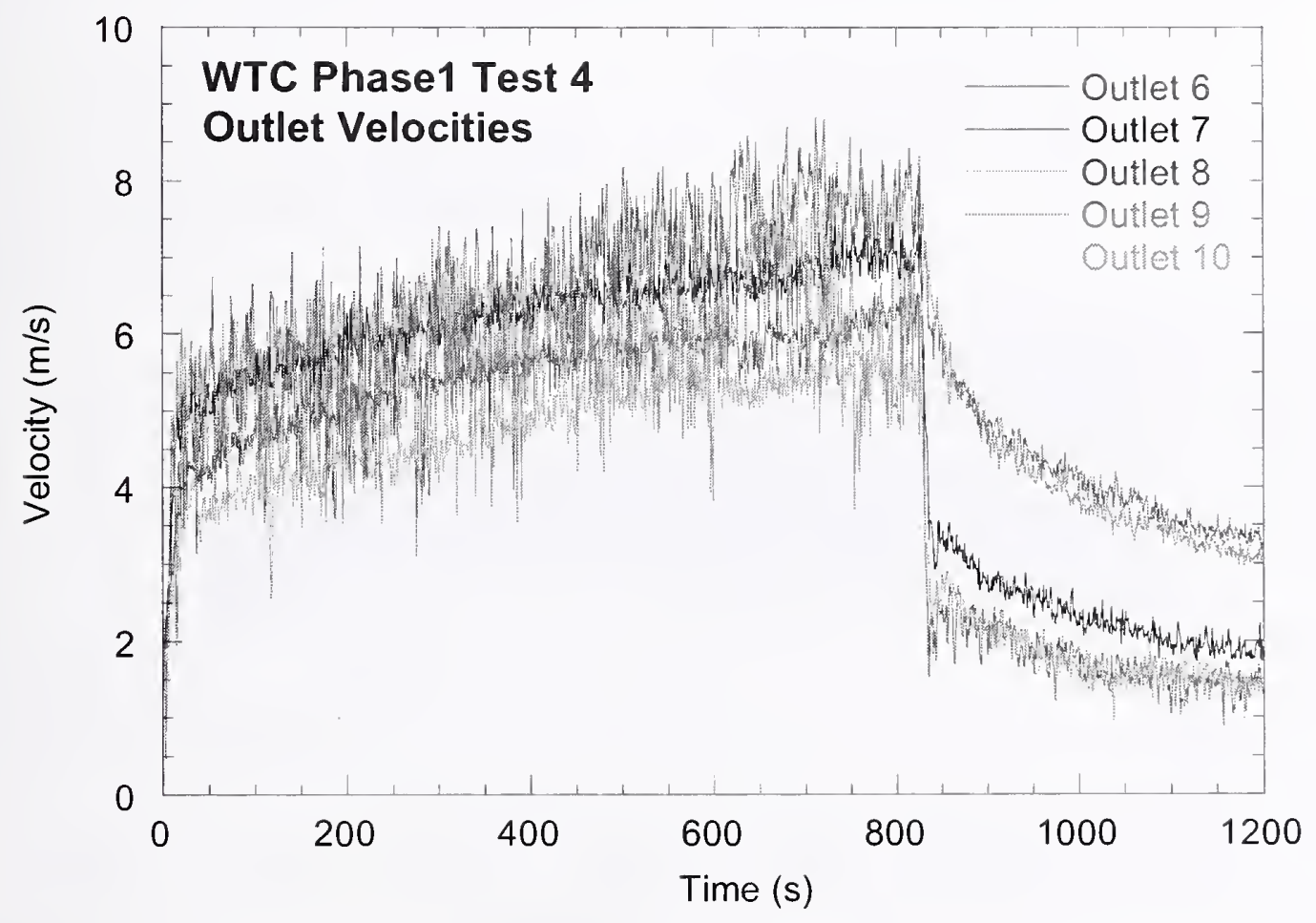

Figure D-26. Outlet velocities for Test 4, outlet locations 6, 7, 8, 9, and 10. 


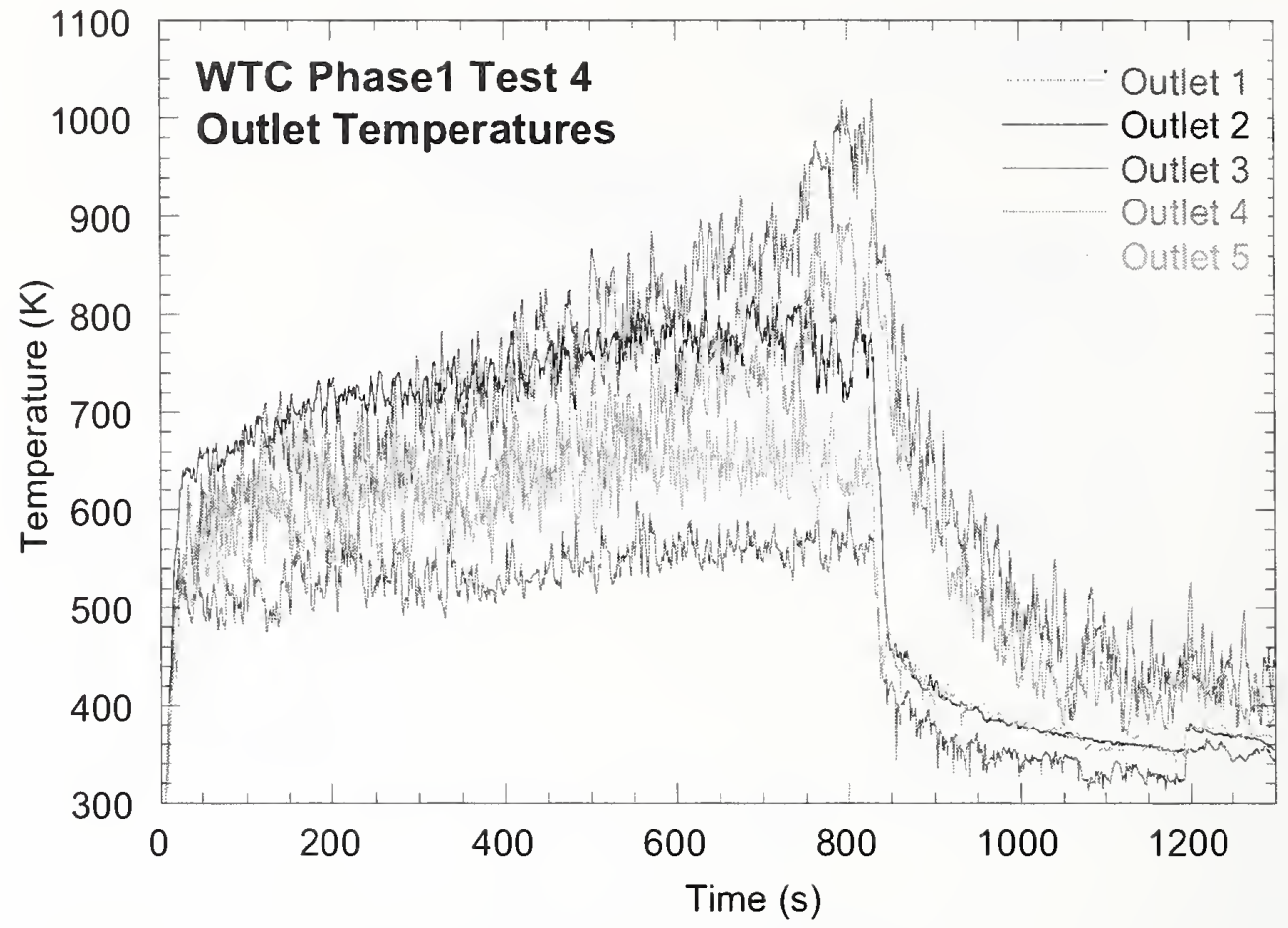

Figure D-27. Outlet temperatures for Test 4, outlet locations 1, 2, 3, 4, and 5.

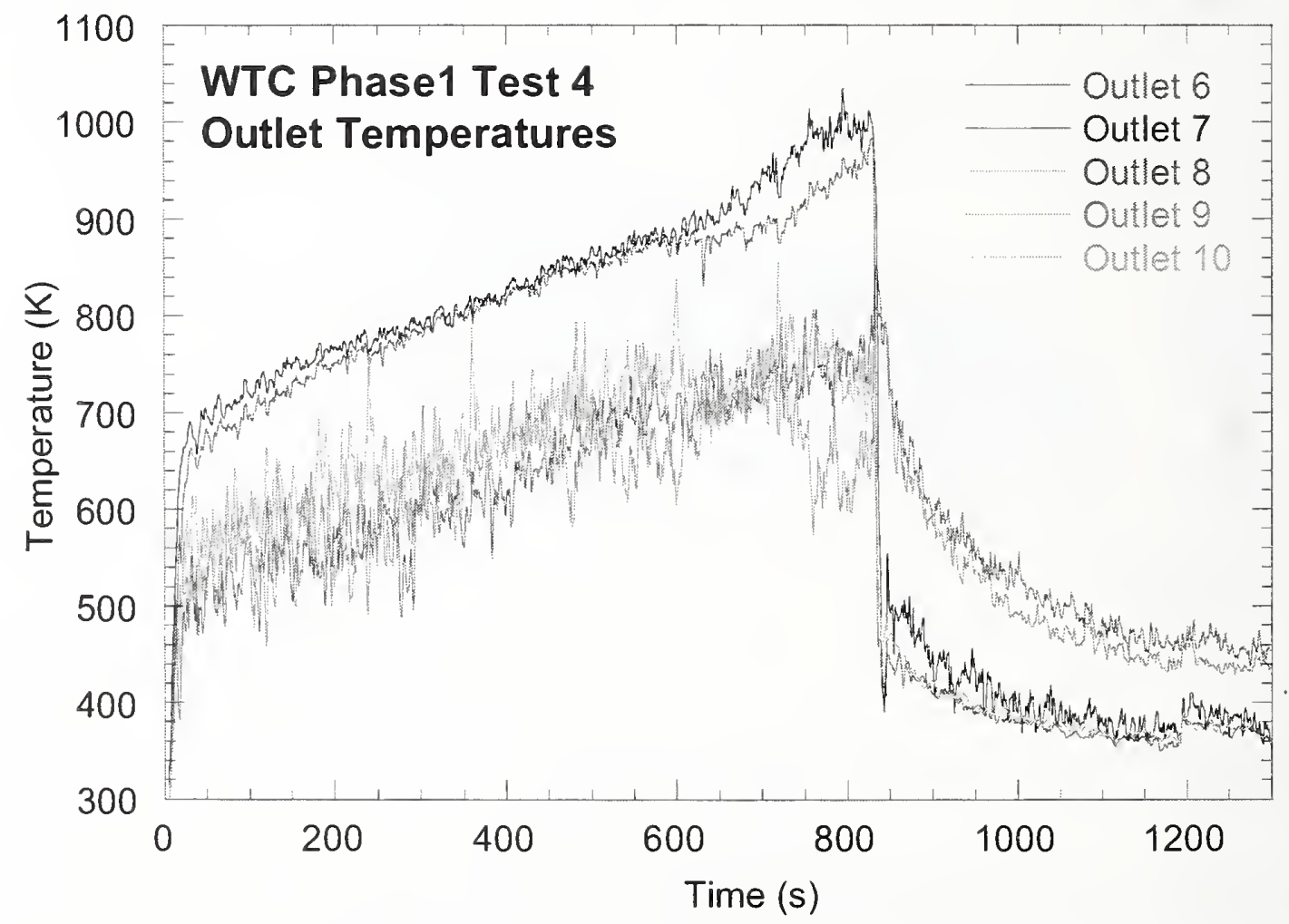

Figure D-28. Outlet temperatures for Test 4, outlet locations 6, 7, 8, 9, and 10. 


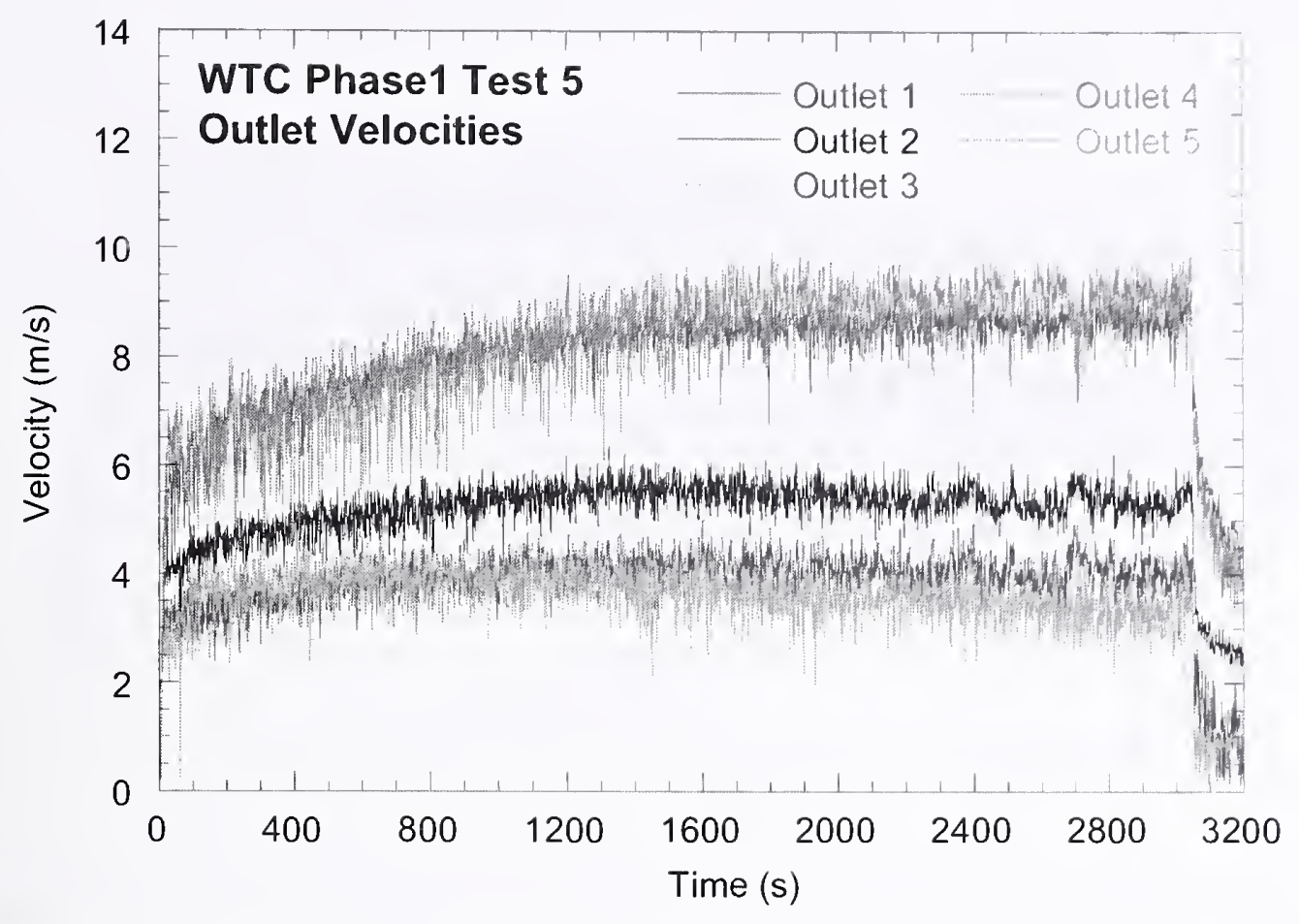

Figure D-29. Outlet velocities for Test 5, outlet locations 1, 2, 3, 4, and 5.

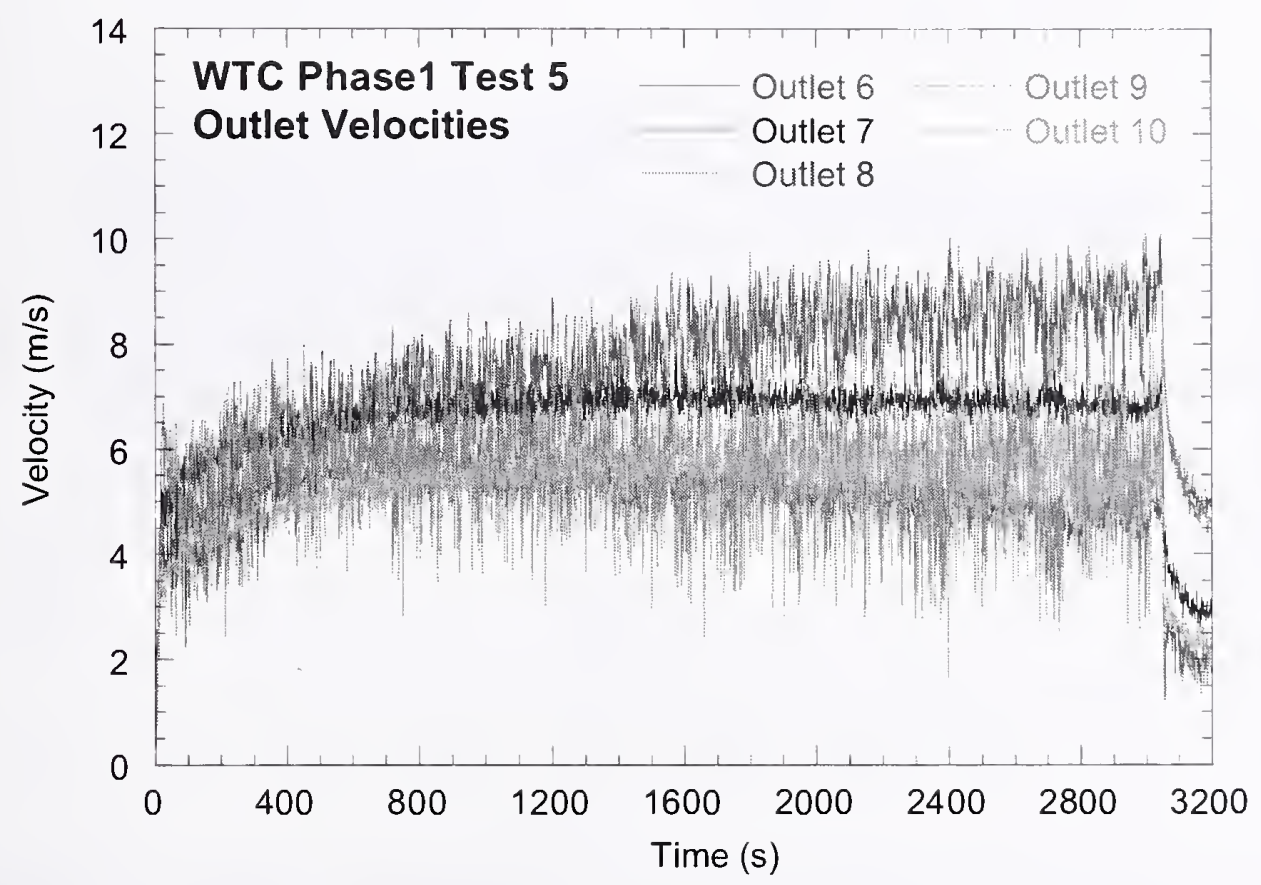

Figure D-30. Outlet velocities for Test 5, outlet locations $6,7,8,9$, and 10. 


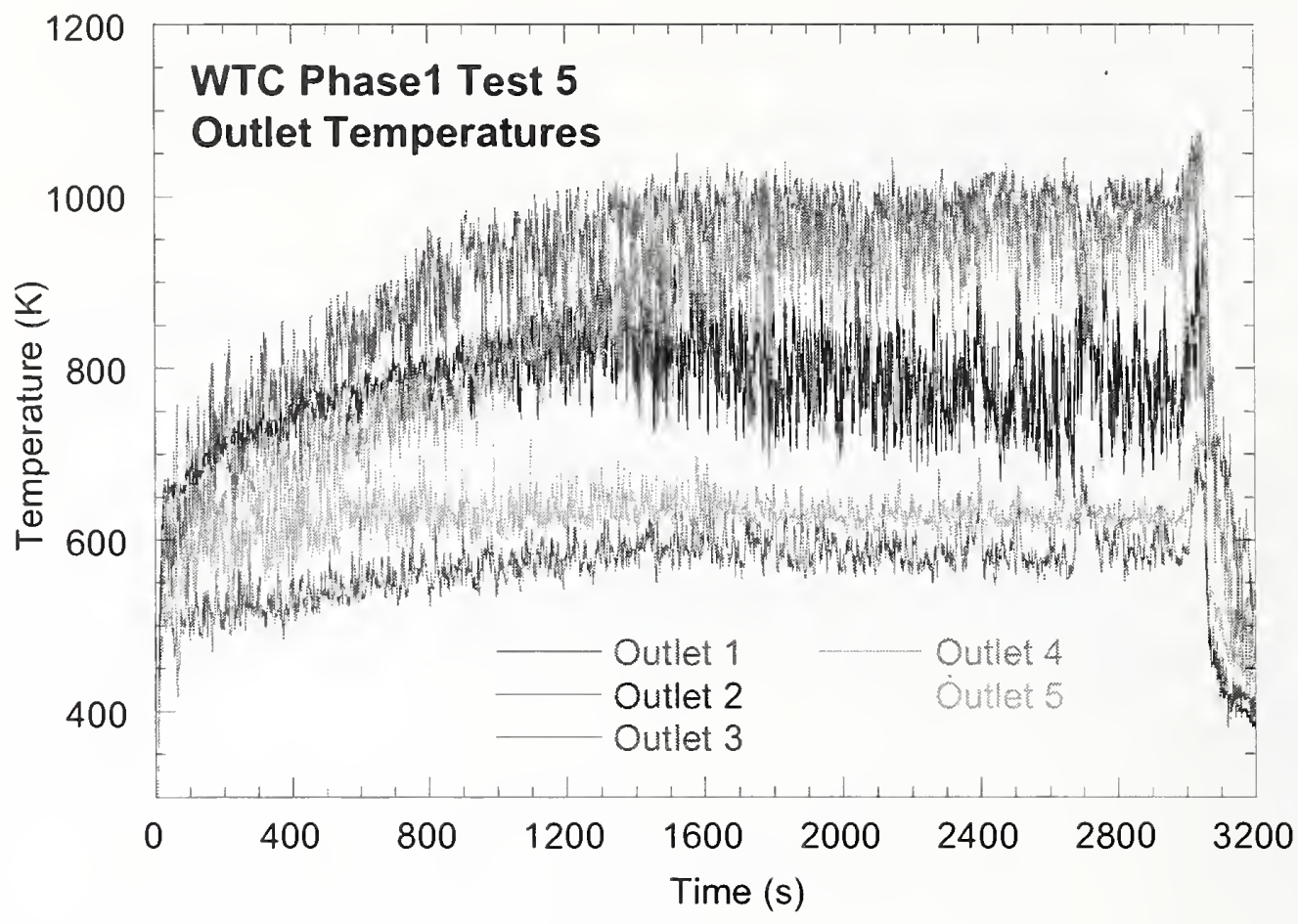

Figure D-31. Outlet temperatures for Test 5, outlet locations 1, 2, 3, 4, and 5.

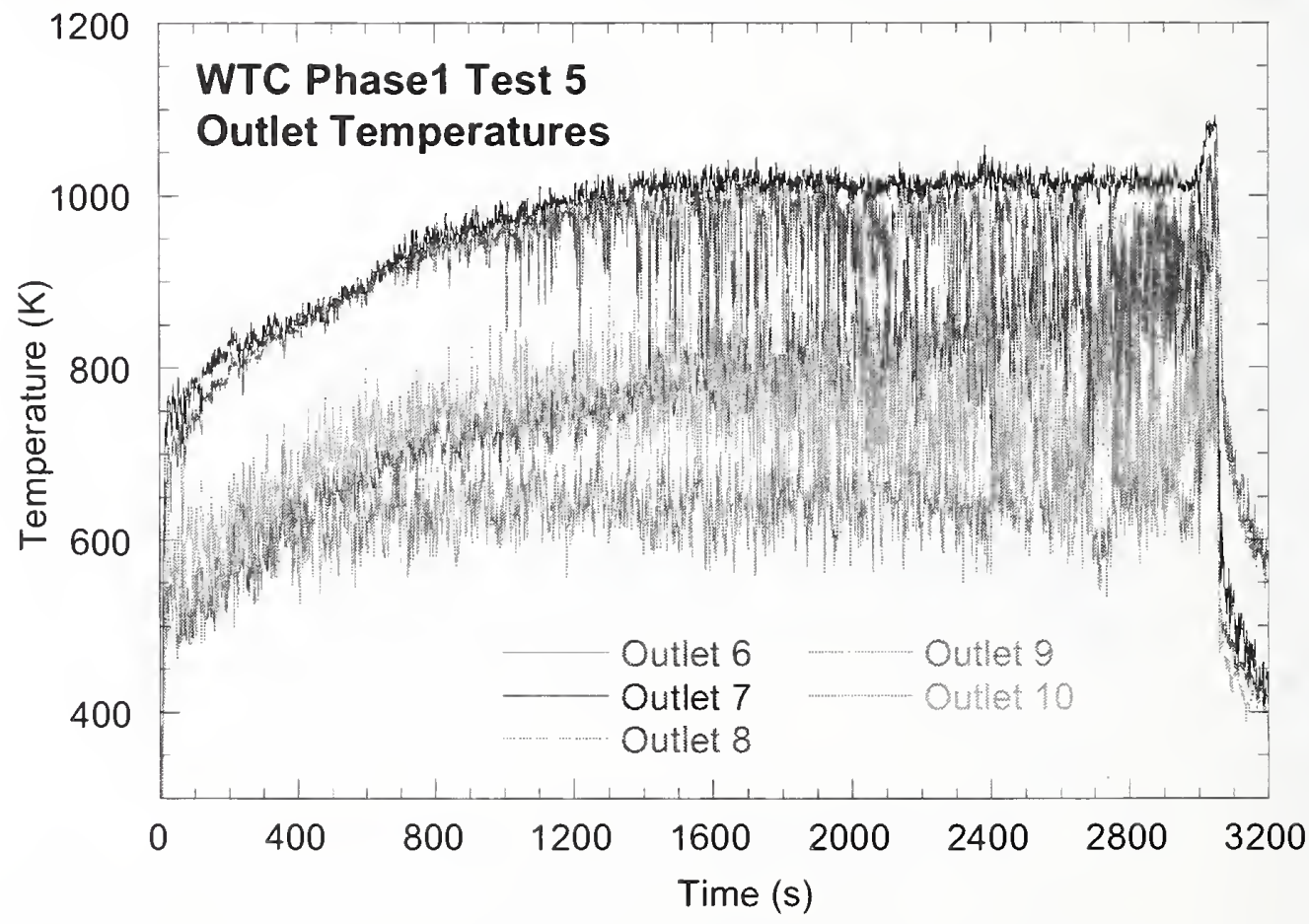

Figure D-32. Outlet temperatures for Test 5, outlet locations 6, 7, 8, 9, and 10. 


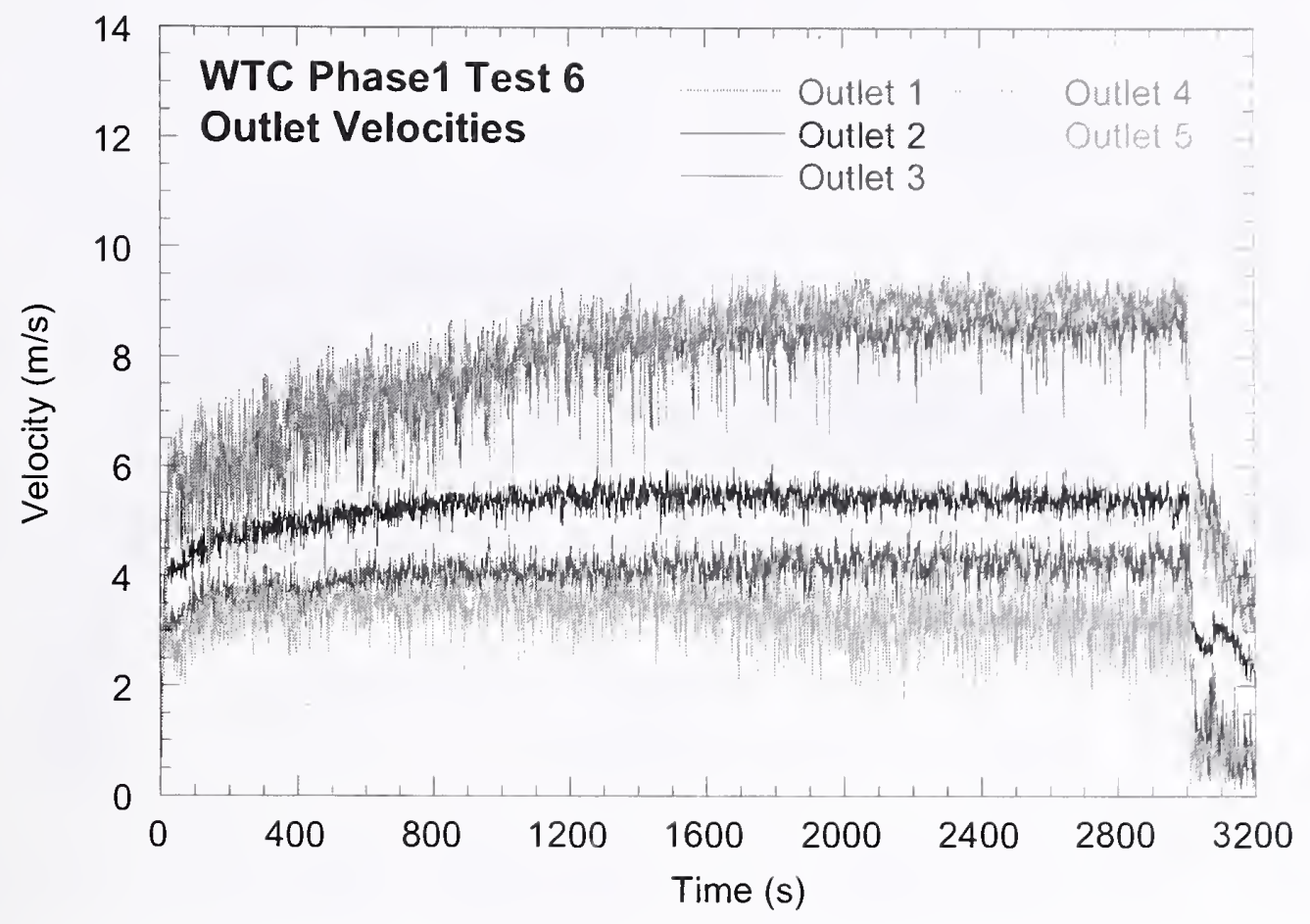

Figure D-33. Outlet velocities for Test 6, outlet locations 1, 2, 3, 4, and 5.

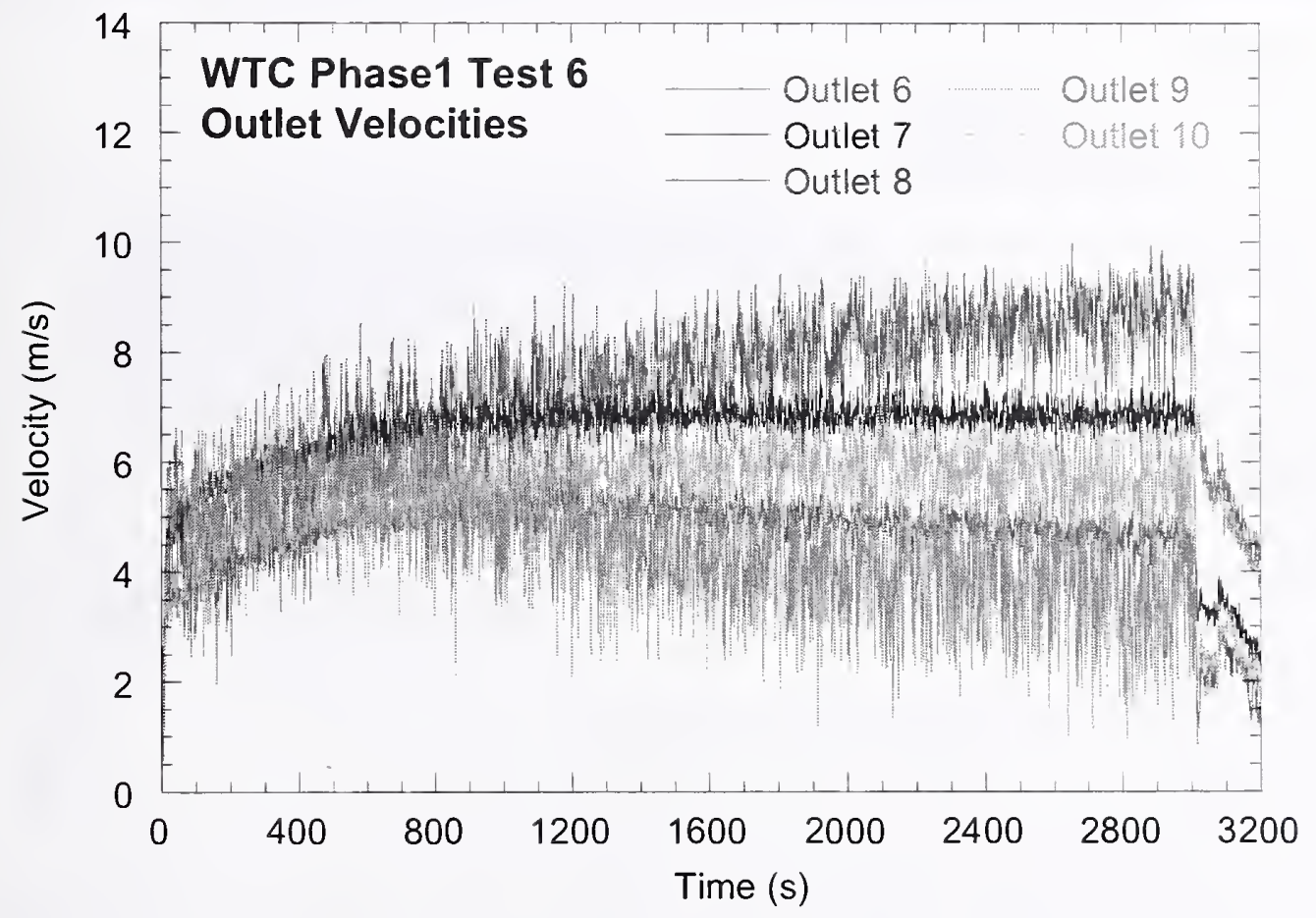

Figure D-34. Outlet velocities for Test 6, outlet locations 6, 7, 8, 9, and 10. 


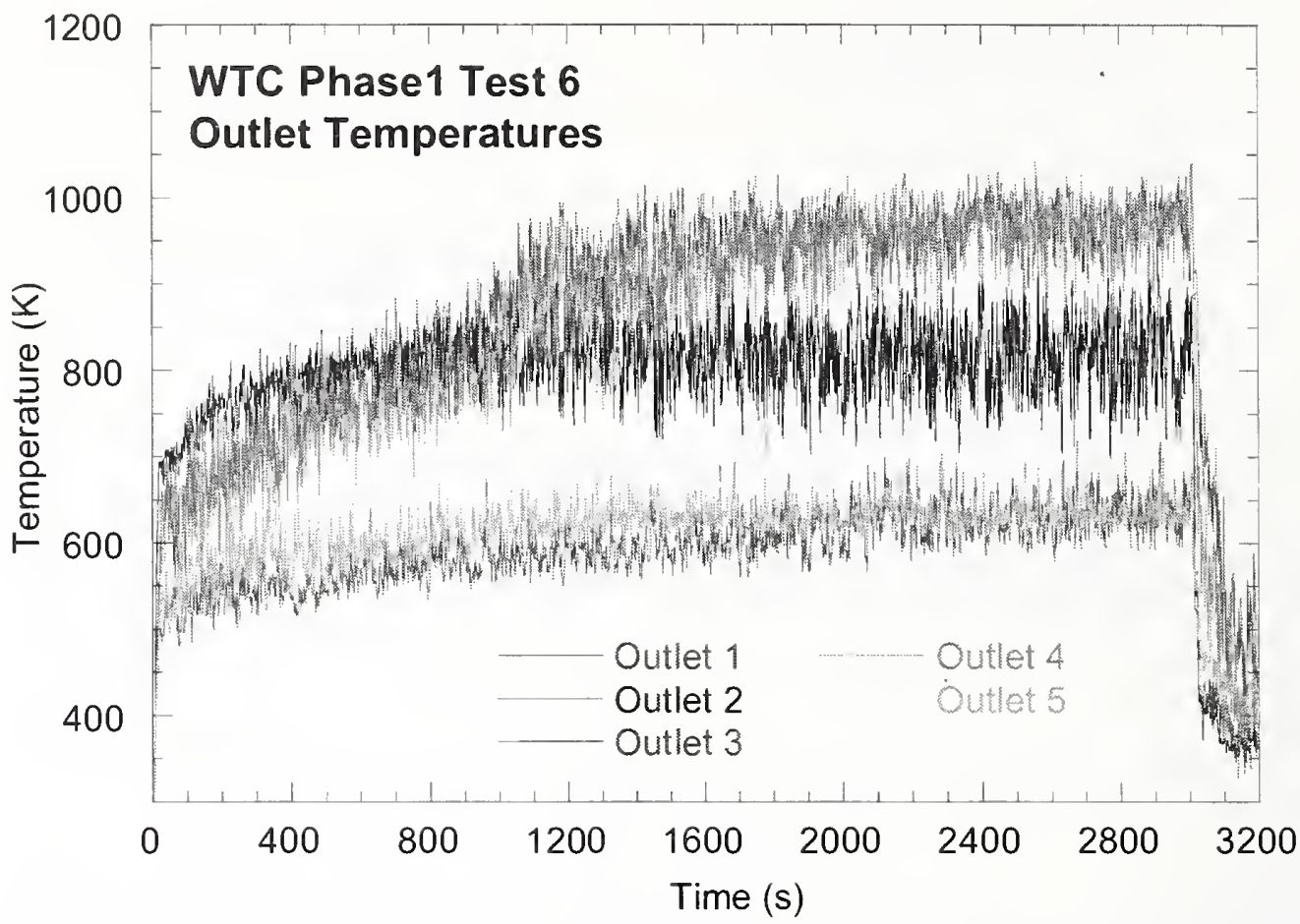

Figure D-35. Outlet temperatures for Test 6, outlet locations 1, 2, 3, 4, and 5.

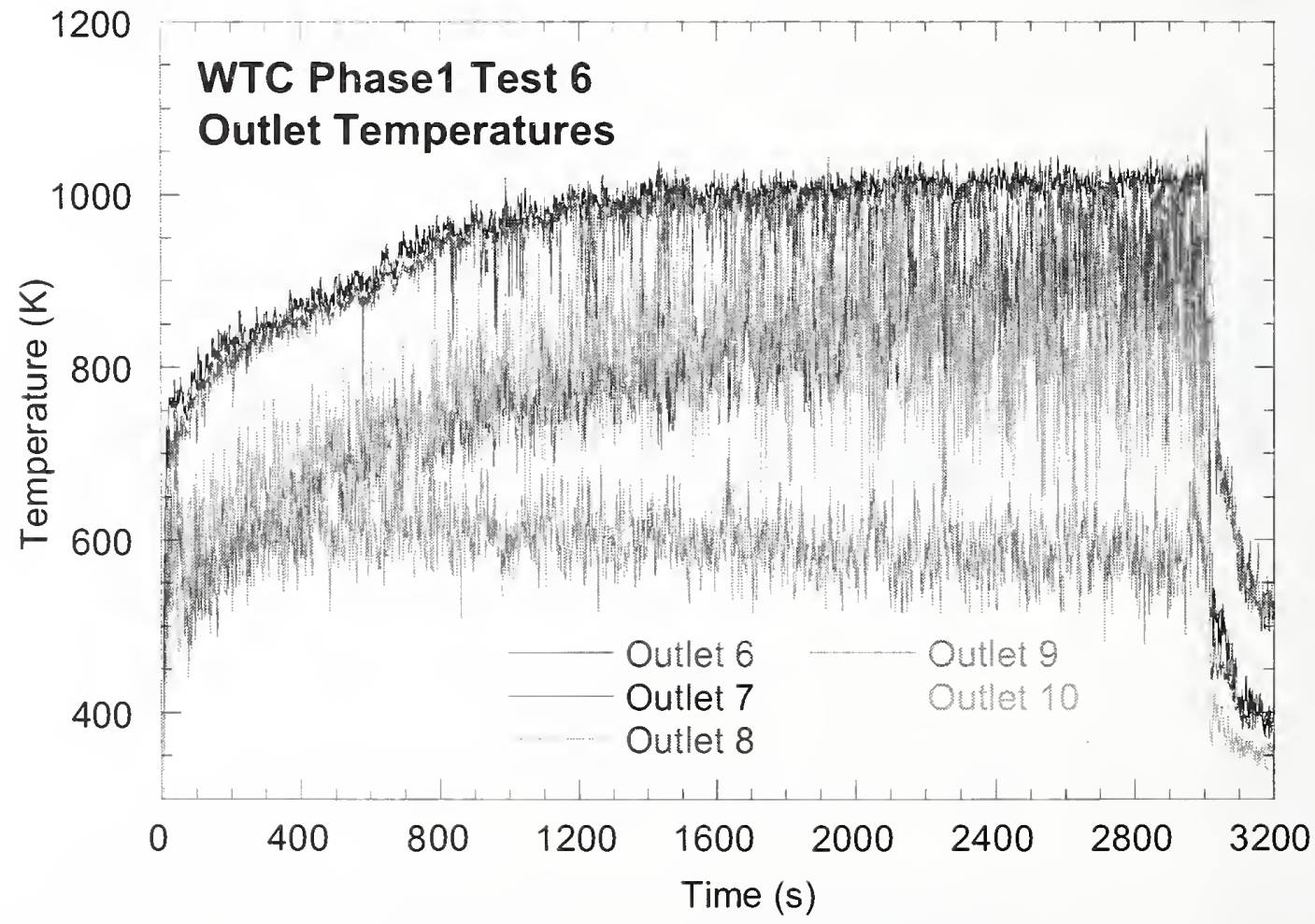

Figure D-36. Outlet temperatures for Test 6, outlet locations 6, 7, 8, 9, and 10. 


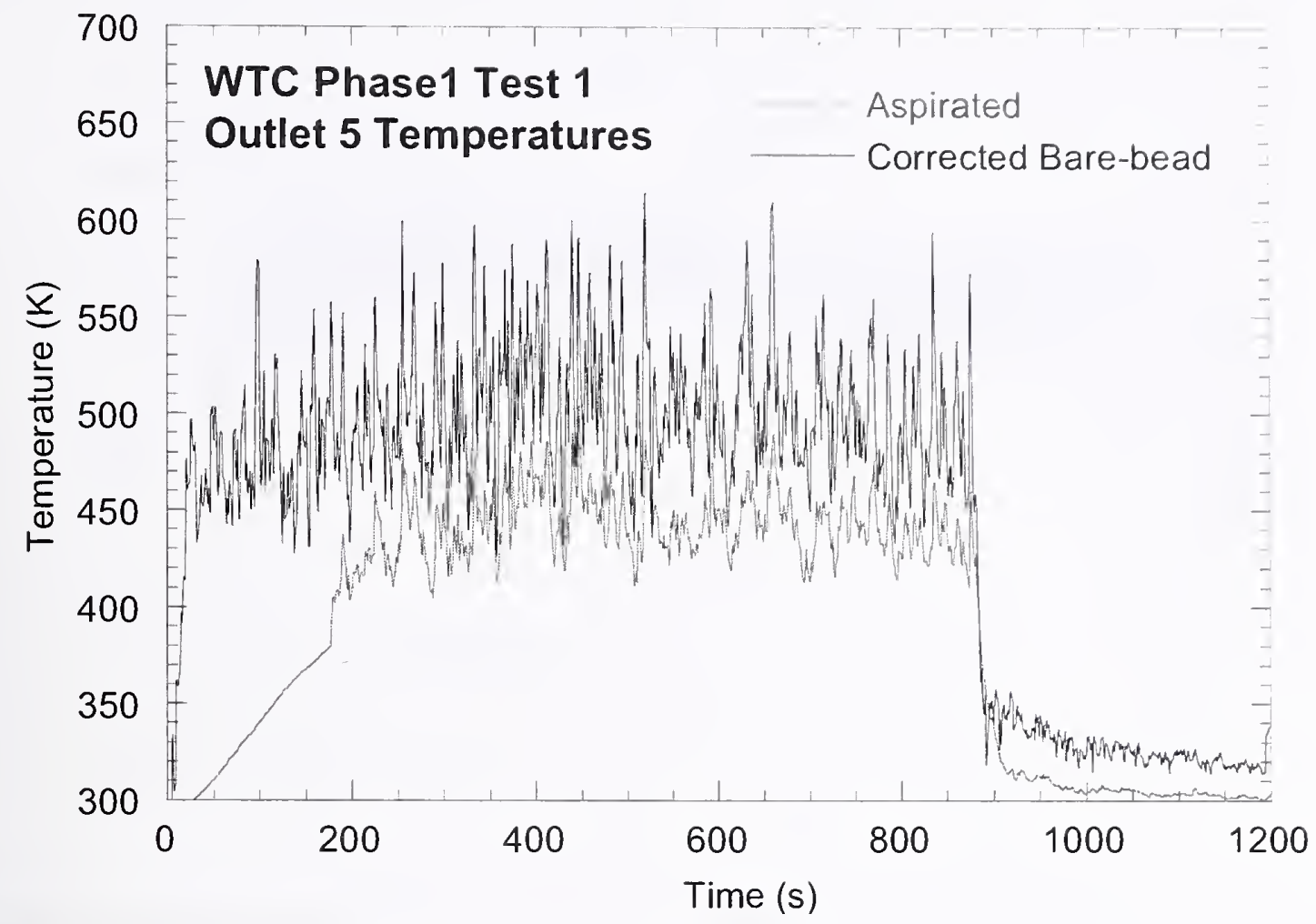

Figure D-37. Aspirated and bare-bead thermocouple temperatures at outlet 5 for Test 1.

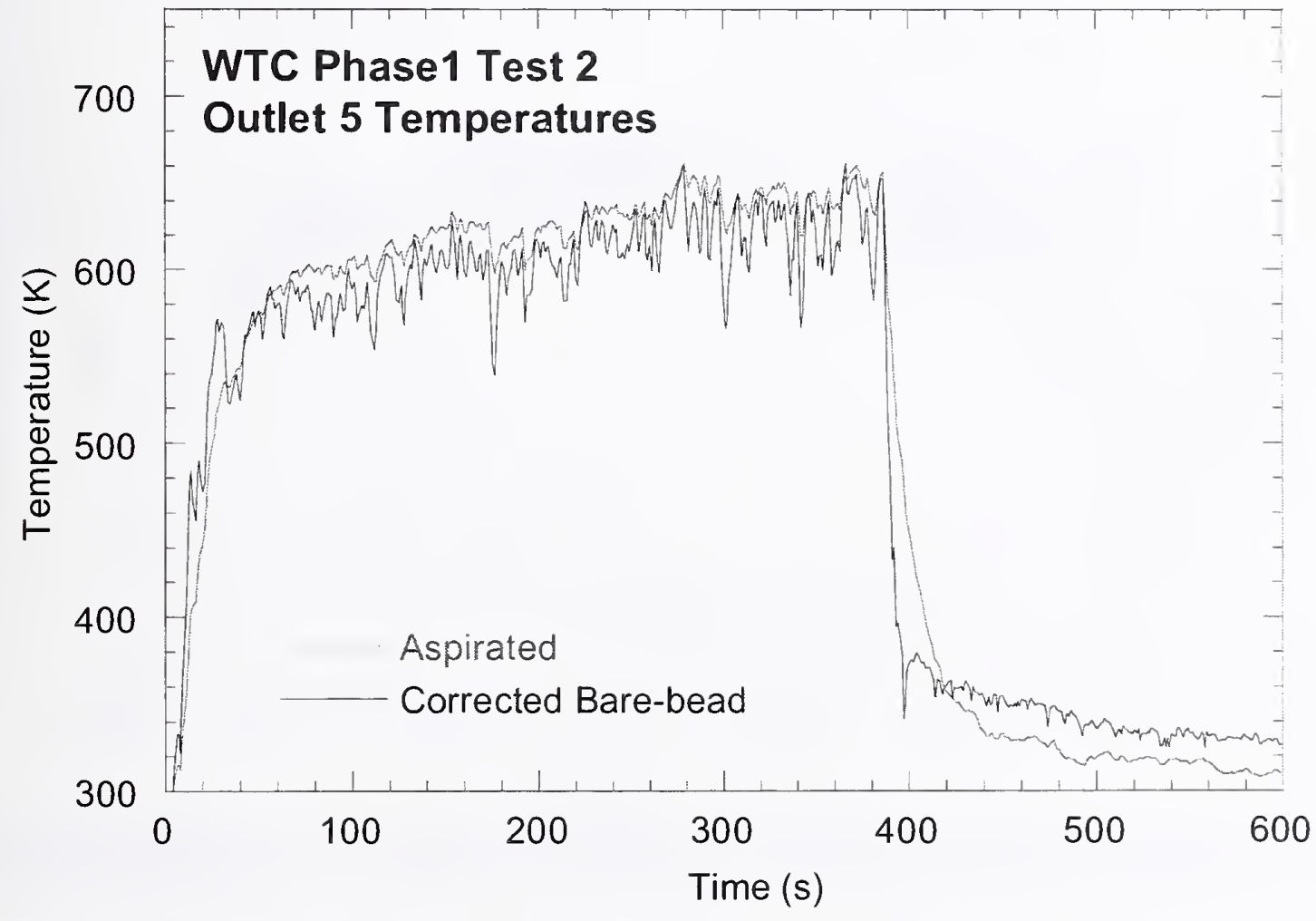

Figure D-38. Aspirated and bare-bead thermocouple temperatures at outlet 5 for Test 2. 


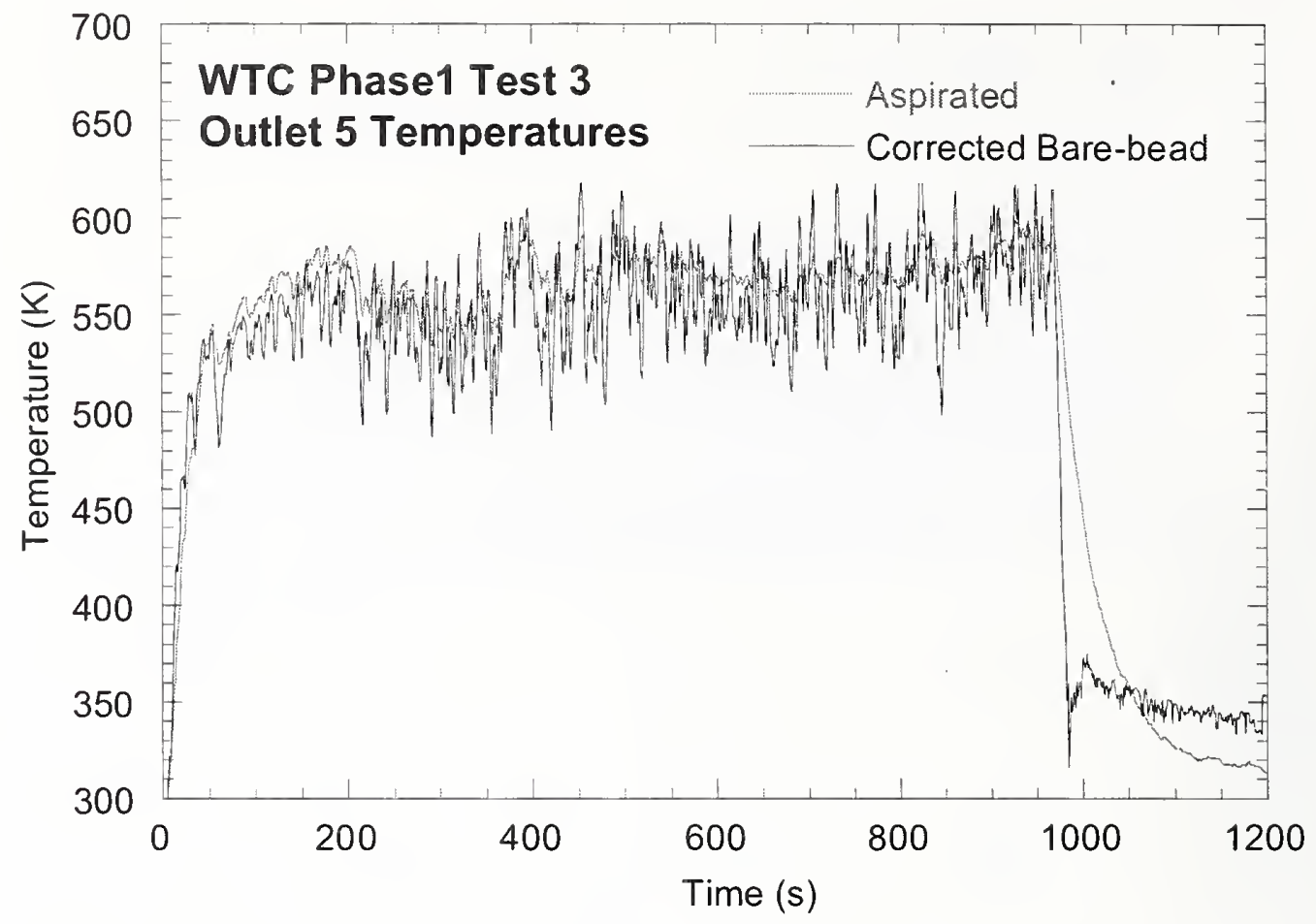

Figure D-39. Aspirated and bare-bead thermocouple temperatures at outlet 5 for Test 3.

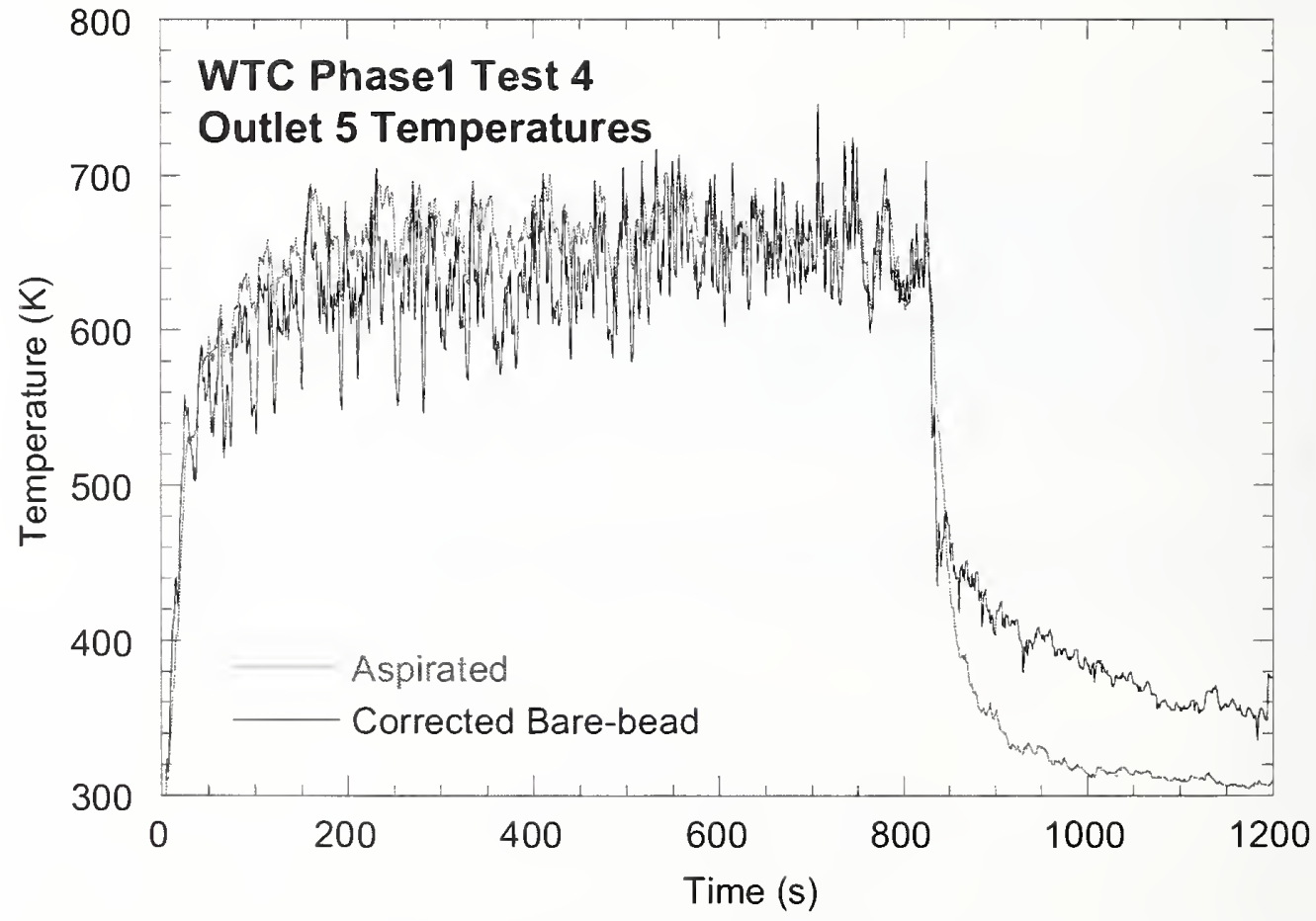

Figure D-40. Aspirated and bare-bead thermocouple temperatures at outlet 5 for Test 4. 


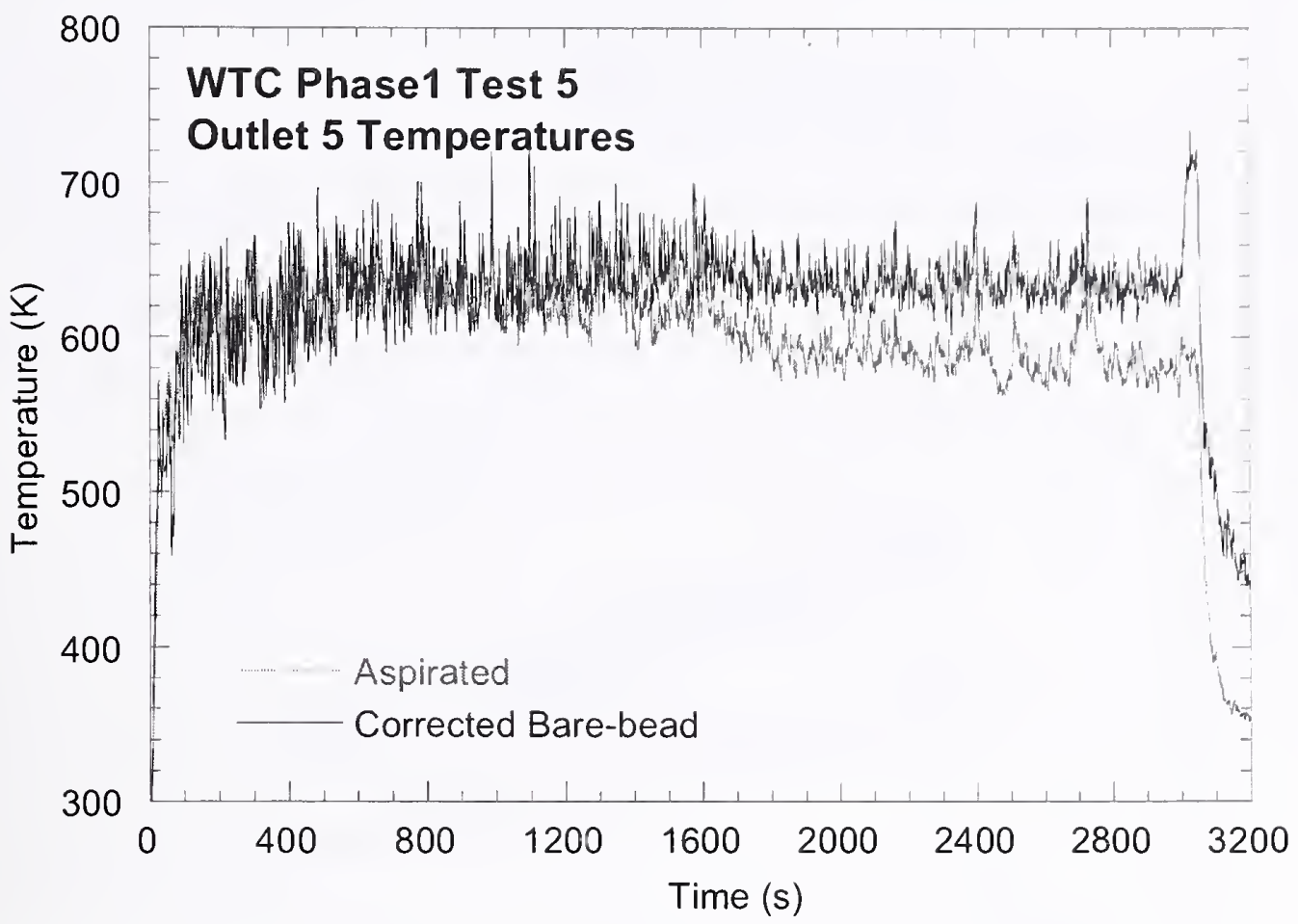

Figure D-41. Aspirated and bare-bead thermocouple temperatures at outlet 5 for Test 5.

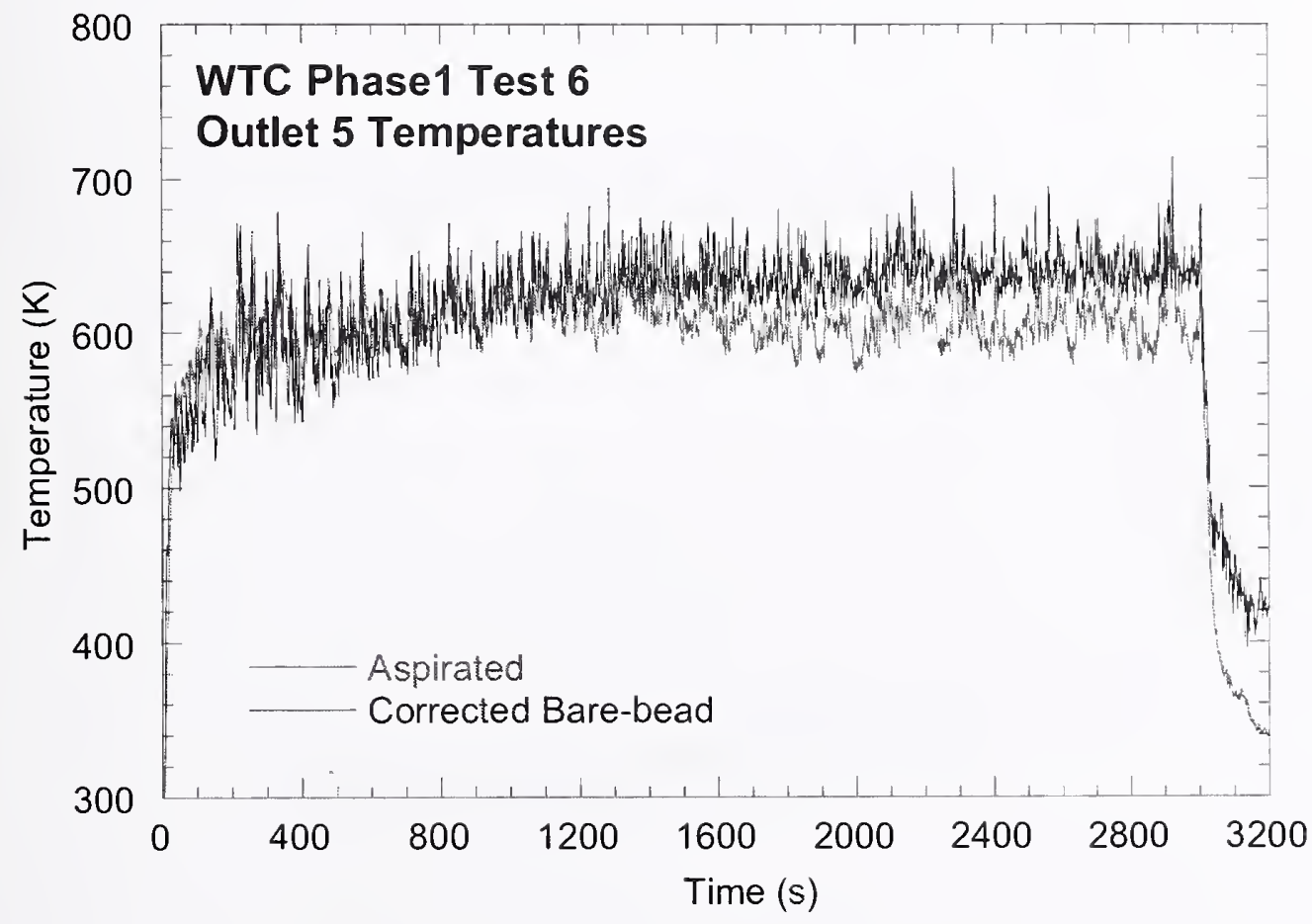

Figure D-42. Aspirated and bare-bead thermocouple temperatures at outlet 5 for Test 6. 
This page intentionally left blank. 


\section{Appendix $E$ \\ Heat Flux Measurements}

This appendix presents heat flux data that was not presented in Chapter 5 of this report (see Figs. E-1 through E-24). Further information on these measurements can be found in Chapter 5.

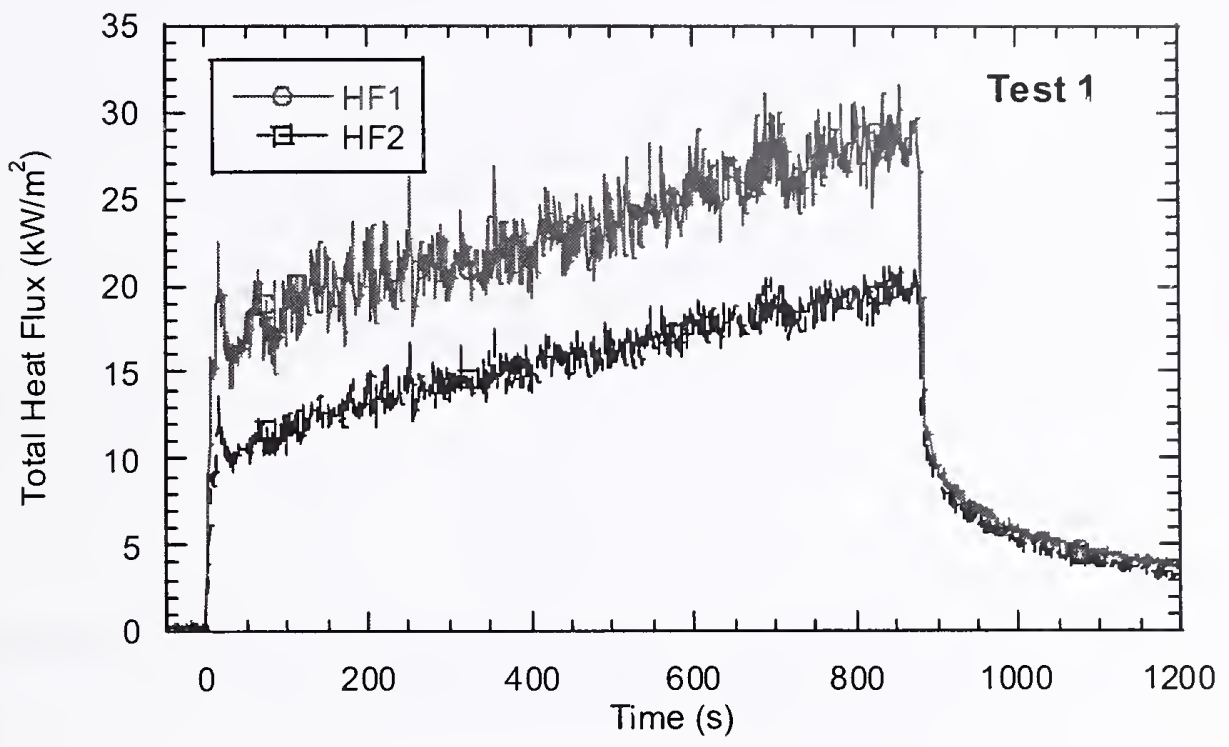

Figure E-1. Total heat flux recorded by the two flux gauges $15 \mathrm{~cm}$ above the floor, just downstream of the fire pan in Test 1.

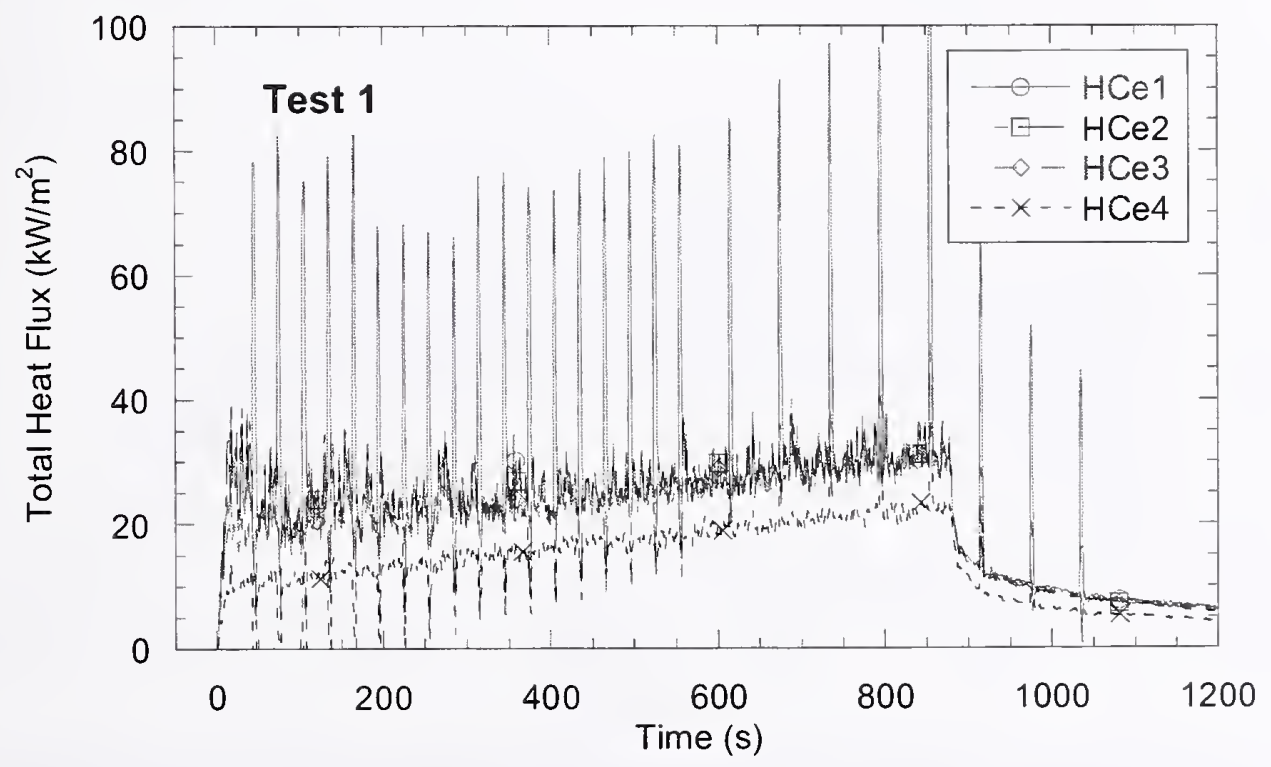

Figure E-2. Total heat flux recorded by the four flux gauges in the compartment ceiling in Test 1. The periodic spikes are due to the soot purge operation. 


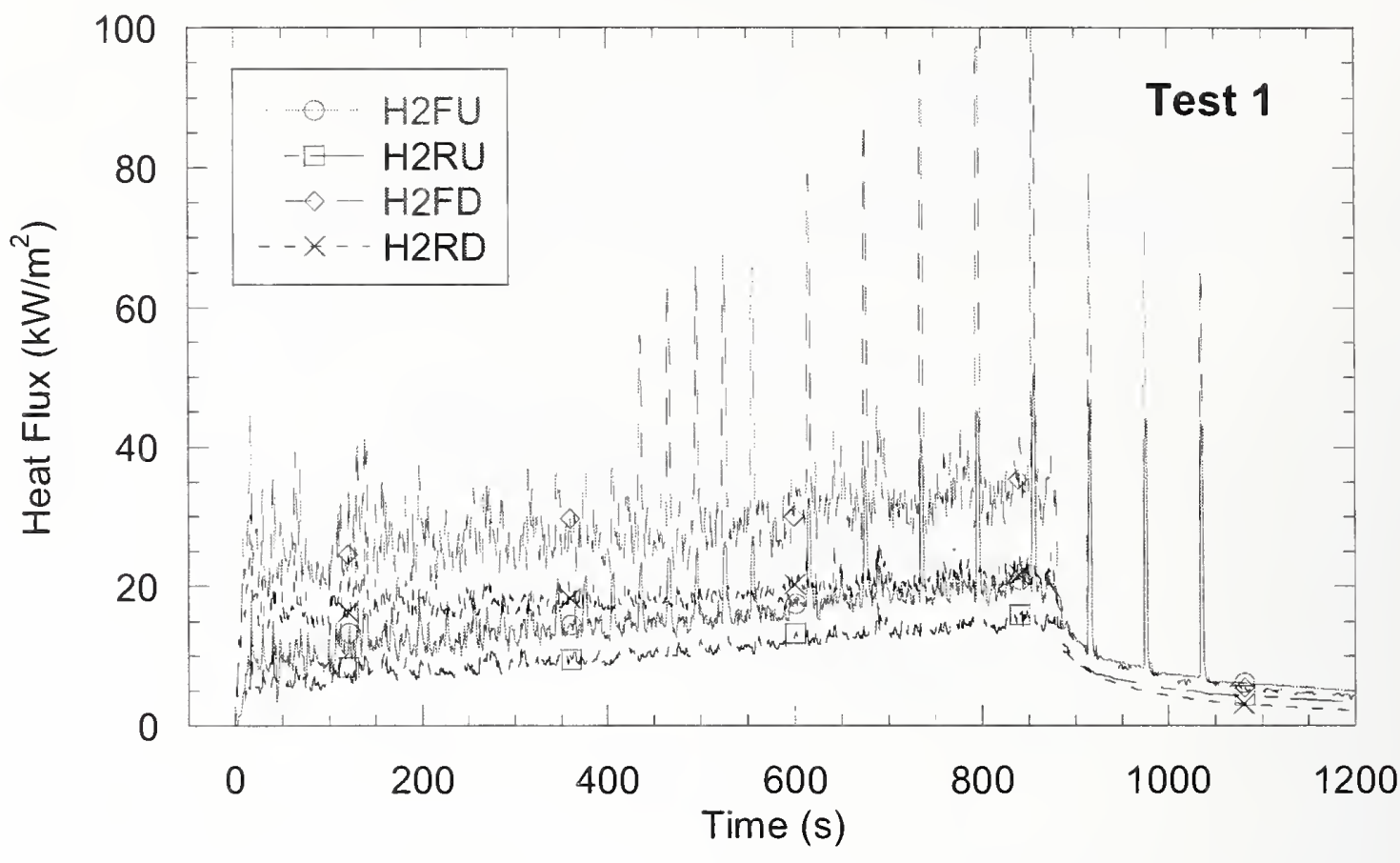

Figure E-3. Heat flux recorded by the two radiometers and two flux gauges in the measurement station in Test 1.

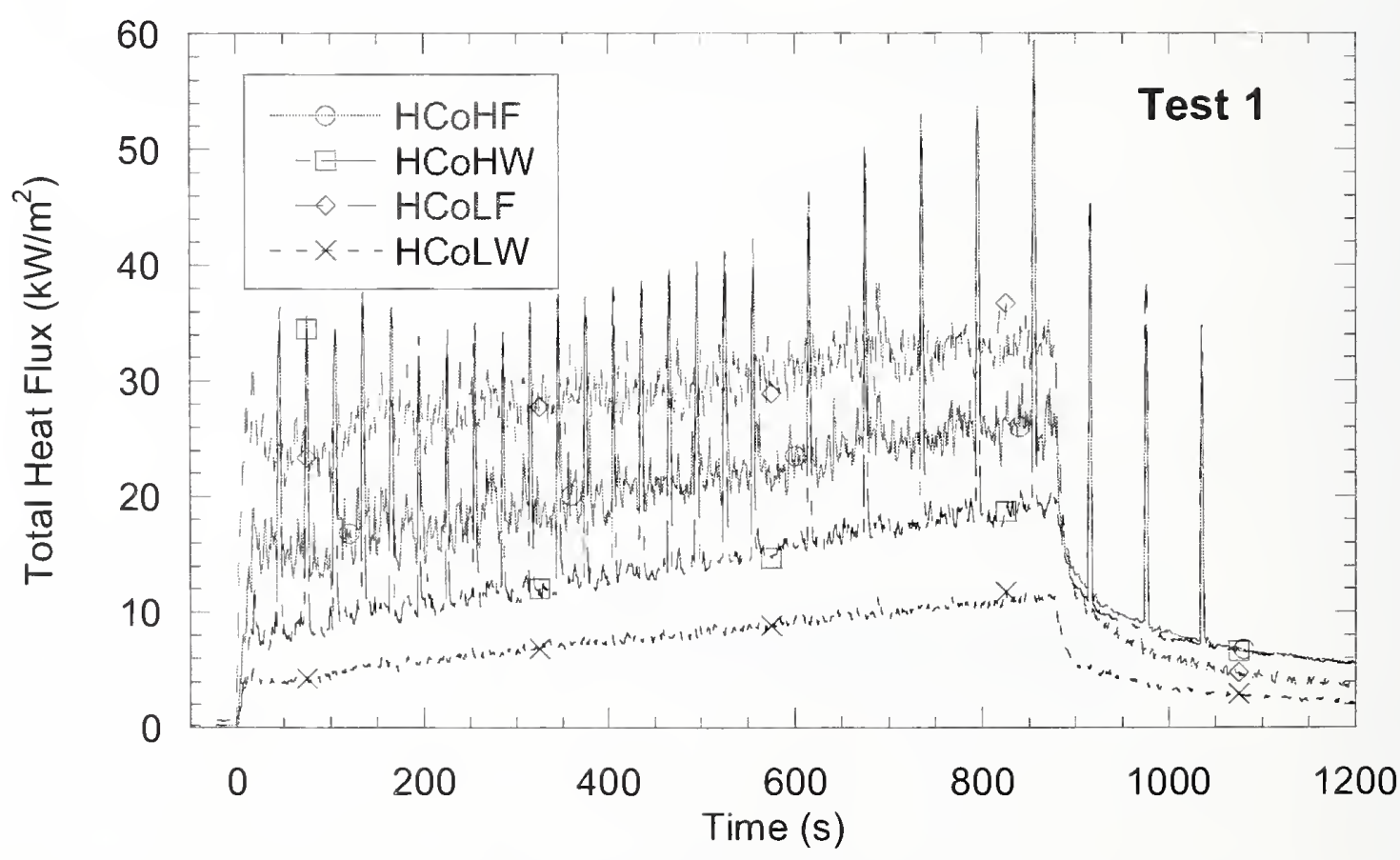

Figure E-4. Heat flux recorded by the two radiometers and two flux gauges on the column in Test 1. 


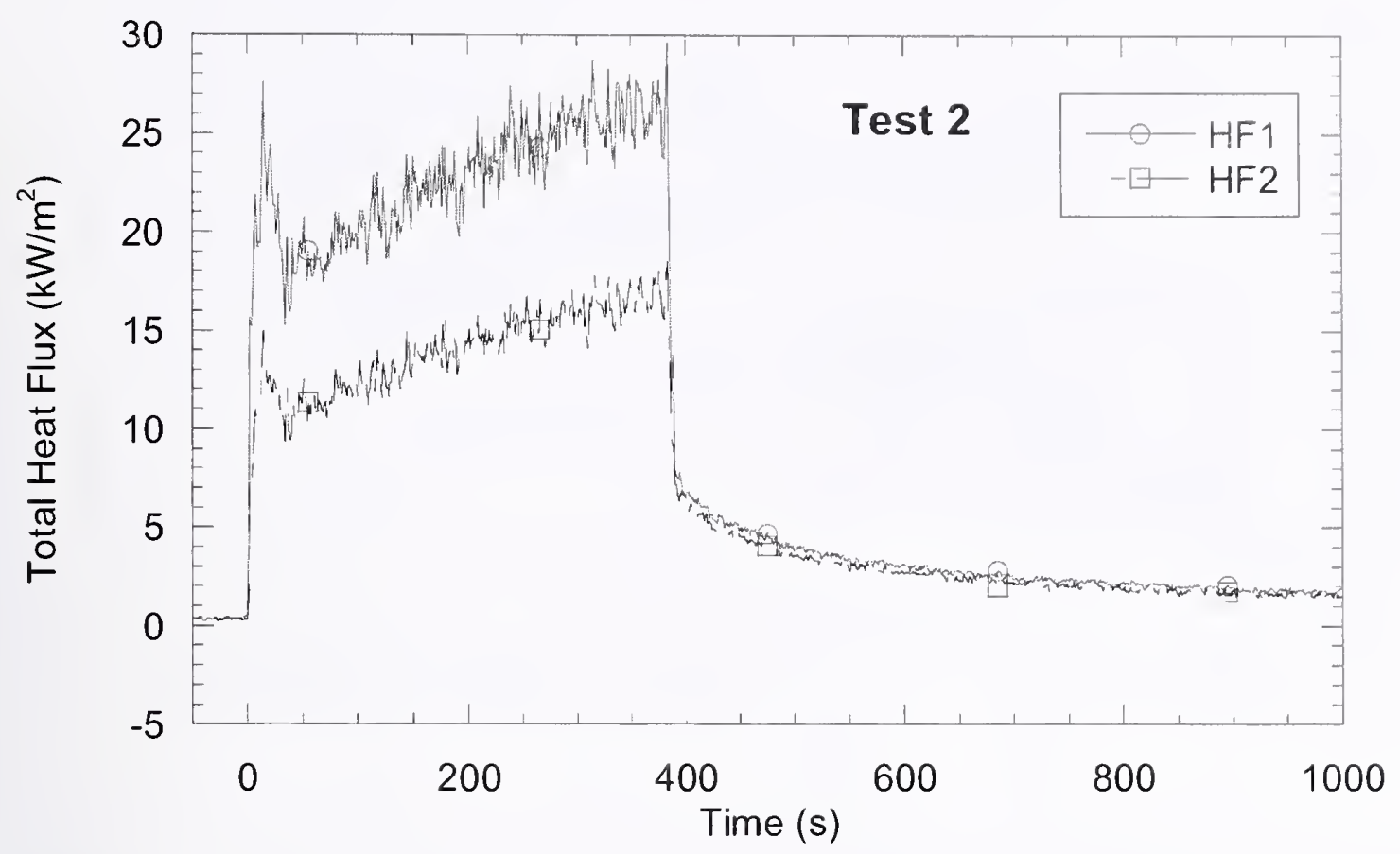

Figure E-5. Total heat flux recorded by the two flux gauges $15 \mathrm{~cm}$ above the floor, just downstream of the fire pan in Test 2.

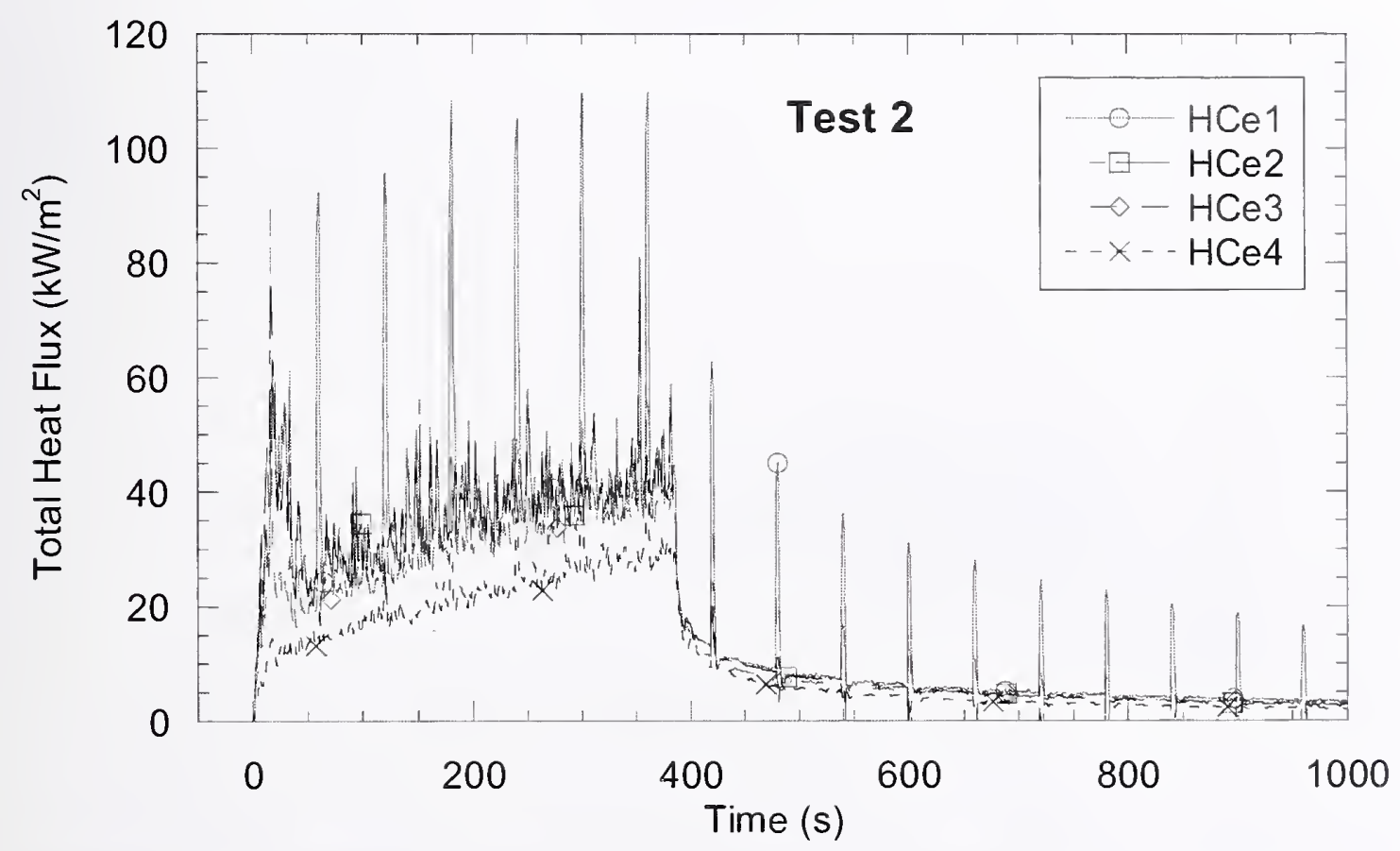

Figure E-6. Total heat flux recorded by the four flux gauges in the compartment ceiling in Test 2. The periodic spikes are due to the soot purge operation. 


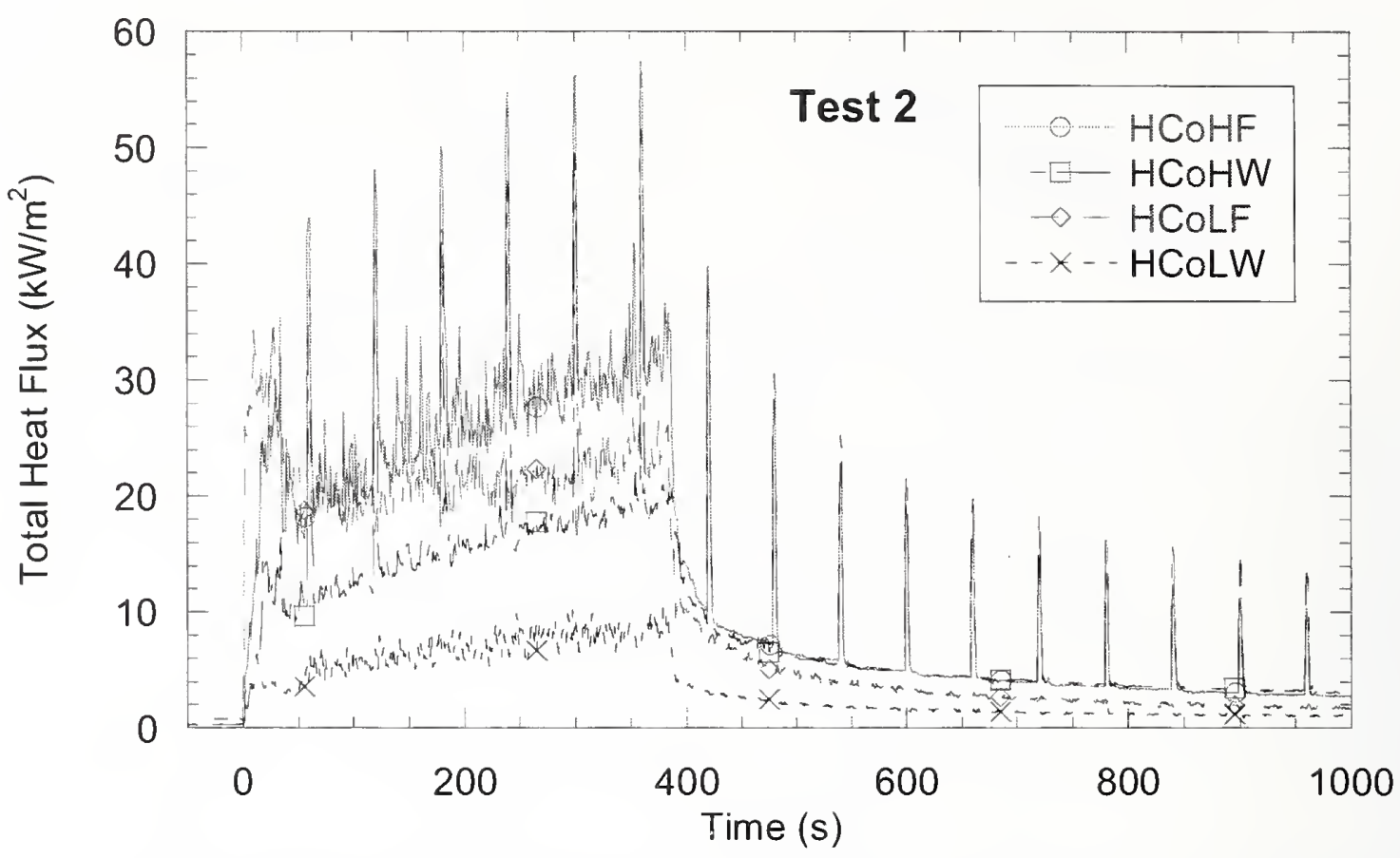

Figure E-7. Total heat flux recorded by the four flux gauges in structures adjacent to the vertical column in Test 2 . The periodic spikes are due to the soot purge operation on the two higher gauges.

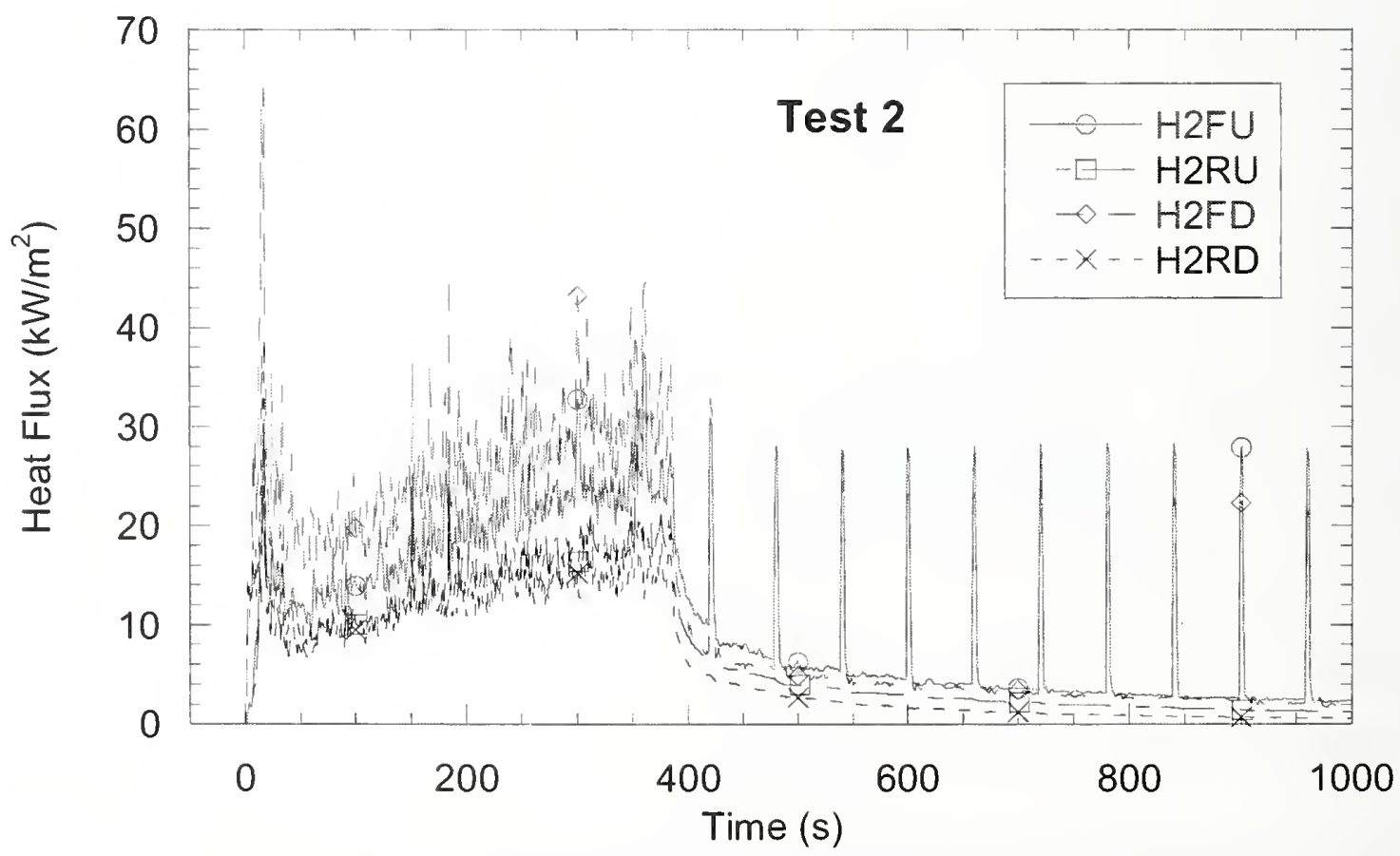

Figure E-8. Heat flux recorded by the two radiometers and two flux gauges in the measurement station in Test 2. 


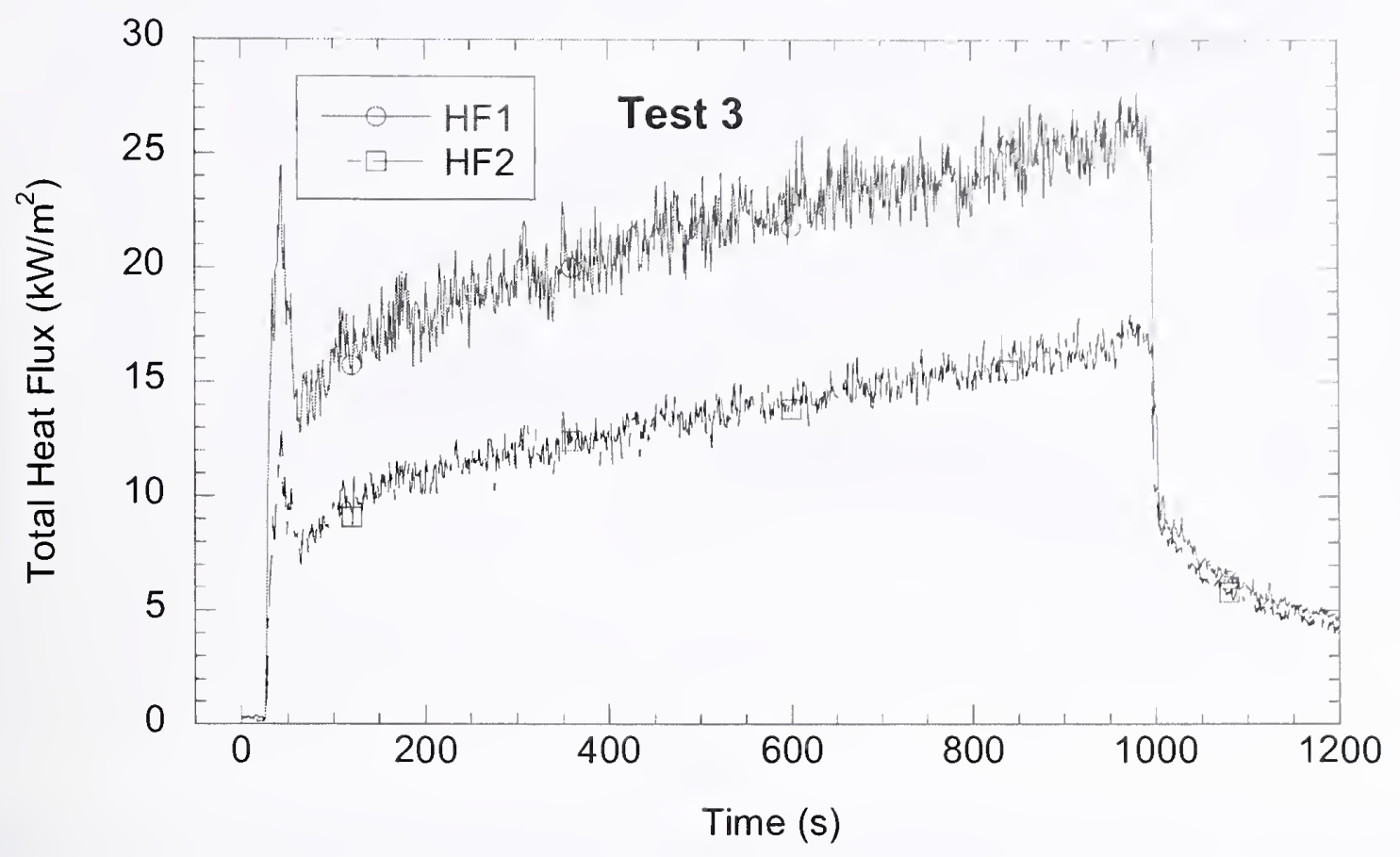

Figure E-9. Total heat flux recorded by the two flux gauges $15 \mathrm{~cm}$ above the floor, just downstream of the fire pan in Test 3.

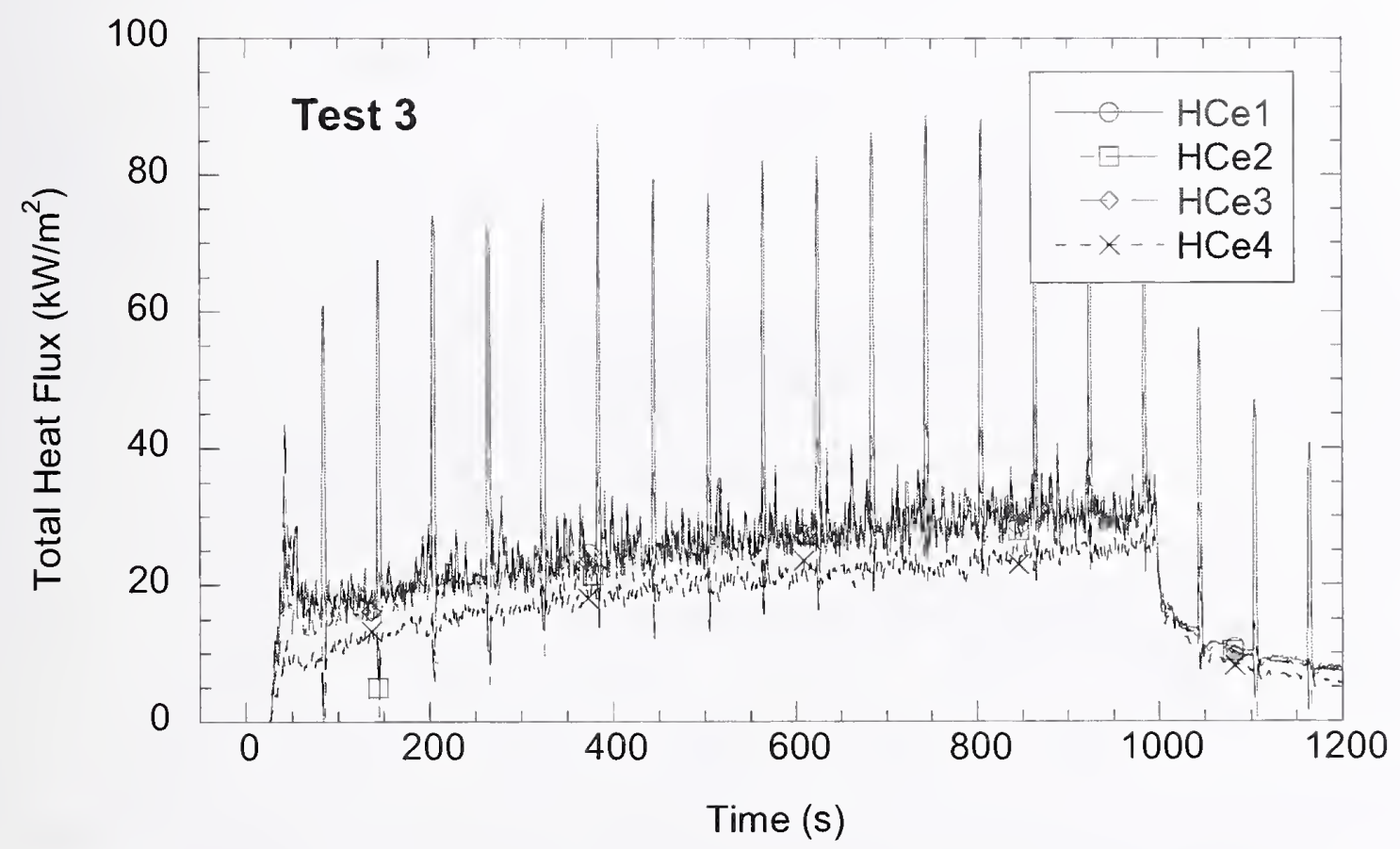

Figure E-10. Total heat flux recorded by the four flux gauges in the compartment ceiling in Test 3. The periodic spikes are due to the soot purge operation. 


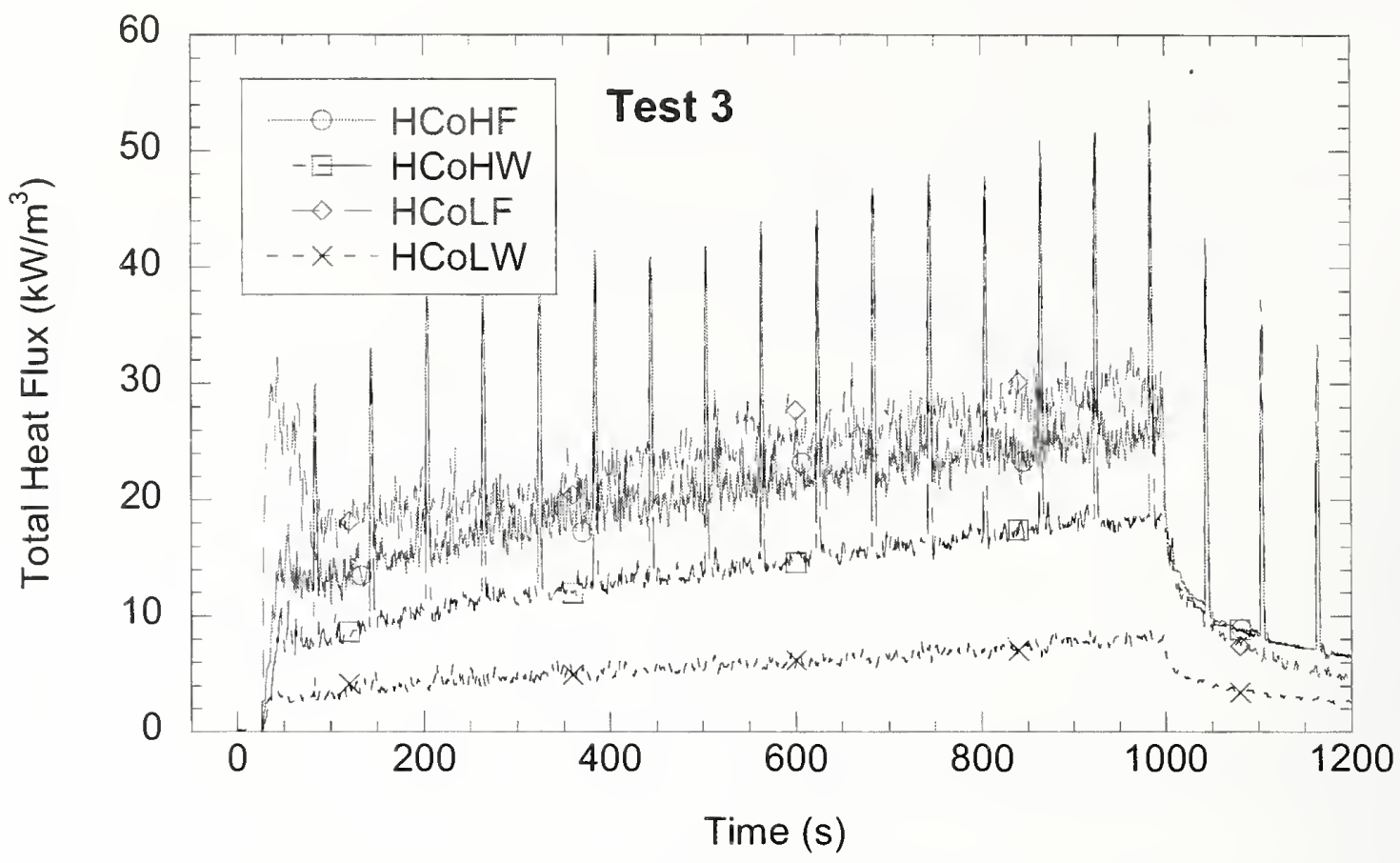

Figure E-11. Total heat flux recorded by the four flux gauges in structures adjacent to the vertical column in Test 3 . The periodic spikes are due to the soot purge operation on the two higher gauges.

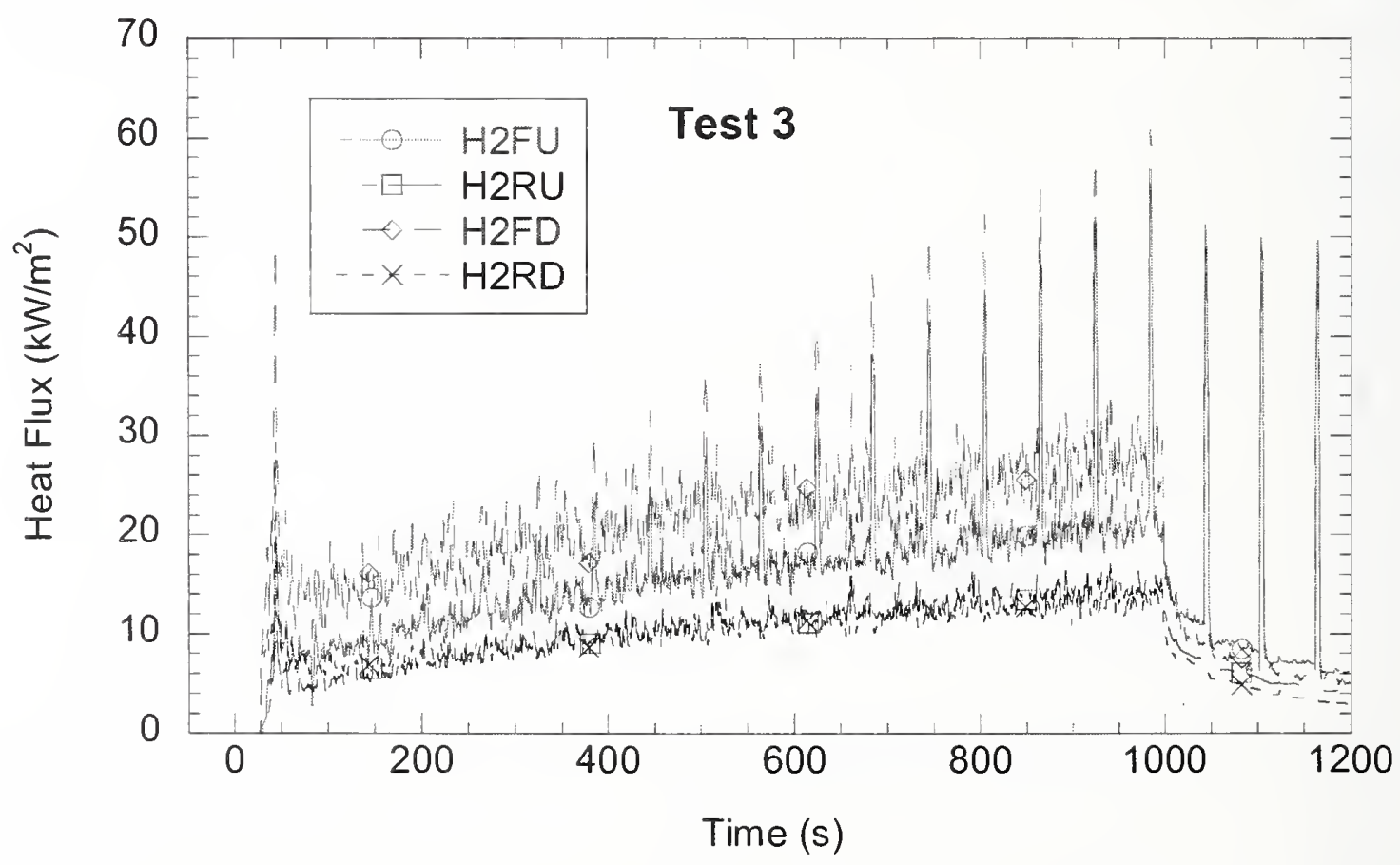

Figure E-12. Heat flux recorded by the two radiometers and two flux gauges in the measurement station in Test 3. 


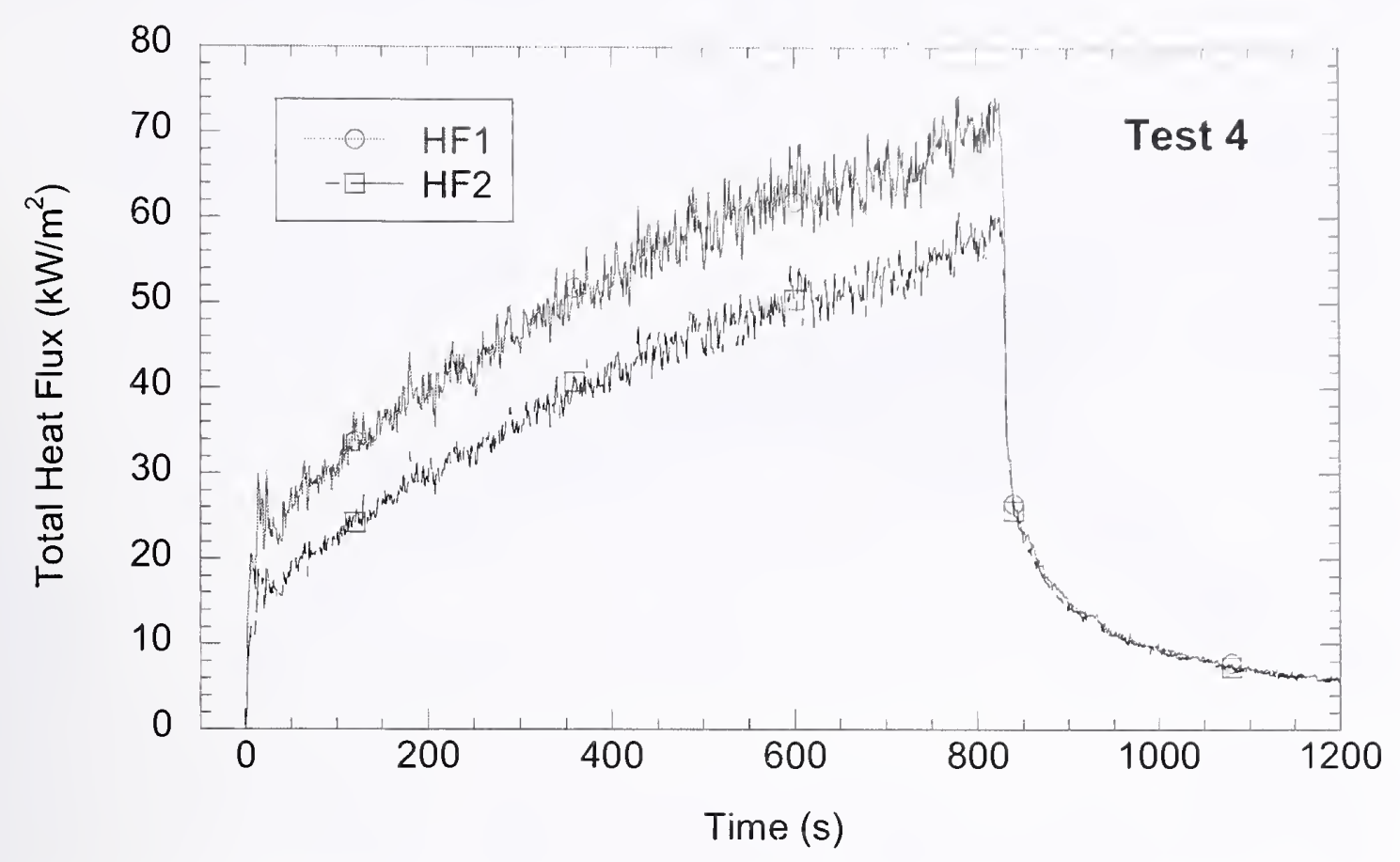

Figure E-13. Total heat flux recorded by the two flux gauges $15 \mathrm{~cm}$ above the floor, just downstream of the fire pan in Test 4.

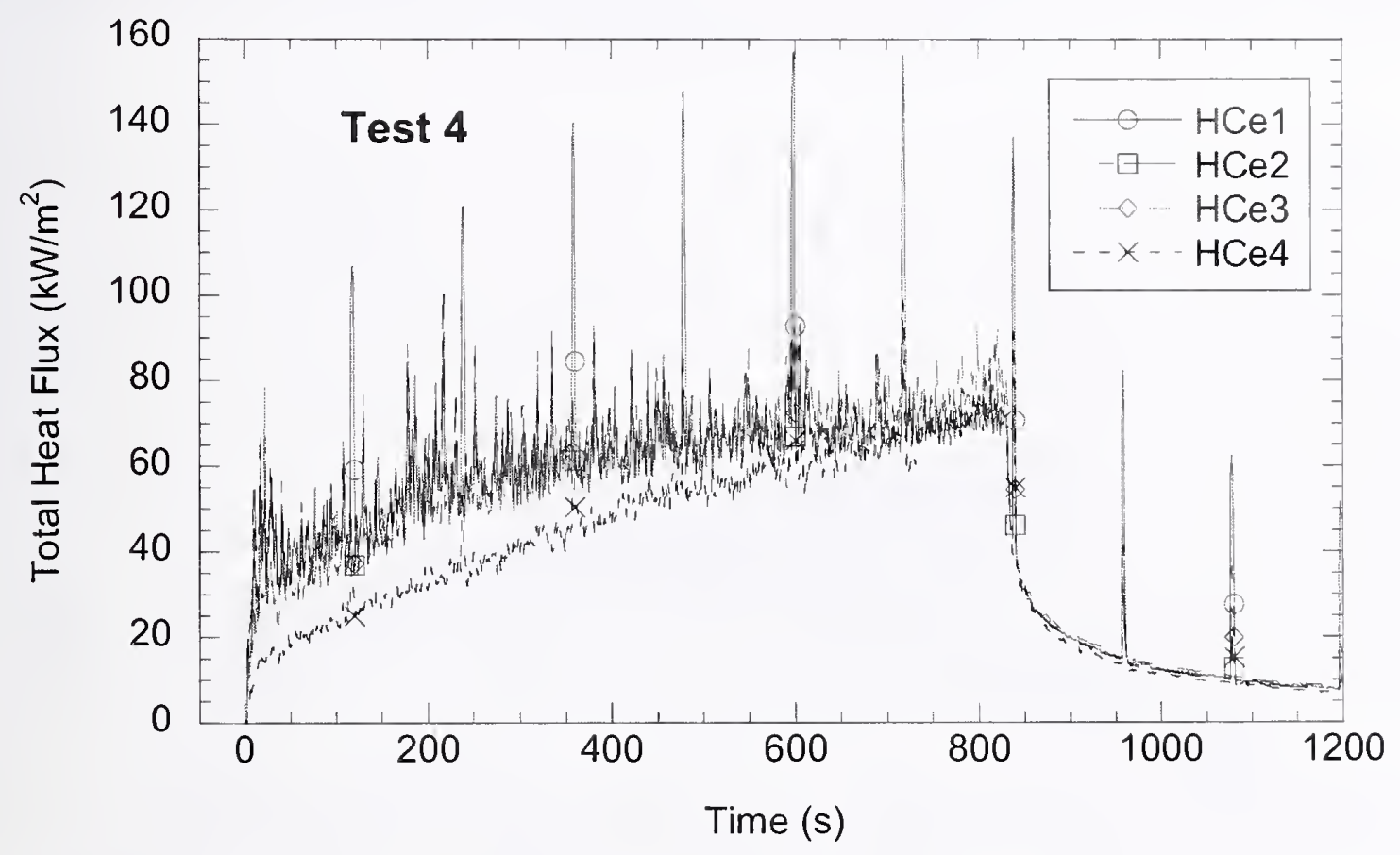

Figure E-14. Total heat flux recorded by the four flux gauges in the compartment ceiling in Test 4. The periodic spikes are due to the soot purge operation. 


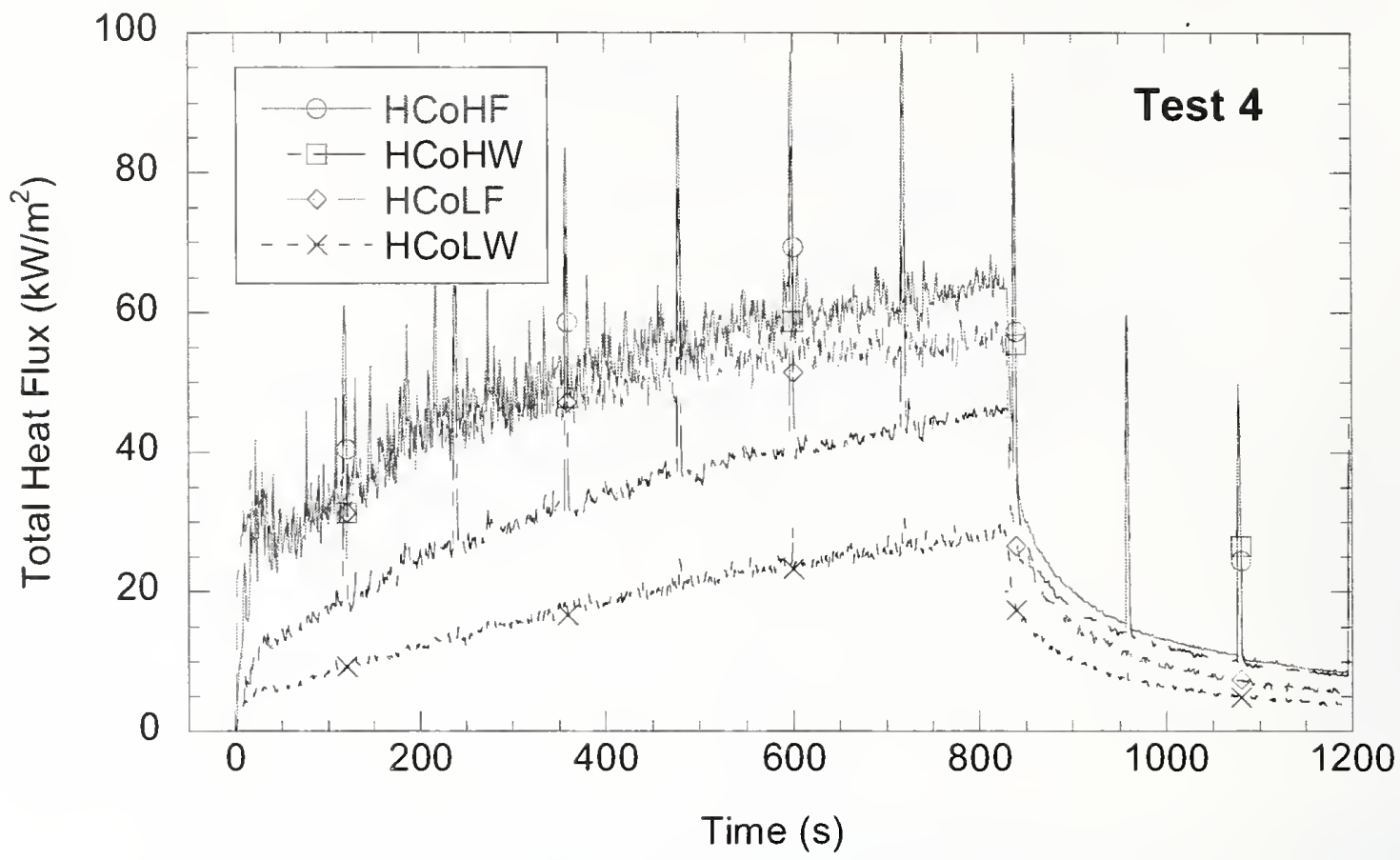

Figure E-15. Total heat flux recorded by the four flux gauges in structures adjacent to the vertical column in Test 4 . The periodic spikes are due to the soot purge operation on the two higher gauges.

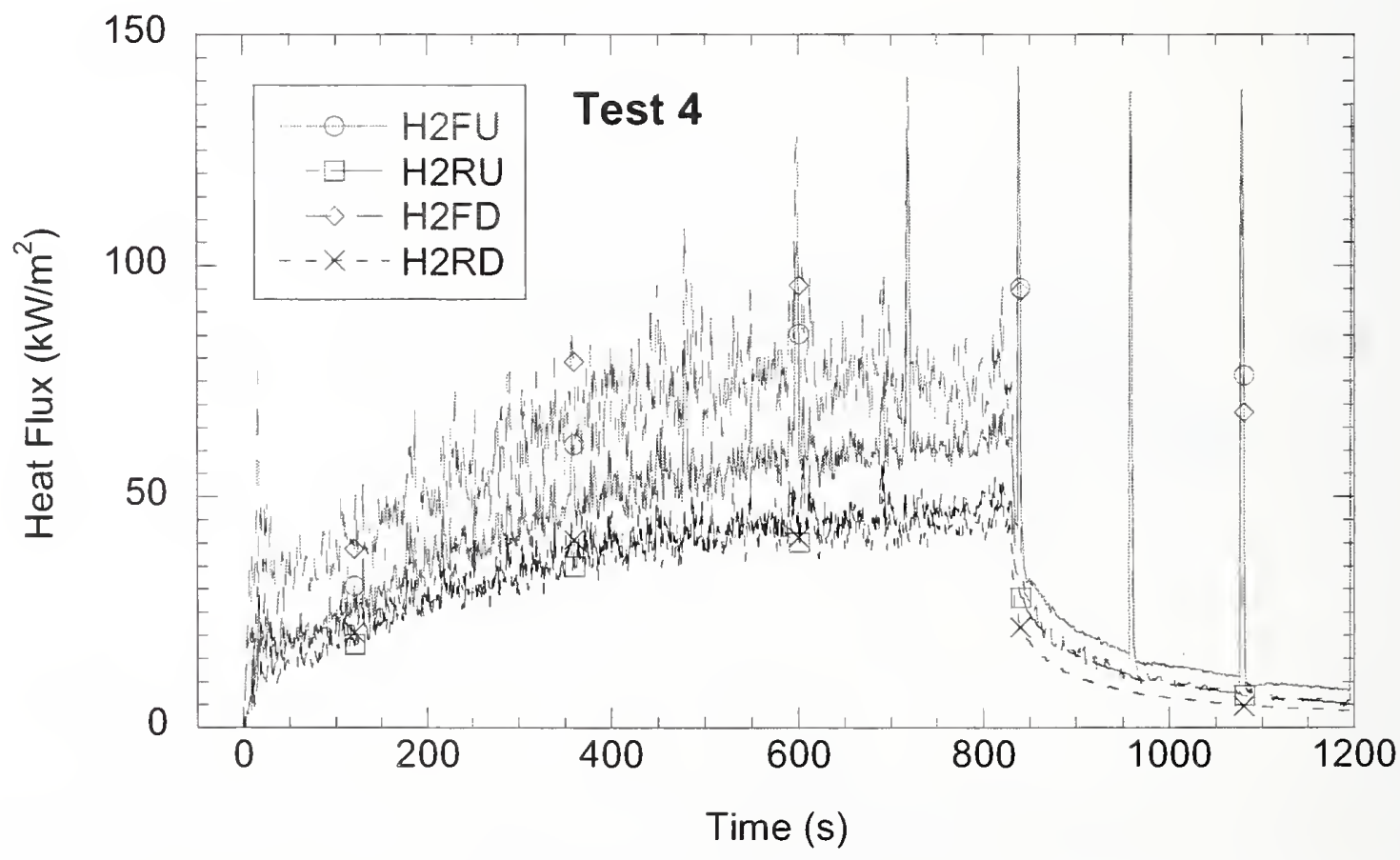

Figure E-16. Heat flux recorded by the two radiometers and two flux gauges in the measurement station in Test 4. 


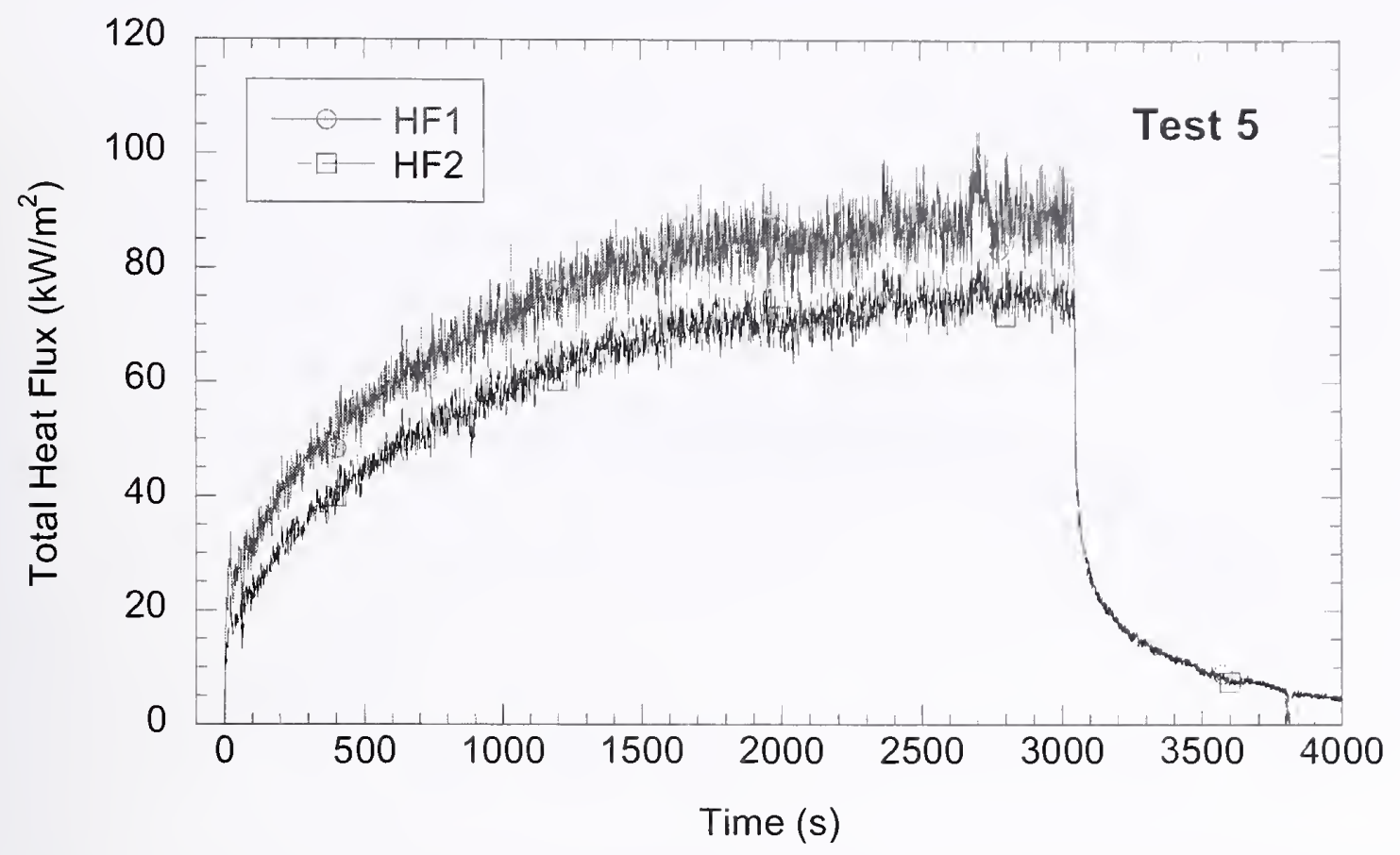

Figure $E-17$. Total heat flux recorded by the two flux gauges $15 \mathrm{~cm}$ above the floor, just downstream of the fire pan in Test 5.

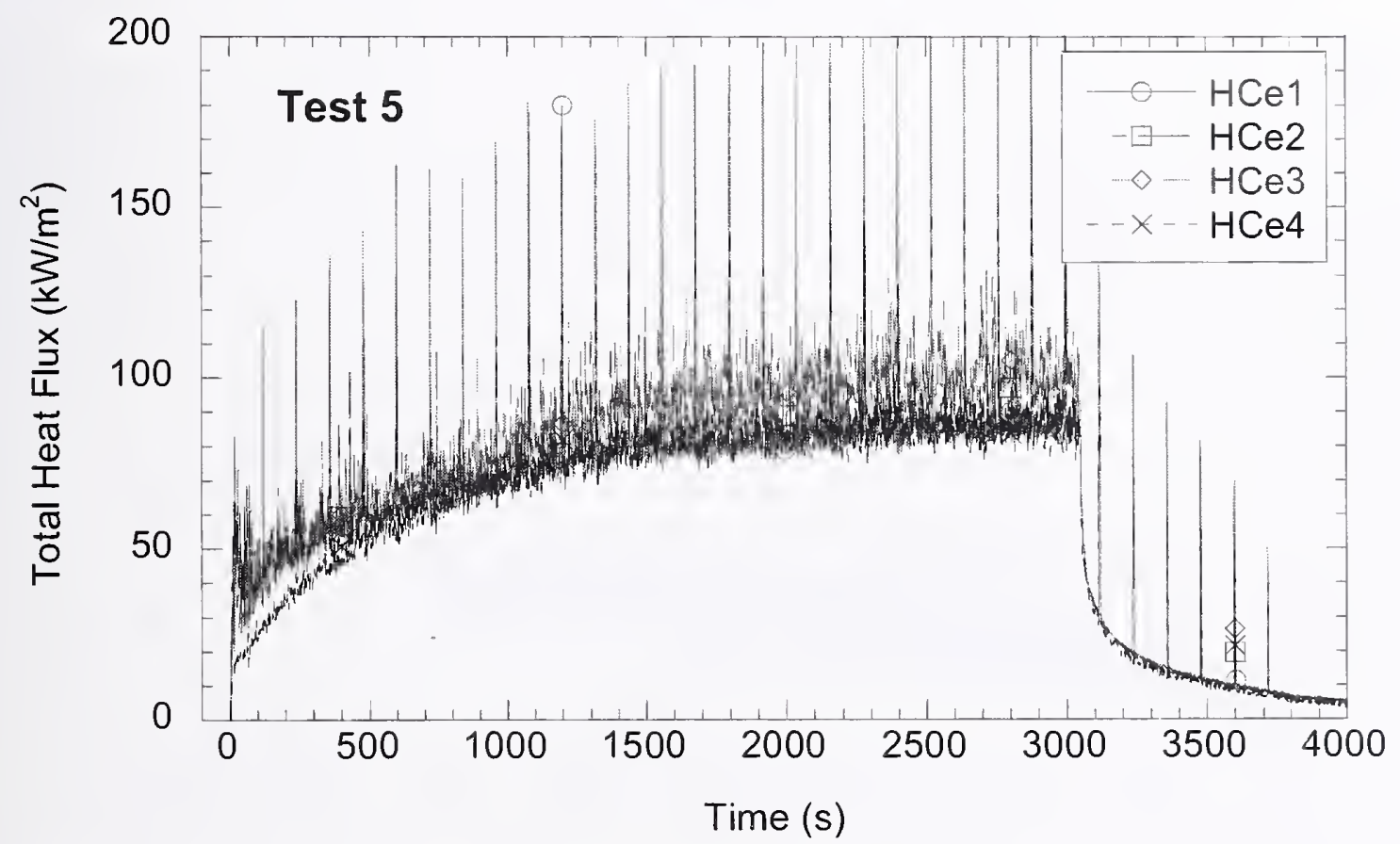

Figure E-18. Total heat flux recorded by the four flux gauges in the compartment ceiling in Test 5 . The periodic spikes are due to the soot purge operation. 


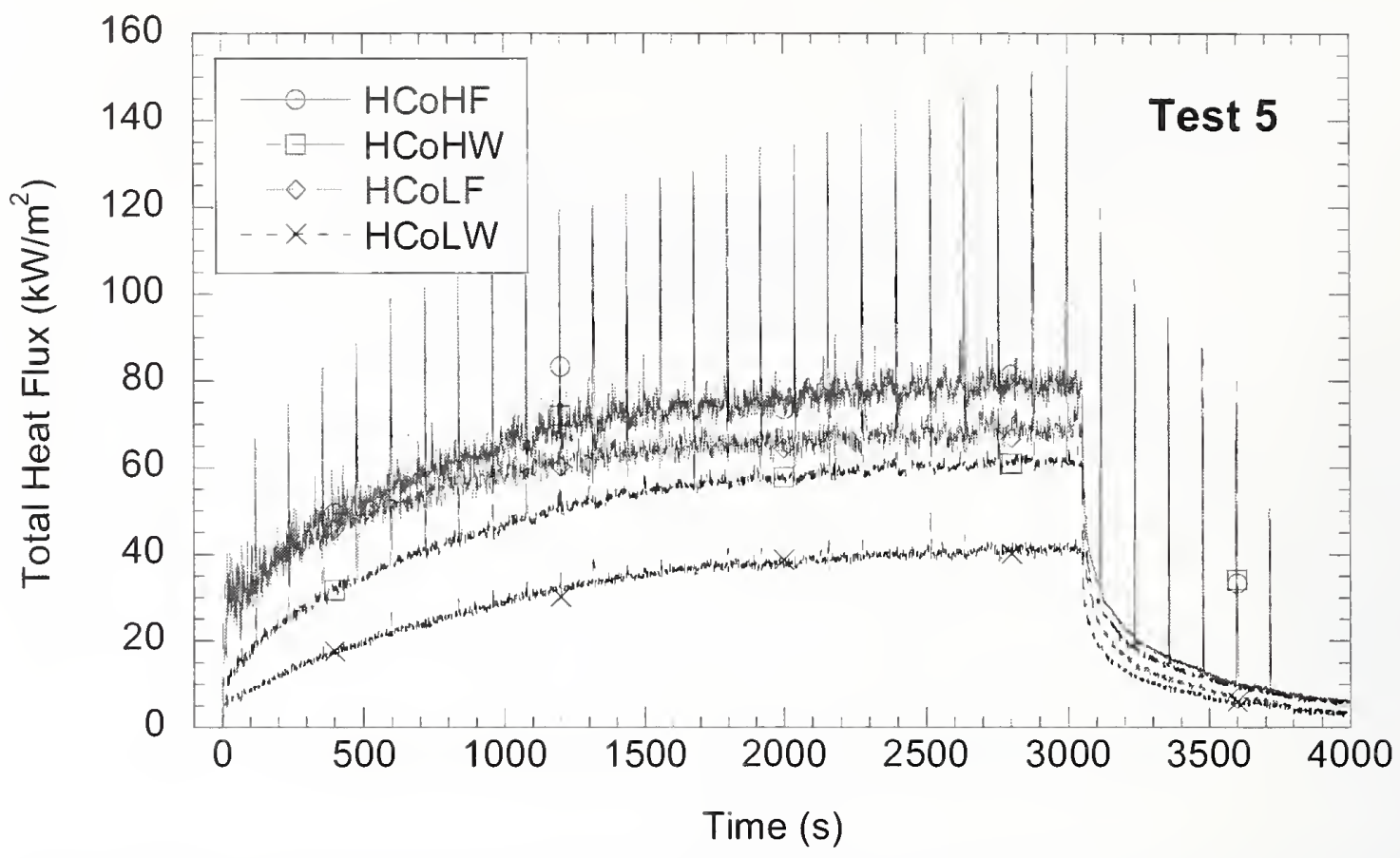

Figure E-19. Total heat flux recorded by the four flux gauges in structures adjacent to the vertical column in Test 5 . The periodic spikes are due to the soot purge operation on the two higher gauges.

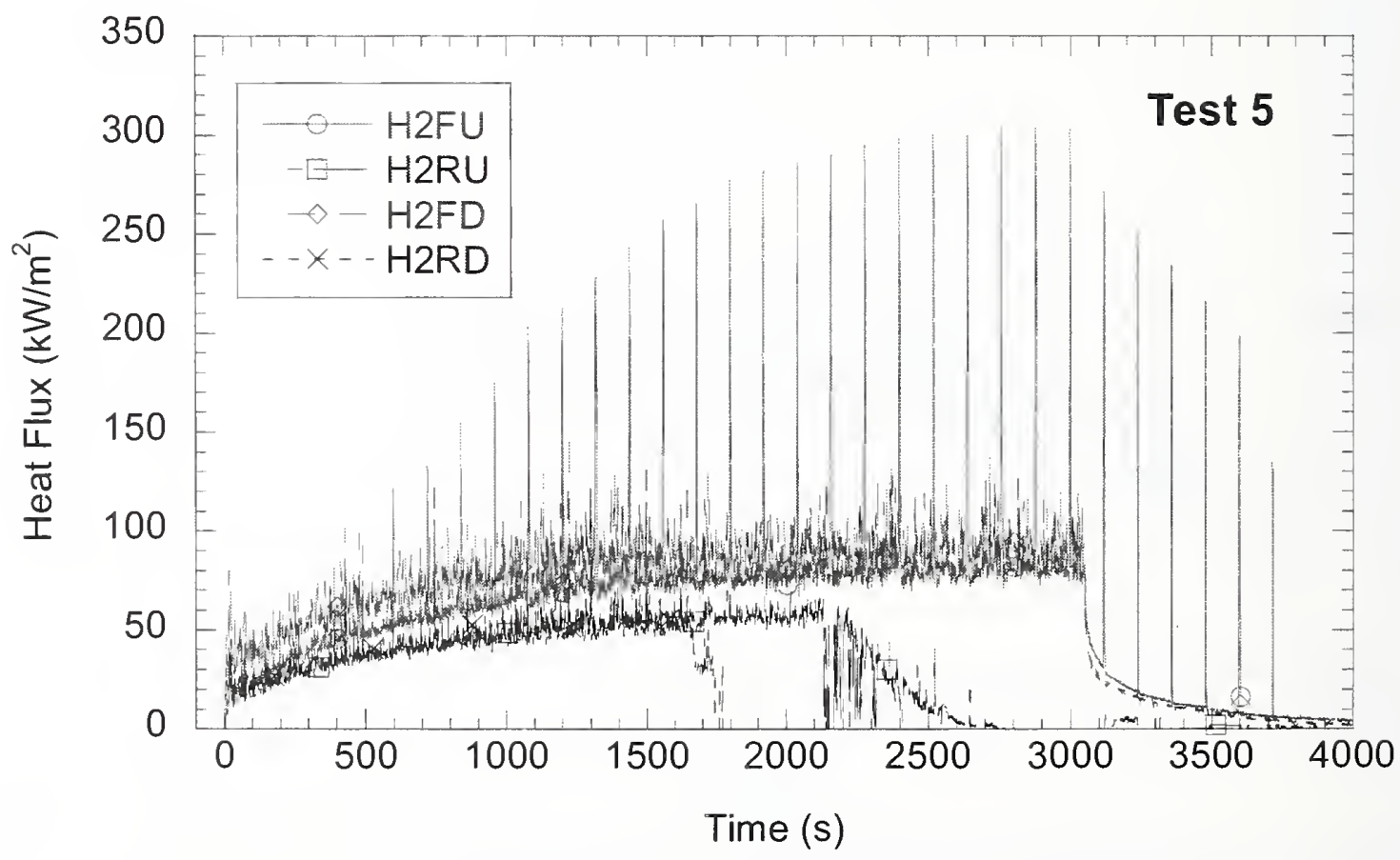

Figure E-20. Heat flux recorded by the two radiometers and two flux gauges in the measurement station in Test 5. Gauges H2RD and H2RU were damaged during the test. 


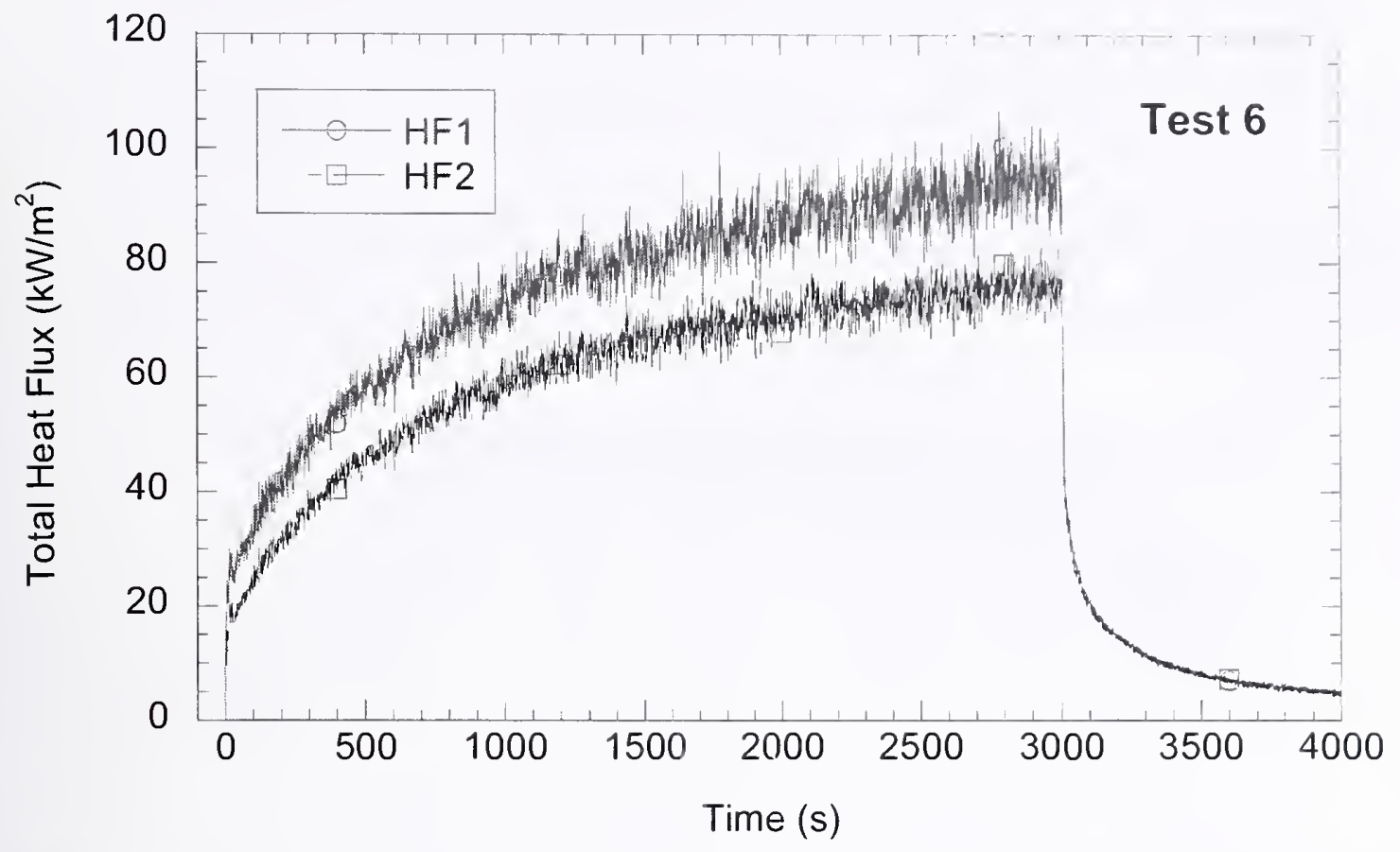

Figure E-21. Total heat flux recorded by the two flux gauges $15 \mathrm{~cm}$ above the floor, just downstream of the fire pan in Test 6.

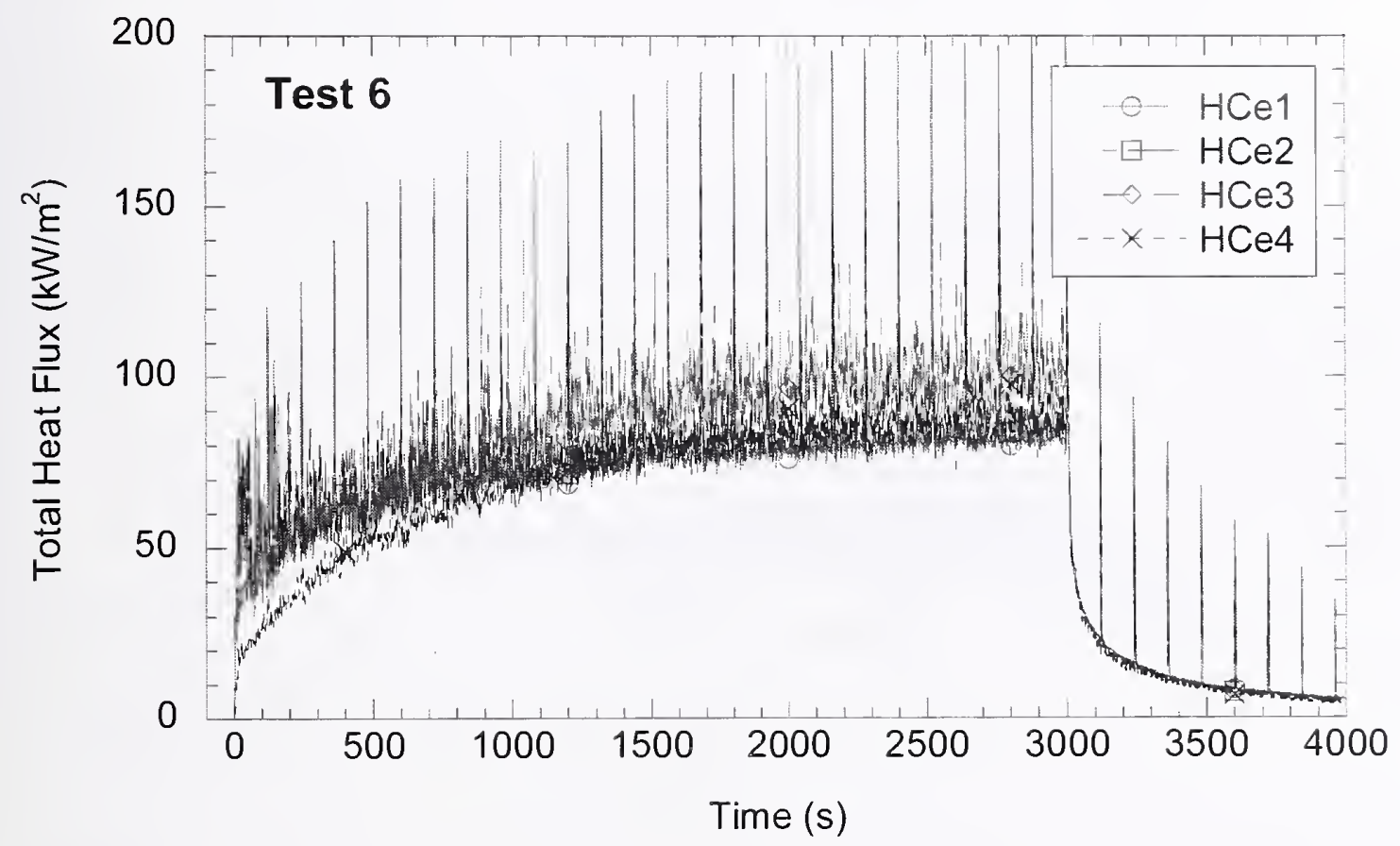

Figure E-22. Total heat flux recorded by the four flux gauges in the compartment ceiling in Test 6 . The periodic spikes are due to the soot purge operation. 


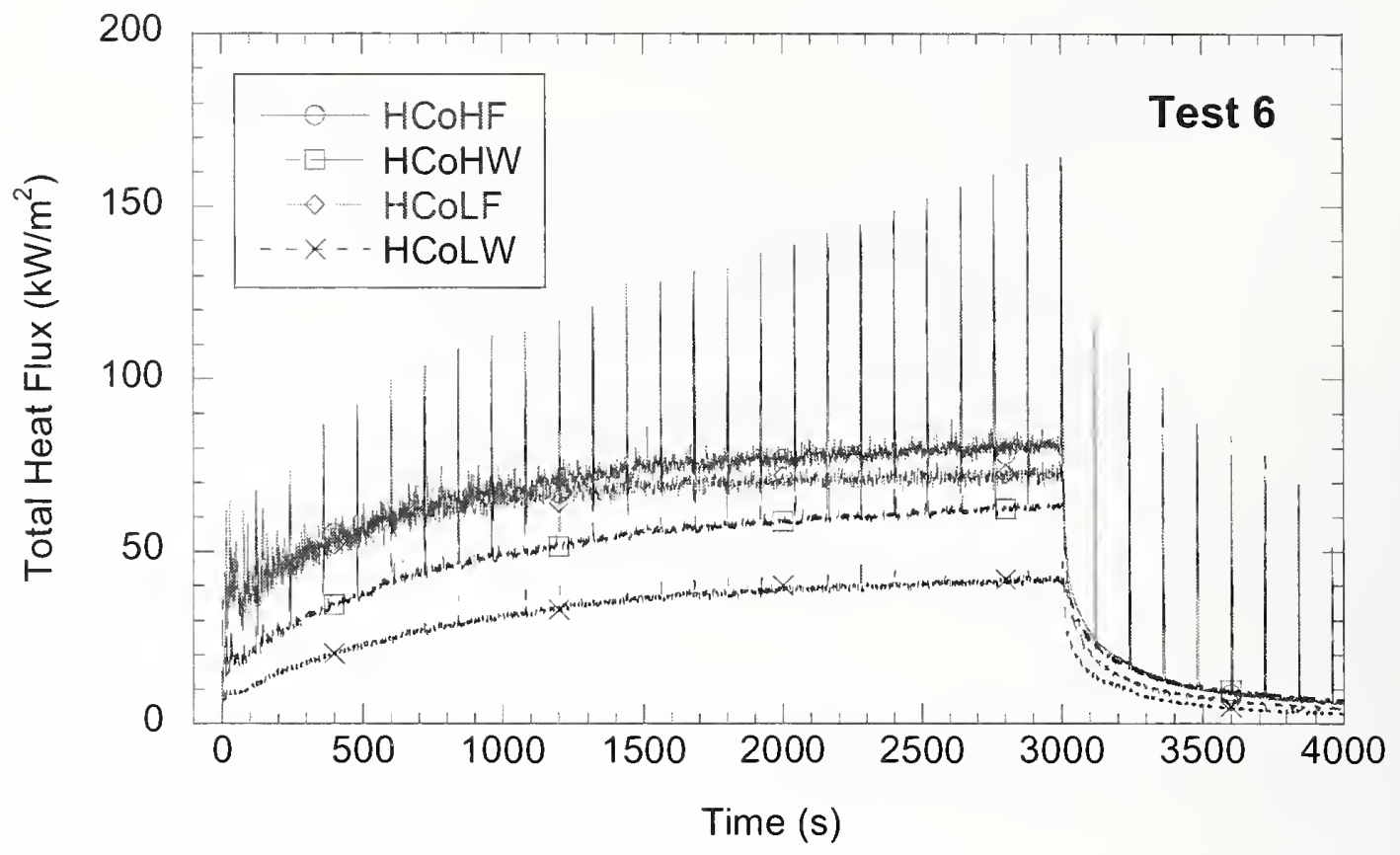

Figure E-23. Total heat flux recorded by the four flux gauges in structures adjacent to the vertical column in Test 6 . The periodic spikes are due to the soot purge operation on the two higher gauges.

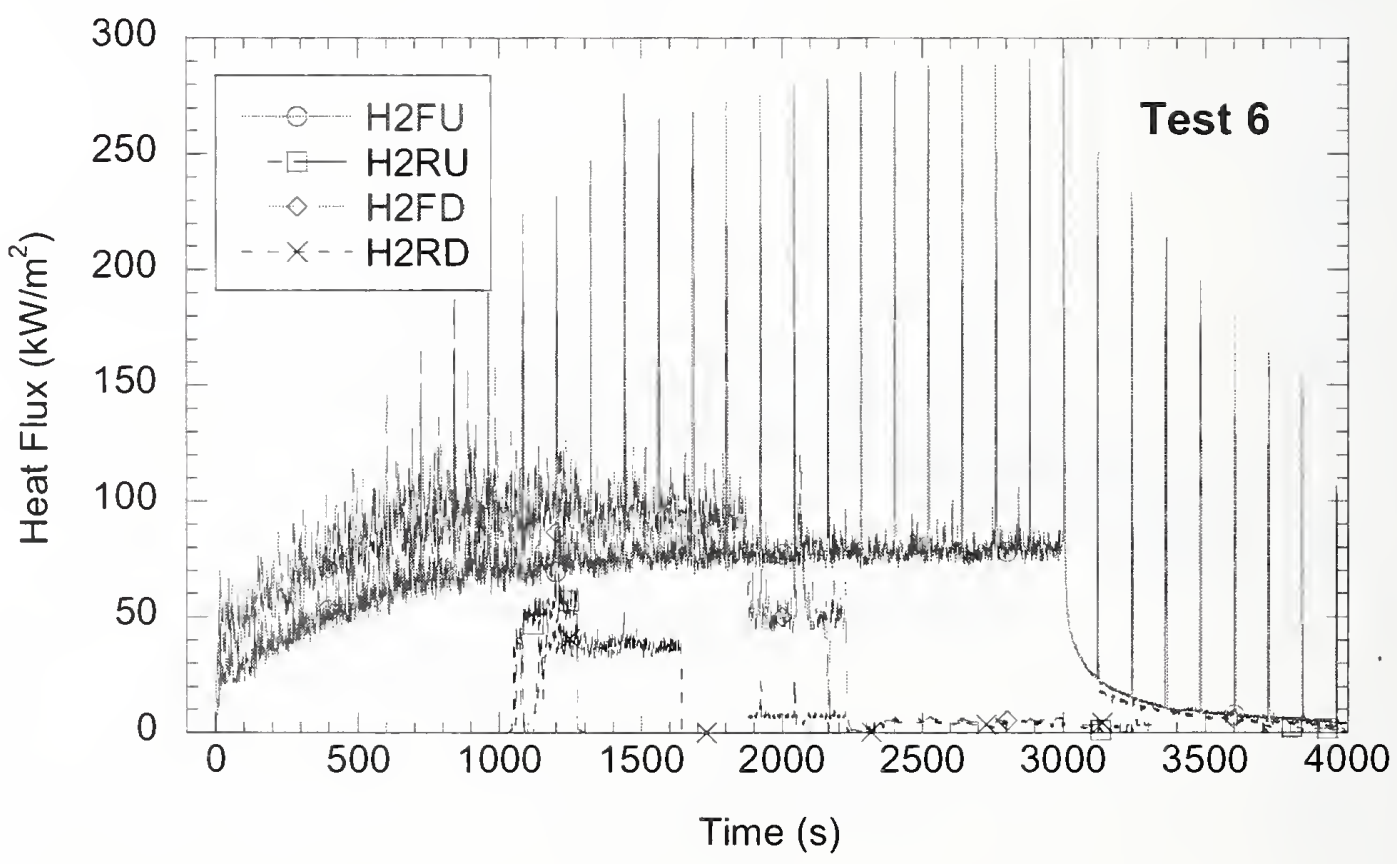

Figure E-24. Heat flux recorded by the two radiometers and two flux gauges in the measurement station in Test 6. Gauges H2FD, H2RU, and H2RD were damaged during the test. 


\section{Appendix F \\ THERMOCOUPLE LOCATIONS ON STEEL COMPONENTS}

Chapter 9 presents representative measurements of the temperature on the surface of the steel components and the sprayed fire-resistive material (SFRM) applied to those components. This appendix documents the location of the thermocouples on the surface of the SFRM and the steel components in terms of their position within the test compartment (Tables F-1 through F-5).

Table F-1. Thermocouple locations on bars in Tests 1, 2, and 3.

\begin{tabular}{|c|c|c|c|}
\hline Simple Bar & \multicolumn{3}{|c|}{ Test Chamber Coordinates (cm) } \\
\hline TC label & $\underline{\mathbf{X}}$ & $\underline{\mathbf{Z}}$ & $\underline{\mathbf{Z}}$ \\
\hline Location 1 & & & \\
\hline B-1 & 350 & 108 & 295 \\
\hline B-2 & 350 & 17 & 295 \\
\hline B-3 & 350 & -43 & 295 \\
\hline B-4 & 350 & -134 & 295 \\
\hline Location 2 & & & \\
\hline B-1 & 500 & 102 & 295 \\
\hline B-2 & 500 & 12 & 295 \\
\hline B-3 & 500 & -49 & 295 \\
\hline B-4 & 500 & -139 & 295 \\
\hline
\end{tabular}

Table F-2. Thermocouple locations on bars in Tests 5 and 6.

\begin{tabular}{|c|c|c|c|}
\hline Simple Bar & \multicolumn{3}{|c|}{ Test Chamber Coordinates $(\mathbf{c m})$} \\
\hline TC Label & $\underline{\mathbf{X}}$ & $\underline{\mathbf{Y}}$ & $\underline{\mathbf{Z}}$ \\
\hline Location 1 & & & \\
\hline B-1 & 350 & 150 & 295 \\
\hline B-2 & 350 & 58 & 295 \\
\hline B-3 & 350 & -3 & 295 \\
\hline B-4 & 350 & -94 & 295 \\
\hline
\end{tabular}


Table F-3. Thermocouple locations on columns.

\begin{tabular}{|c|c|c|c|}
\hline $\begin{array}{c}\text { Column } \\
\text { Face Orientation } \\
1 \text { North } 2 \text { East } \\
3 \text { South } 4 \text { West }\end{array}$ & \multicolumn{3}{|c|}{ Test Chamber Coordinates $(\mathrm{cm})$} \\
\hline TC Label & $\underline{\mathbf{x}}$ & $\underline{Y}$ & $\underline{\mathbf{Z}}$ \\
\hline CU-1 & 281 & 69 & 369 \\
\hline $\mathrm{CU}-2$ & 299 & 55 & 369 \\
\hline $\mathrm{CU}-3$ & 281 & 41 & 369 \\
\hline $\mathrm{CU}-4$ & 263 & 55 & 369 \\
\hline $\mathrm{CM}-1$ & 281 & 69 & 213 \\
\hline $\mathrm{CM}-2$ & 299 & 55 & 213 \\
\hline $\mathrm{CM}-3$ & 281 & 41 & 213 \\
\hline $\mathrm{CM}-4$ & 263 & 55 & 213 \\
\hline CL-1 & 281 & 69 & 77 \\
\hline $\mathrm{CL}-2$ & 299 & 55 & 77 \\
\hline CL-3 & 281 & 41 & 77 \\
\hline CL-4 & 263 & 55 & 77 \\
\hline
\end{tabular}

Key: CU, column upper; CM, column middle; CL, column lower.

Table F-4. Thermocouple locations on truss A (location 1).

\begin{tabular}{|c|c|c|c|}
\hline Truss $\mathbf{A}$ & \multicolumn{3}{|c|}{ Test Chamber Coordinates $(\mathbf{c m})$} \\
\hline TC Label & $\underline{\mathbf{X}}$ & $\underline{\mathbf{Y}}$ & $\underline{\mathbf{Z}}$ \\
\hline TU-1 & 164 & -8 & 370 \\
\hline TU-2 & 313 & -8 & 370 \\
\hline TU-3 & 388 & -8 & 370 \\
\hline TU-4 & 537 & -8 & 370 \\
\hline TM-1 & 199 & -8 & 329 \\
\hline TM-2 & 335 & -8 & 329 \\
\hline TM-3 & 365 & -8 & 329 \\
\hline TM-4 & 502 & -8 & 329 \\
\hline TL-1 & 250 & -8 & 289 \\
\hline TL-2 & 300 & -8 & 289 \\
\hline TL-3 & 401 & -8 & 289 \\
\hline TL-4 & 451 & -8 & 289 \\
\hline
\end{tabular}

Key: TU, truss upper chord; TM, truss middle (web); TL, truss lower chord. 
Table F-5. Thermocouple locations on truss B (location 2).

\begin{tabular}{|c|c|c|c|}
\hline \multirow{2}{*}{ Truss B } & \multicolumn{3}{|c|}{ Test Chamber Coordinates $(\mathrm{cm})$} \\
\hline TC Label & $\underline{\mathbf{X}}$ & $\underline{\mathbf{Y}}$ & $\underline{\mathbf{Z}}$ \\
\hline TU-1 & 164 & -56 & 370 \\
\hline TU-2 & 313 & -56 & 370 \\
\hline TU-3 & 388 & -56 & 370 \\
\hline TU-4 & 537 & -56 & 370 \\
\hline TM-1 & 199 & -56 & 329 \\
\hline TM-2 & 335 & -56 & 329 \\
\hline TM-3 & 365 & -56 & 329 \\
\hline TM-4 & 502 & -56 & 329 \\
\hline TL-1 & 250 & -56 & 289 \\
\hline TL-2 & 300 & -56 & 289 \\
\hline TL-3 & 401 & -56 & 289 \\
\hline TL-4 & 451 & -56 & 289 \\
\hline
\end{tabular}

Key: TU, truss upper chord; TM, truss middle (web); TL, truss lower chord. 
This page intentionally left blank. 


\section{Appendix G \\ Temperature Histories of Bare and CoAted Steel COMPONENTS}

Chapter 9 presents represcntative mcasurcments of the temperaturc on the surfacc of the stccl components and the sprayed firc-resistive matcrial (SFRM) applied to thosc components. This appendix prescnts the measured temperature histories recorded for steel components and not shown in Chaptcr 9.

\section{G.1 BARE STEEL COMPONENTS}

Tests 1, 2, and 3 exposed the same set of two bars, one eolumn, and two trusses to dircct cxposurc of heat flux and temperatures from a fuel pan firc. In all three tests, the thermal responsc of thesc components to flame proximity or immcrsion was similar. The steel began to heat immediately upon initiation of the fire and to cool immediatcly after the fire was extinguished. The rccordcd response showed no lag timc between the steel and gas for transfcrring radiant hcat from the higher to lower tempcraturc mcdiums. Test 1 steel surface temperatures are shown in See. G.1.1, Figs. G-1 through G-5; Tcst 2 tempcraturcs arc shown in See. G.1.2, Figs. G-6 through G-10; Test 3 tempcraturcs arc shown in Sec. G.1.3, Figs. G-11 through $\mathrm{G}-15$.

Bar A and both truss A and truss B were loeated over the fire pan, but the firc tended to lean with the airflow through the chamber and primarily immerse bar $\mathrm{A}$ and truss $\mathrm{B}$ in flames. The recorded thermoeouple temperatures for these components (1) are $50{ }^{\circ} \mathrm{C}$ to $75^{\circ} \mathrm{C}$ higher than those recorded for bar B (Figs. G-2, G-7, and G-12) and truss A (Figs. G-4, G-9, and G-14) and (2) have a high frequency component imposed upon the average temperature. These bchaviors can be seen for thermocouples TB3 and TB4 on the bars and thermoeouples TL3, TU3, TL4, and TU2 on the trusses. See Figs. G-1, G-6, and G-11 for bar A and Figs. G-5, G-10, G-15 for truss B. Notc that thermocouples TM2 and TM4 on truss B showed some irregularities in the eool down phase in Test 1, after the fire was extinguished, which was not evident in Test 2 but was more pronounced in Test 3. The causc of this irregularity is not known.

The columns were loeated next to the fire pan, but the airflow through the test chamber resulted in the fire leaning toward the exhaust outlet and away from the columns, so that they were heated primarily by radiation from the fire and the hot gas layer near the eeiling. The sides of the eolumn facing the fire were heated more quickly, with TCU3 (at the ceiling level facing south), TCU2 (at the ceiling level facing east), and TCL2 (at the floor level facing east) reeording maximum temperatures during the tests (Figs. G-3, G-8, and $\mathrm{G}-13$ ). 
The thermocouple naming convention used in the figures is as follows:

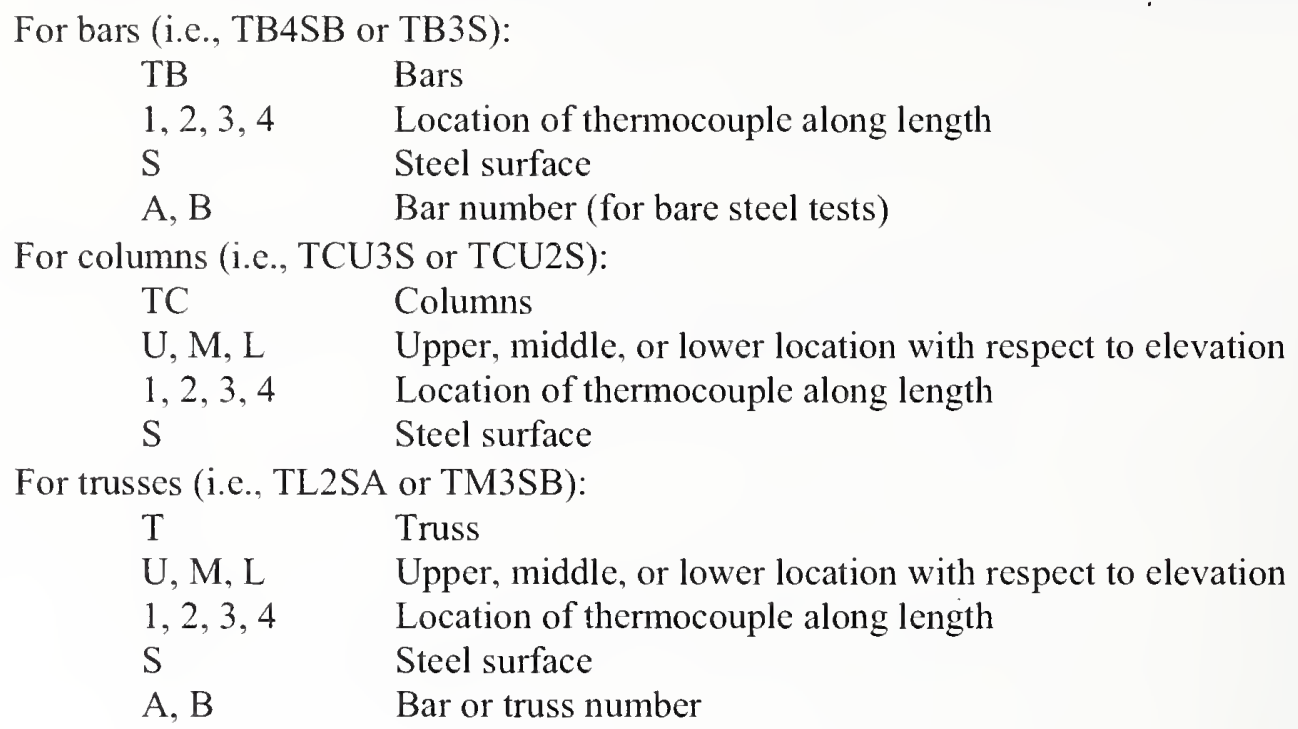

\section{G.1.1 Bare Steel Components Exposed to a $2 \mathrm{MW}$ Fire for 15 Min in Test 1}

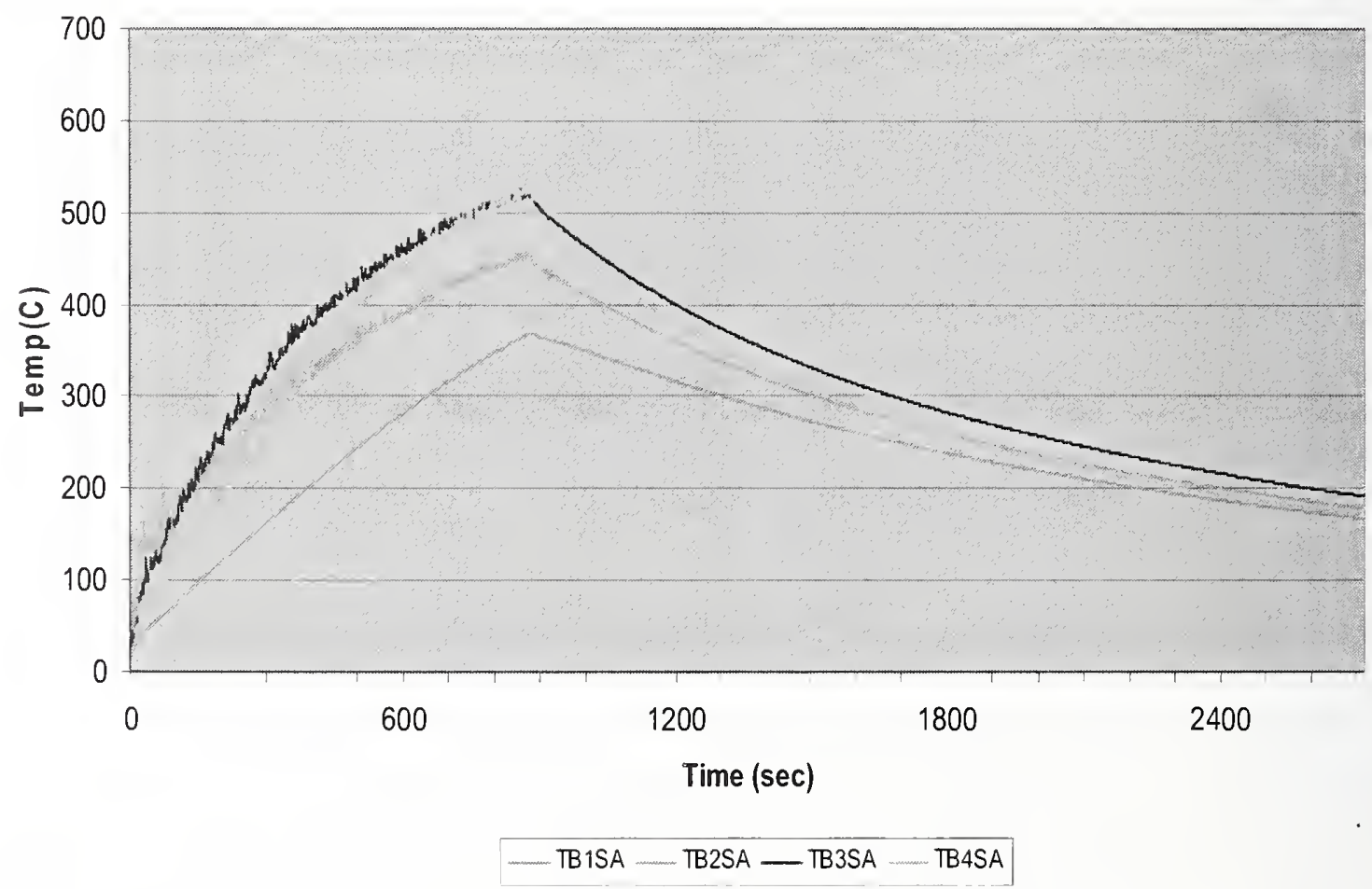

Figure G-1. Bare steel bar A in Test 1. 


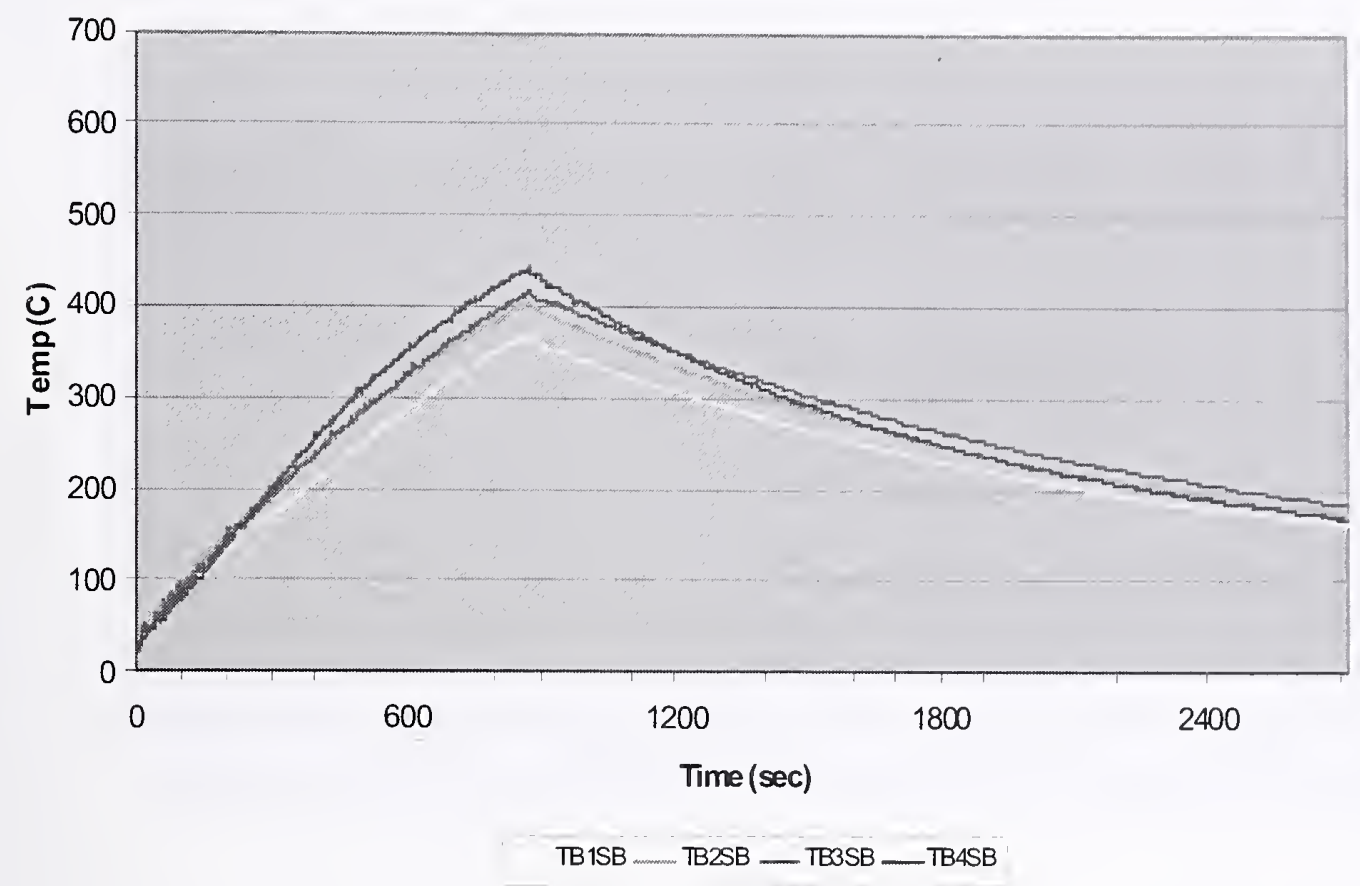

Figure G-2. Bare steel bar B in Test 1.

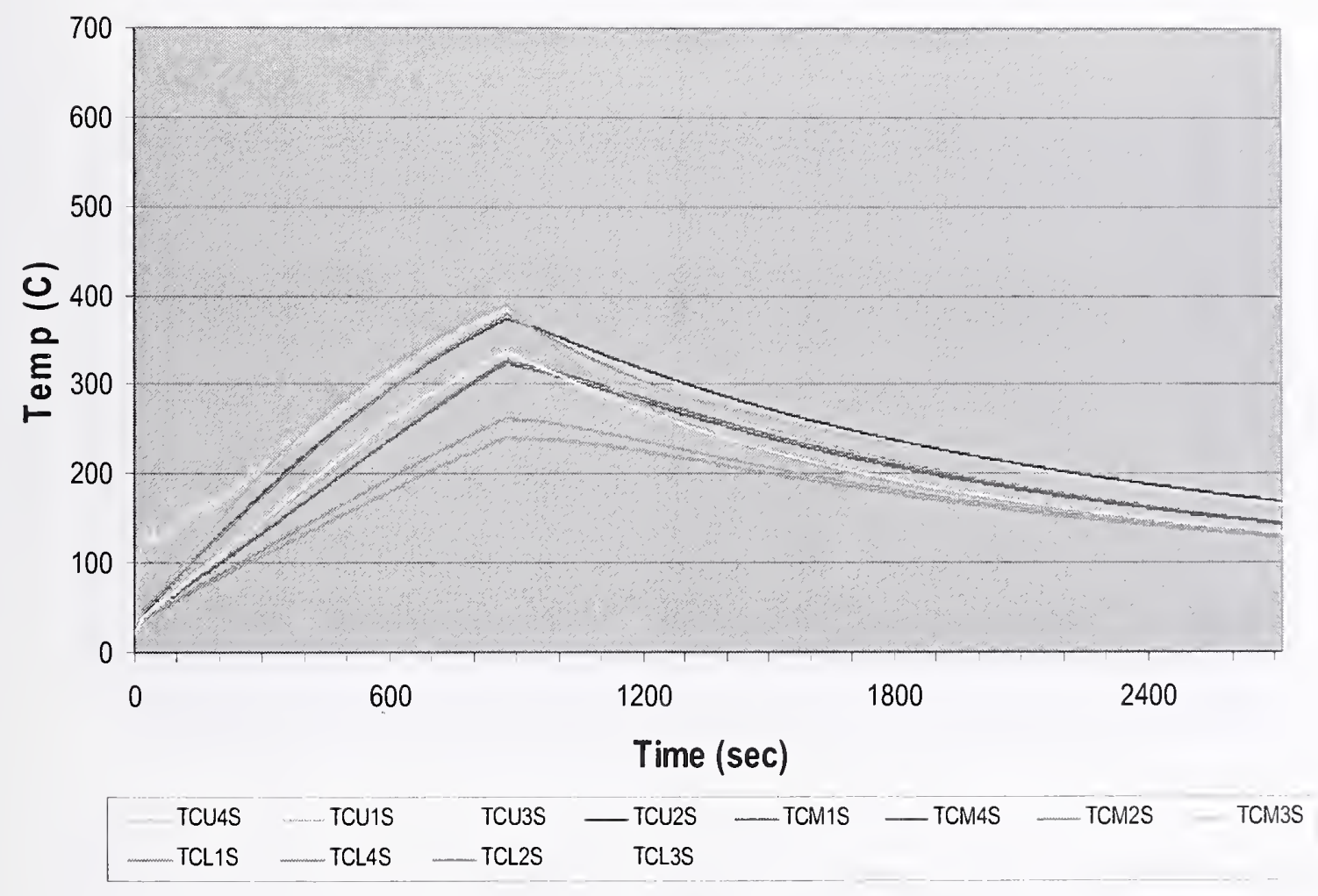

Figure G-3. Bare steel column in Test 1. 


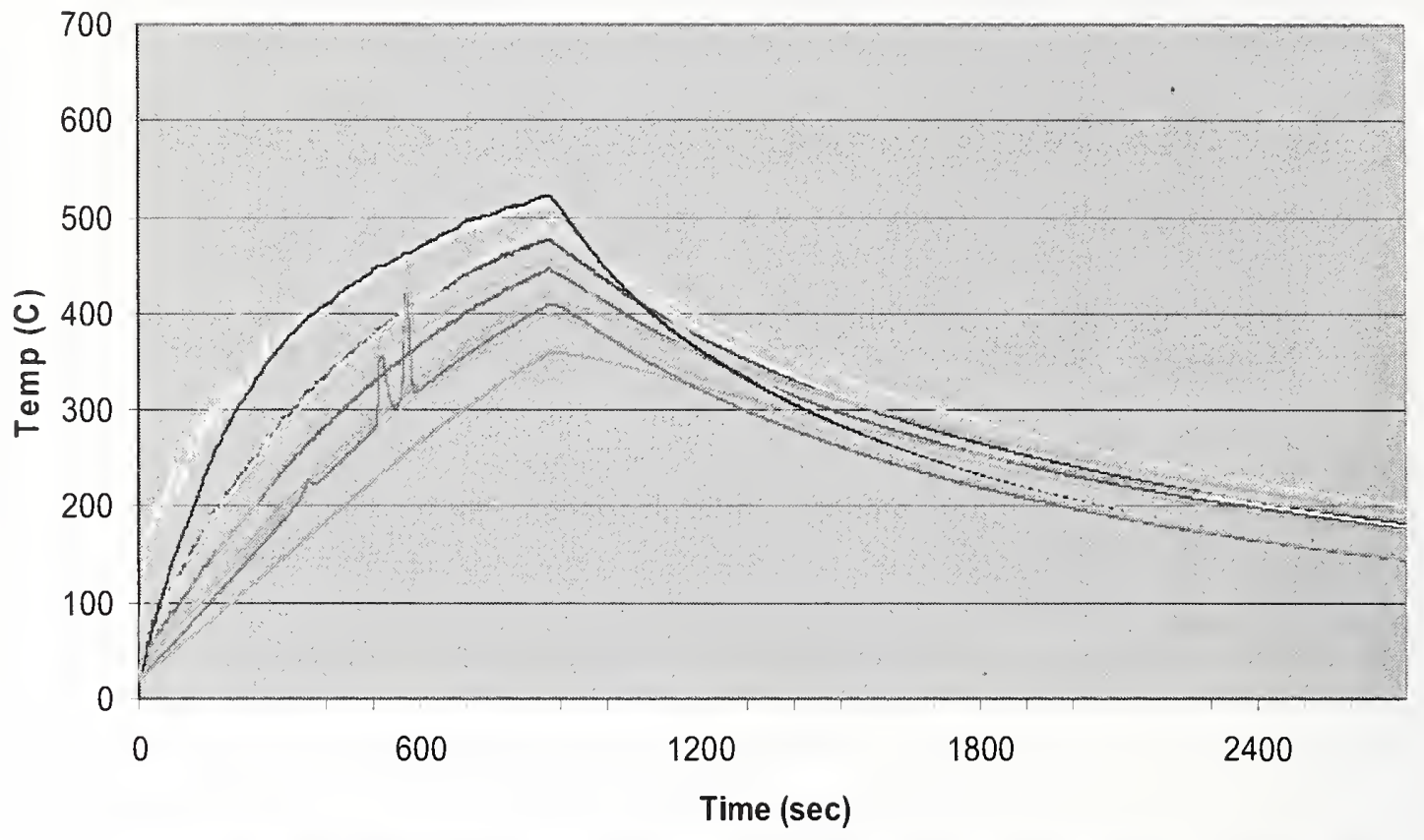

$\begin{array}{rrrrrr}- \text { TU4SA } & \text { TU3SA } & - \text { TU2SA } & \text { TU1SA } & \text { TM4SA TM3SA } & \text { TM2SA } \\ - \text { TL1SA } & \text { TL4SA } & \text { TL3SA } & \text { TL2SA } & \text { TM1SA }\end{array}$

Figure G-4. Bare steel truss A in Test 1.

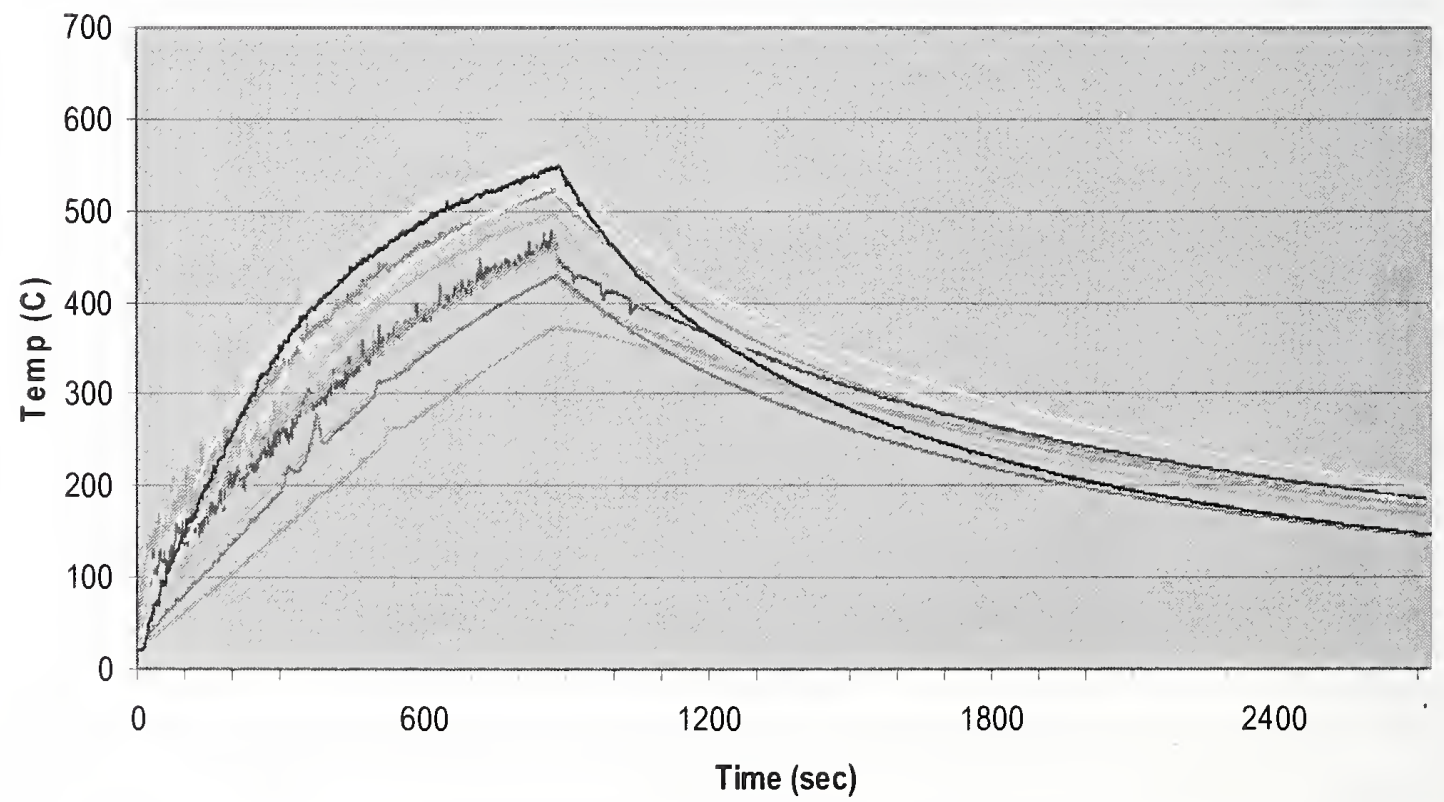

\begin{tabular}{|c|c|c|c|c|c|c|}
\hline TU1SB & TU2SB & TU3SB & TU4SB & TM1SB & - TM2SB & $T M 3 S B-T M 4 S B$ \\
\hline$-\mathrm{TL} 1 \mathrm{SB}$ & $-\mathrm{TL} 2 \mathrm{SB}$ & TL3SB & $\ldots$ TL4SB & & & \\
\hline
\end{tabular}

Figure G-5. Bare steel truss B in Test 1. 


\section{G.1.2 Bare Steel Components Exposed to a 3 MVV Fire for 7 Min in Test 2}

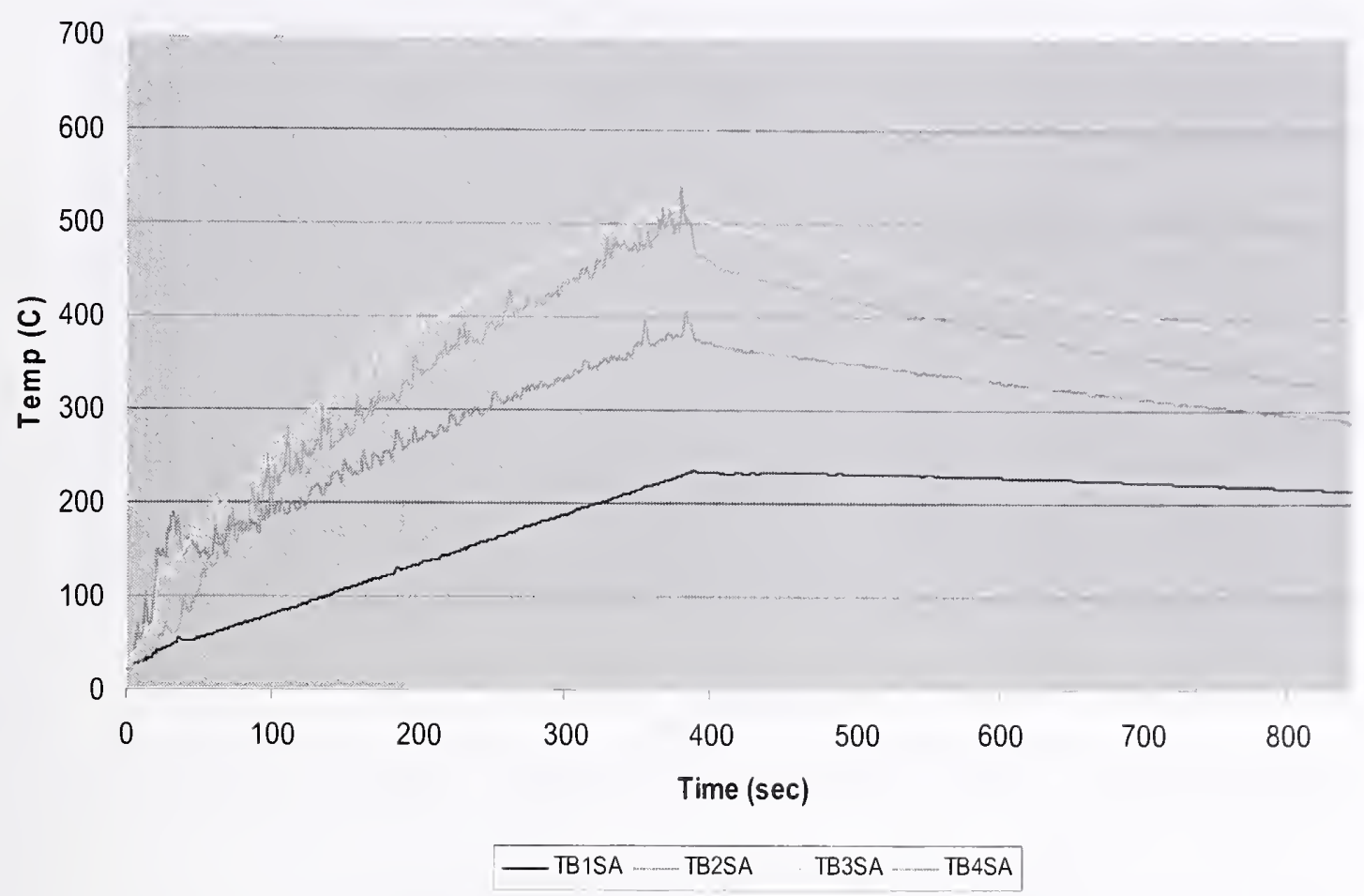

Figure G-6. Bare steel bar A in Test 2.

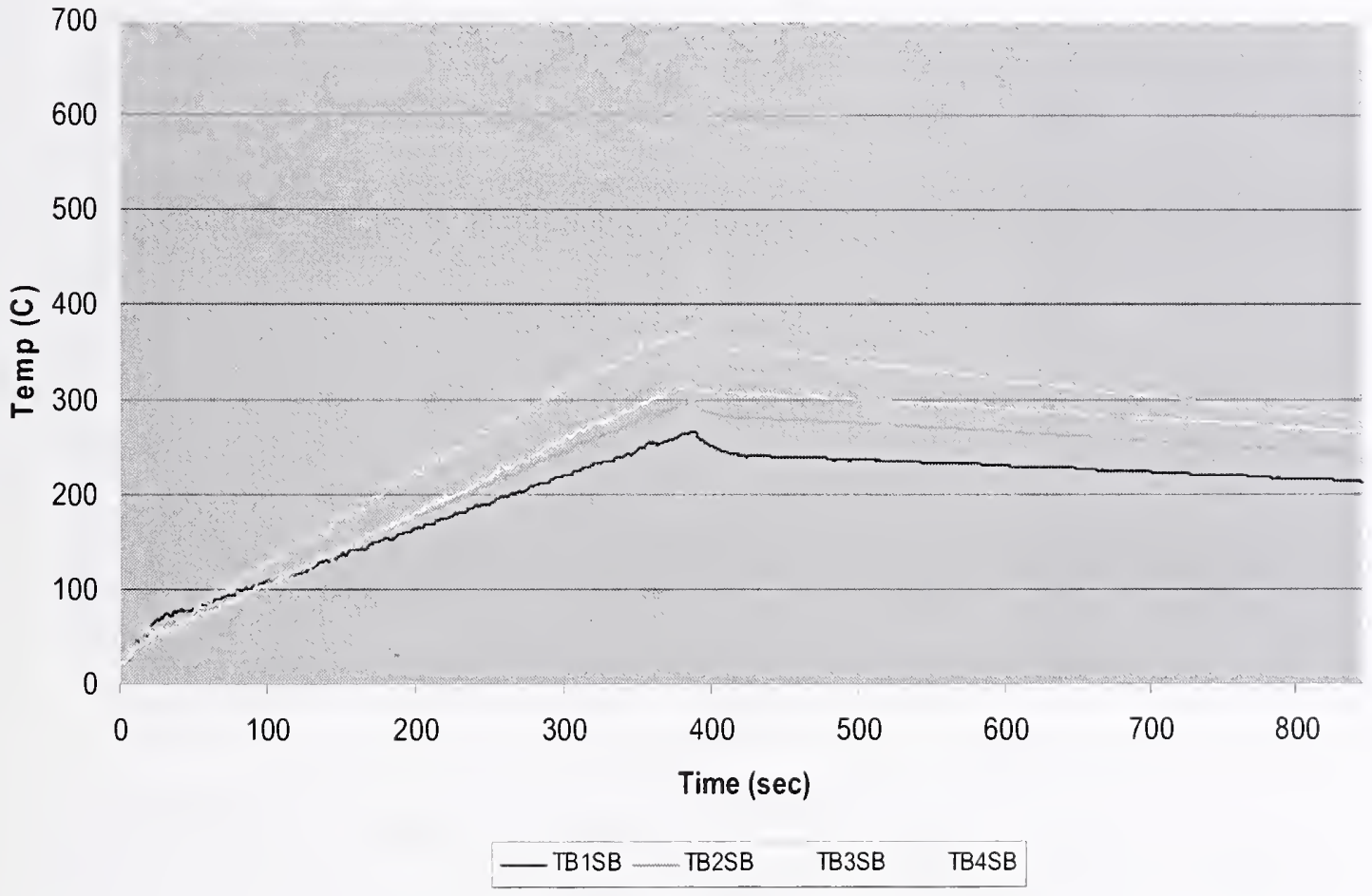

Figure G-7. Bare steel bar B in Test 2. 


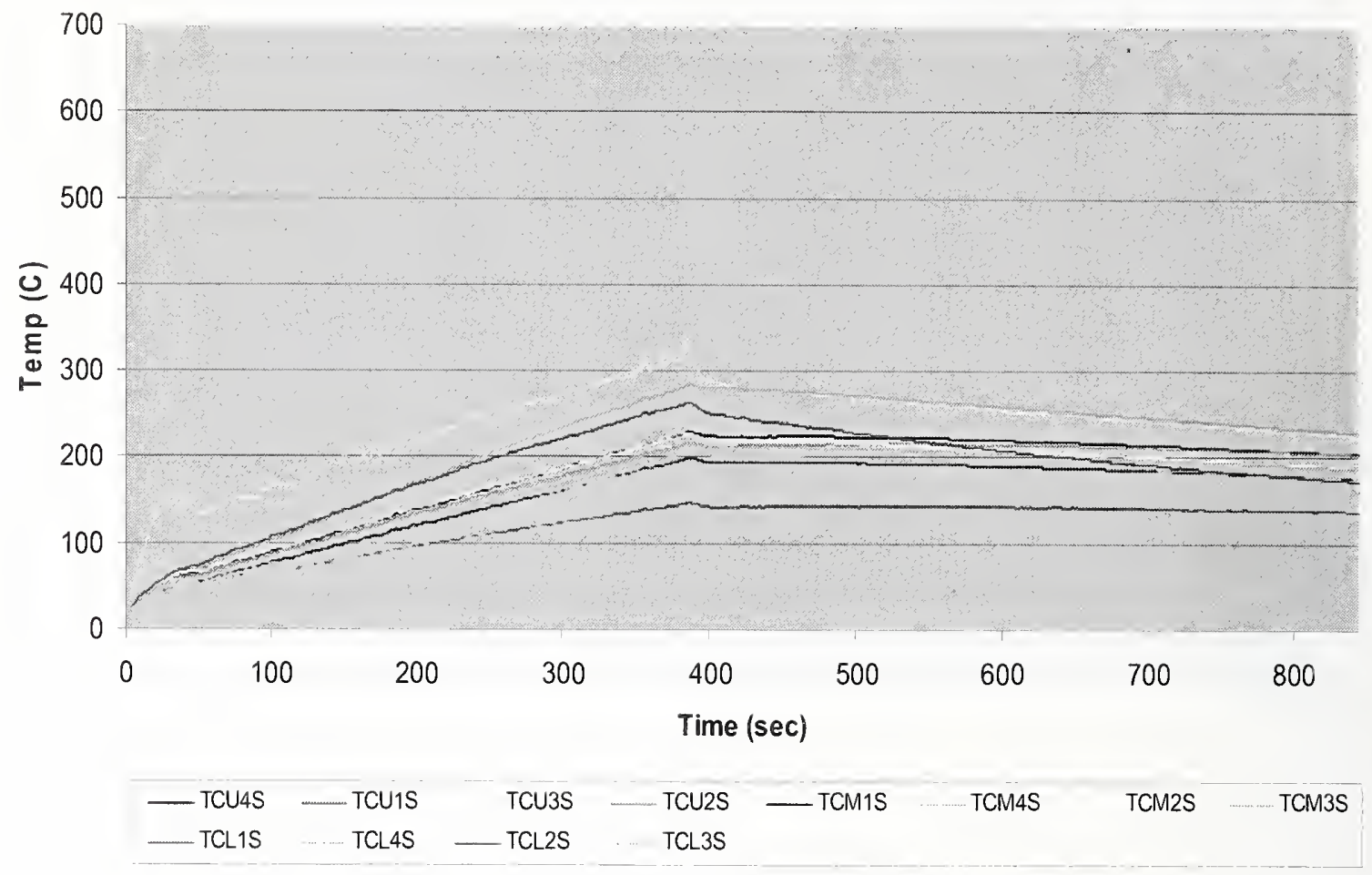

Figure G-8. Bare steel column in Test 2.

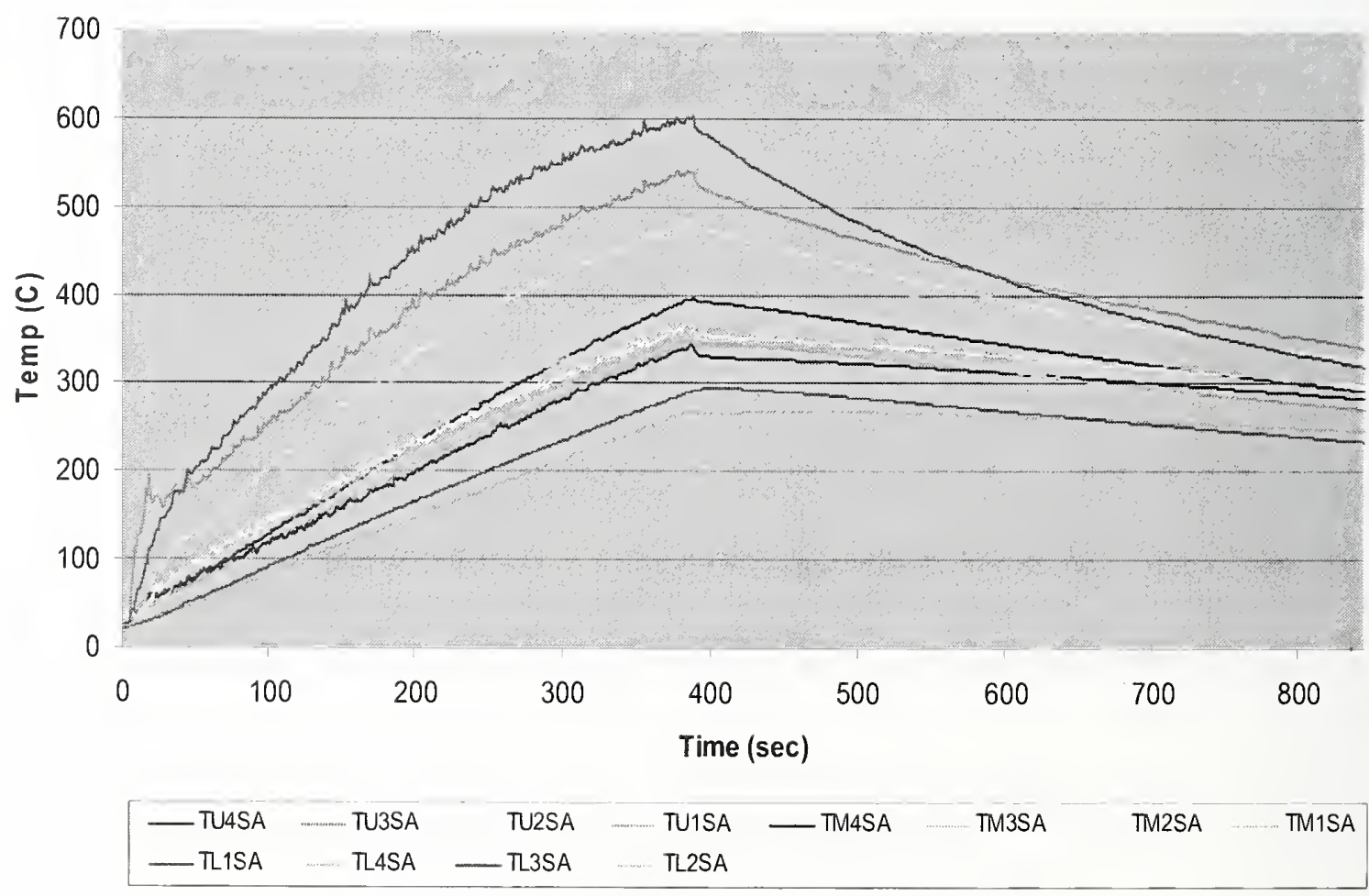

Figure G-9. Bare steel truss A in Test 2. 


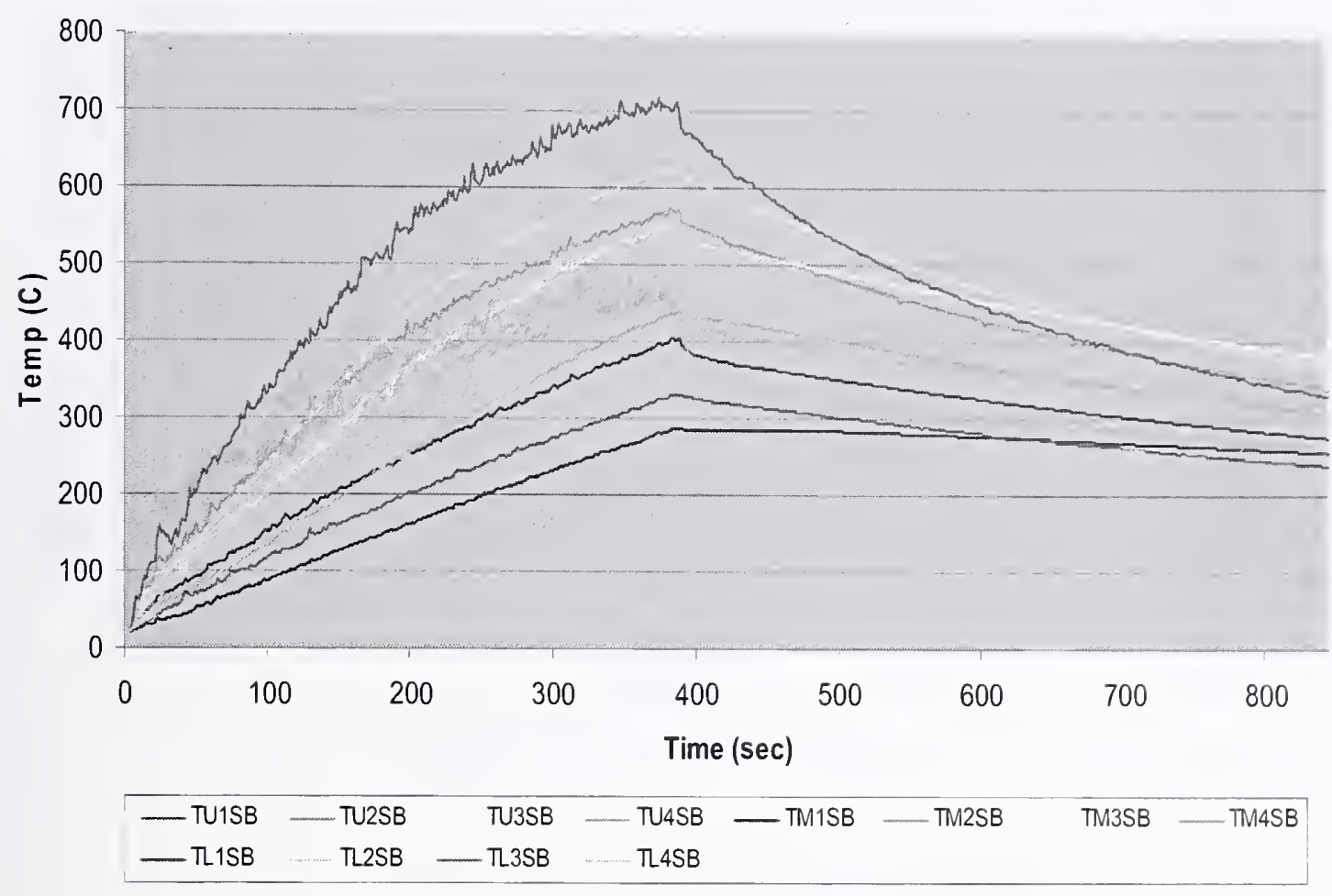

Figure G-10. Bare steel truss B in Test 2.

\section{G.1.3 Bare Steel Components Exposed to a 2 MW Fire for 15 Min in Test 3}

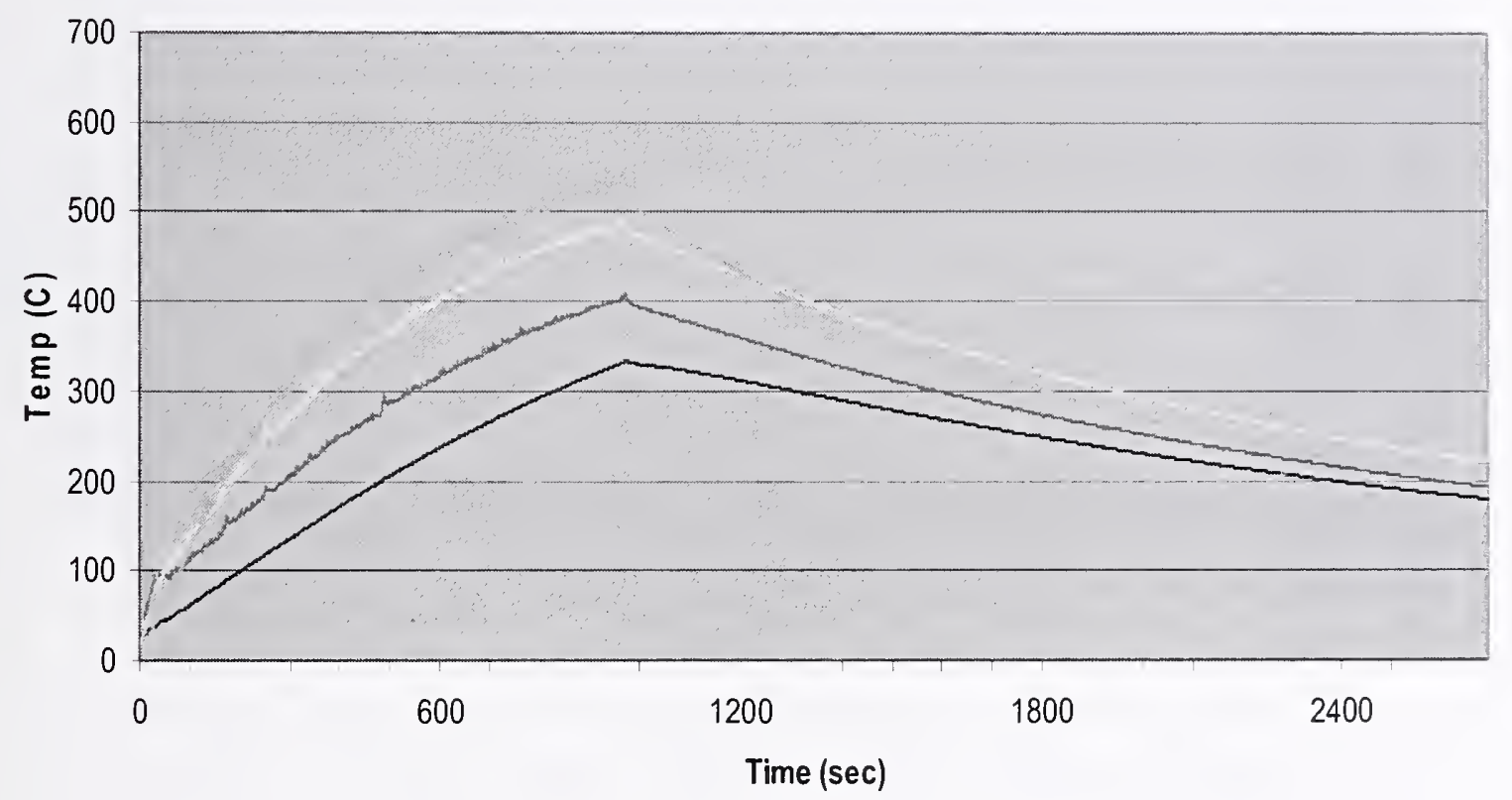

- TB1SA - TB2SA TB3SA TB4SA

Figure G-11. Bare steel bar A in Test 3. 


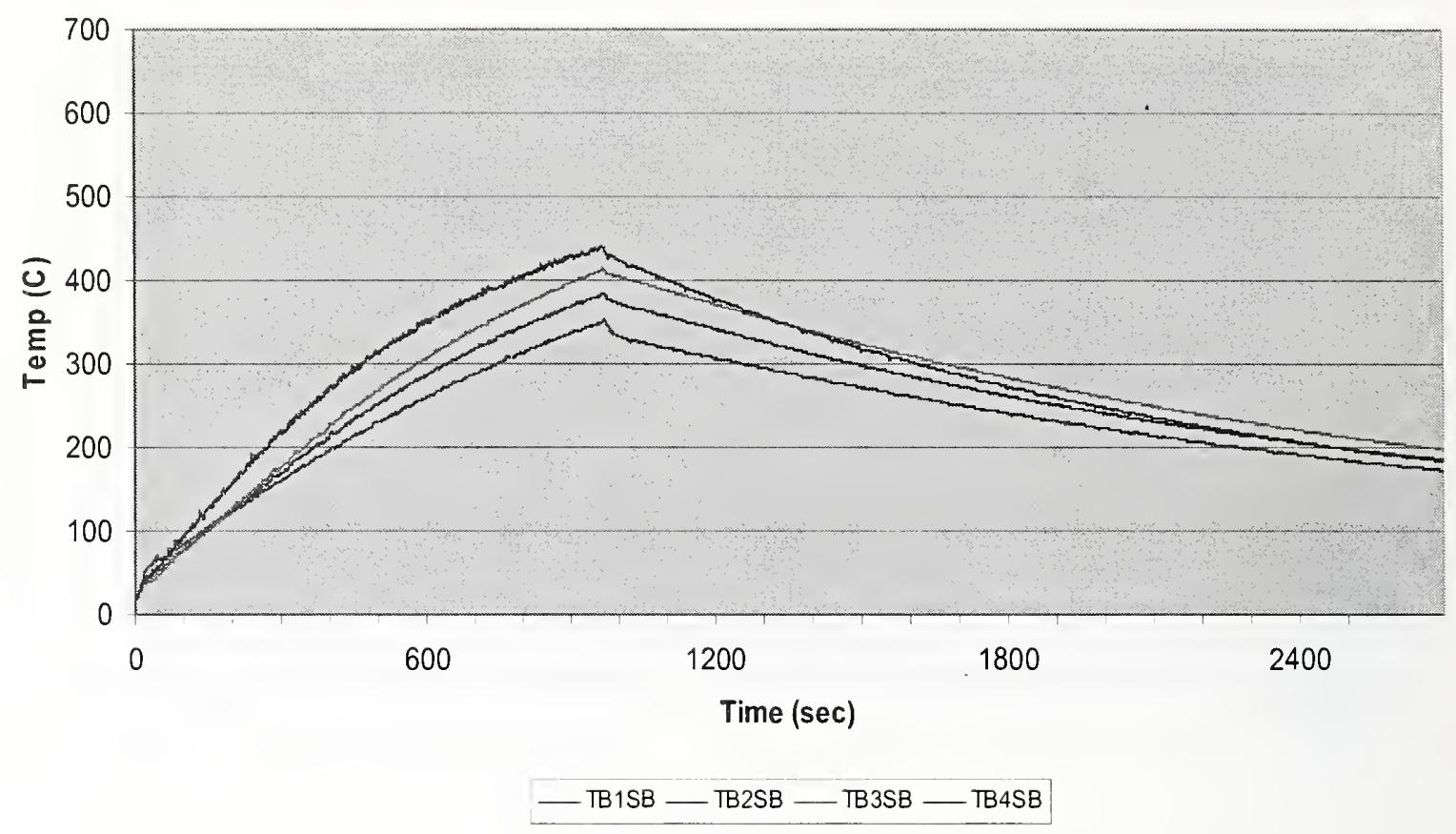

Figure G-12. Bare steel bar B in Test 3.

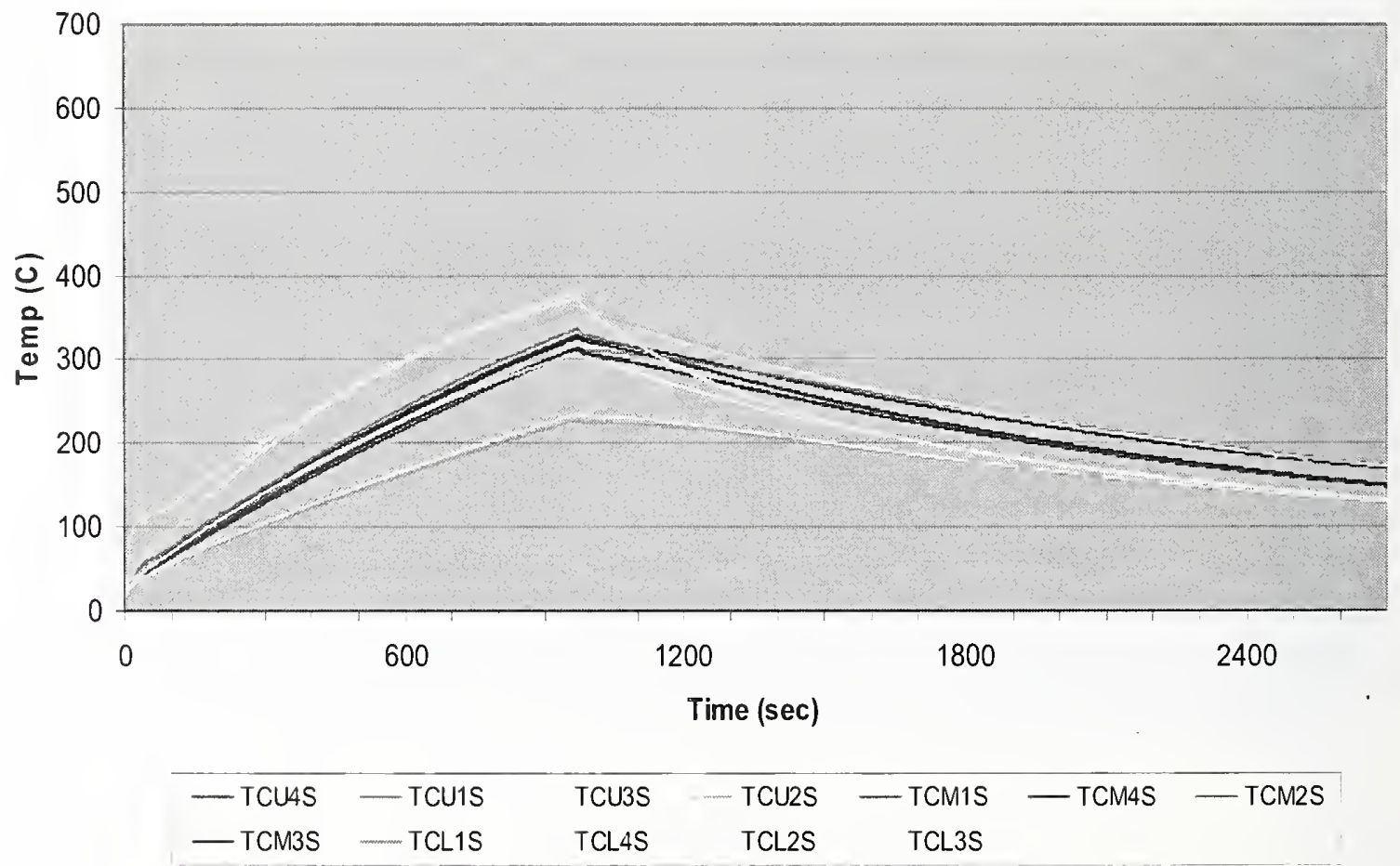

Figure G-13. Bare steel column in Test 3. 


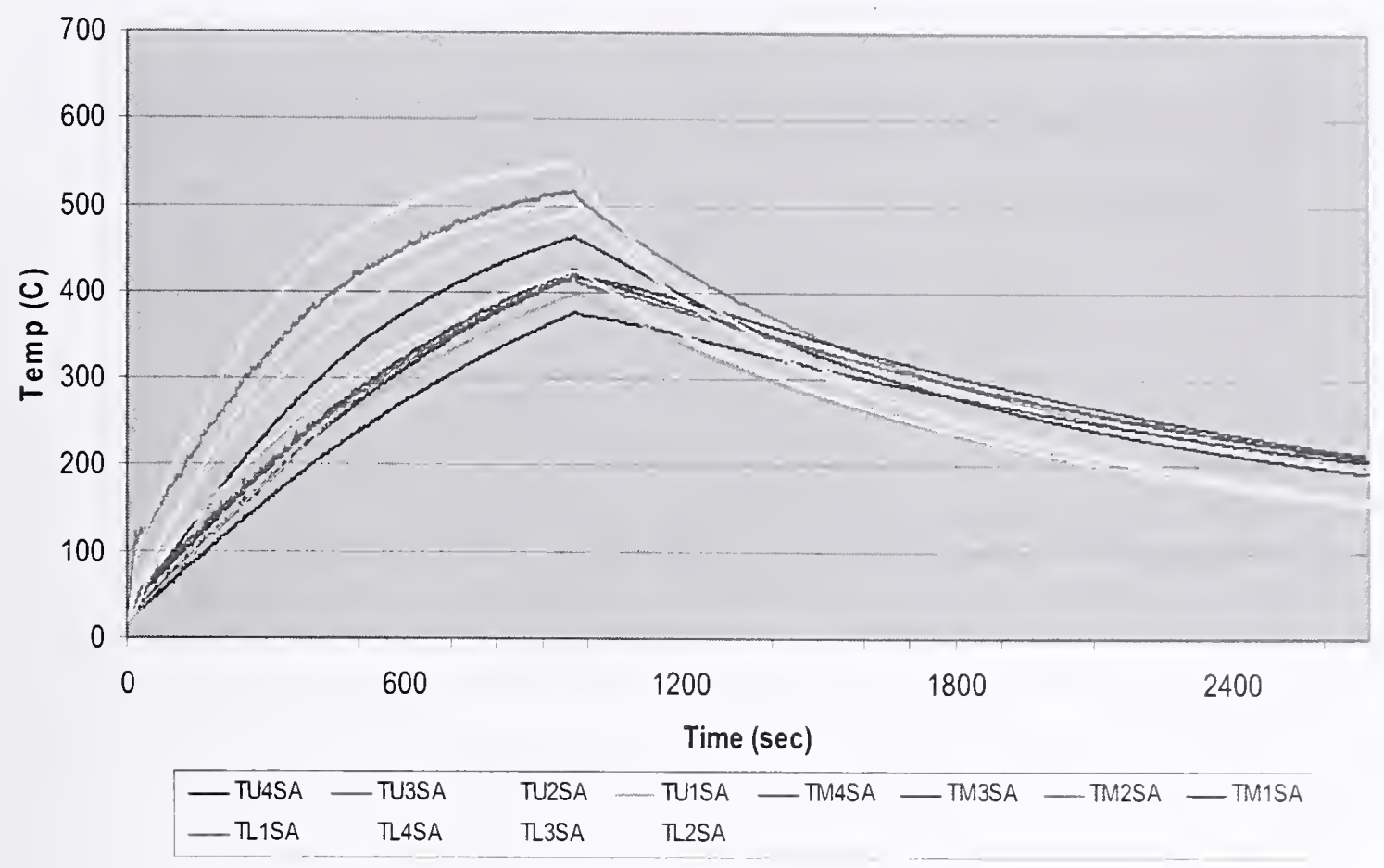

Figure G-14. Bare steel truss A in Test 3.

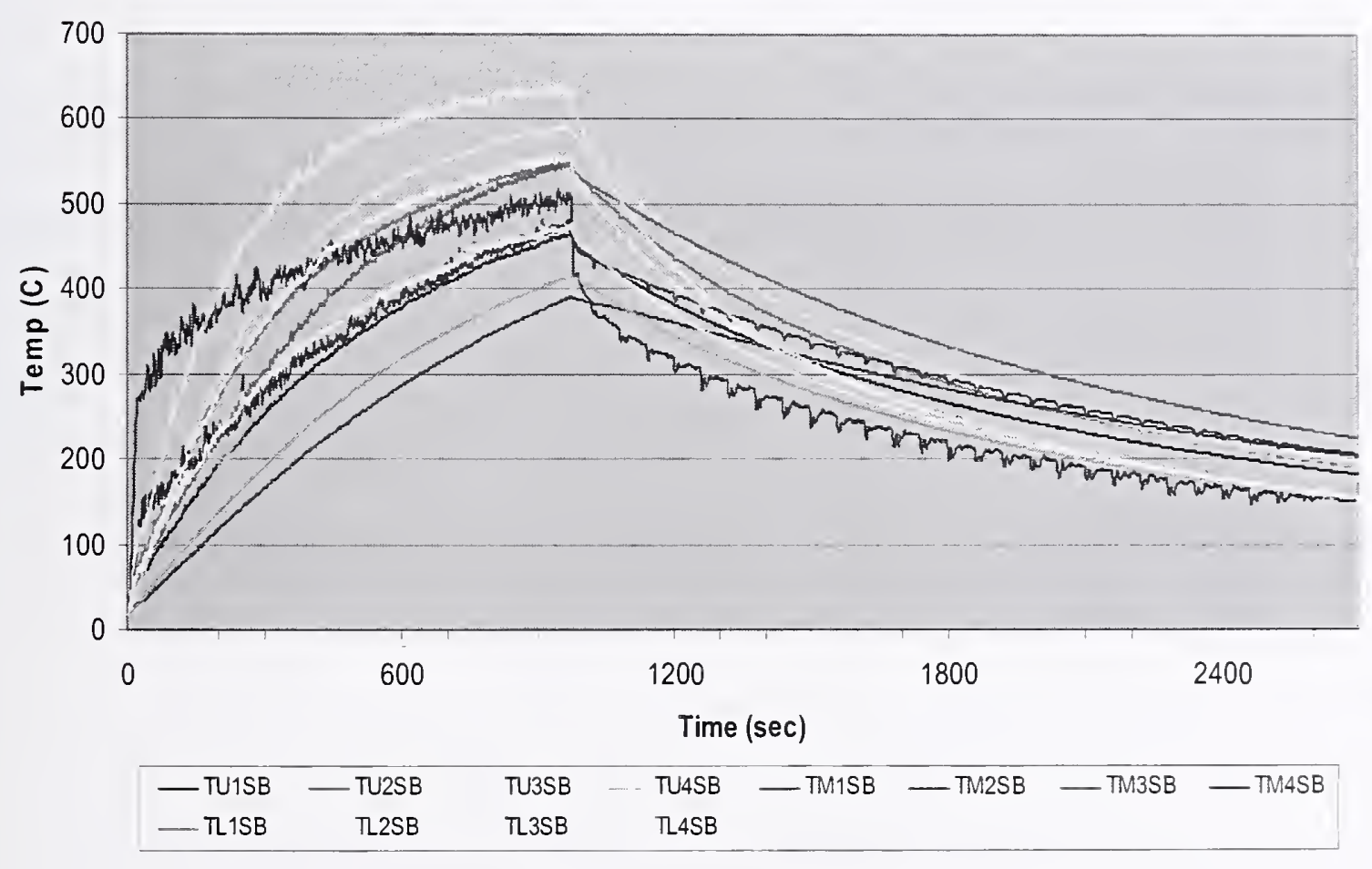

Figure G-15. Bare steel truss B in Test 3. 


\section{G.2 INSULATED STEEL COMPONENTS}

Tests 5 and 6 exposed separate sets of one bar, one column, and two trusses, insulated with sprayed fireresistive materials (SFRM), to direct exposure of heat flux and temperatures from a fuel pan fire. Test 4 was truncated after approximately $15 \mathrm{~min}$, due to a malfunction of the thermocouples that started a few minutes after the tests began. As no useful steel temperature data was obtained, Test 4 data are not included in this report. Test 5 SFRM and steel surface temperatures are shown in Sec. G.2.1, Figs. G-16 through G-19; Test 6 temperatures are shown in Sec. G.2.2, Figs. G-20 through G-23.

In both tests, the thermal response of these components to flame proximity or immersion was similar. The SFRM surface began to heat immediately upon initiation of the fire, reaching close to their peak temperatures in $5 \mathrm{~min}$ to $10 \mathrm{~min}$, and to cool immediately after the fire was extinguished. The protected steel responded more slowly, taking approximately $50 \mathrm{~min}$ with $1.91 \mathrm{~cm}(0.75 \mathrm{in}$.) of SFRM to reach $600{ }^{\circ} \mathrm{C}$ temperatures as compared to $7 \mathrm{~min}$ when bare steel was subjected to a similar $3 \mathrm{MW}$ fire. The steel temperature rise was essentially uniform for all thermocouples until the steel temperatures reached $100{ }^{\circ} \mathrm{C}$, when the rate of temperature rise increased for all thermocouples, but at different rates. Steel temperatures continued to rise approximately $25^{\circ} \mathrm{C}$ to $50{ }^{\circ} \mathrm{C}$ after the fire was extinguished over a 5 min to $10 \mathrm{~min}$ period, before cooling began to take place by transmitting heat through the insulation back into the relatively cooler gases.

The bar in each test was located over the fire and recorded similar tempcratures for the SFRM and steel surface. Thermocouples TB1S and TB4S in Test 5 (Fig. G-16) were damaged during the SFRM application process. Thermocouples TB4 in Test 6 (Fig. G-20) showed some signal noise in the cool down phase in Test 1 after the fire was extinguished. The cause of this noise is not known.

The columns were located next to the fire pan, but the fire leaned toward the exhaust outlet and away from the columns, so that they were heated primarily by radiation from the hot gas layer near the ceiling. In Test 5 (Fig. G-17), the steel temperature rise was uniform for all thermocouples until the steel temperatures reached $100{ }^{\circ} \mathrm{C}$, when the rate of temperature rise increased for all the thermocouples but at different rates. Note that thermocouple TCU1S in Test 5 was damaged during the SFRM application process. In Test 6 (Fig. G-21), however, the steel temperatures increased at different rates during the entire test. Reasons for the difference in the steel surface response between these two column tests are not apparent. (A short in the thermocouple signal appeared around 1,500 s to 1,600 s, but the recorded temperatures appear to be reasonable after this event and have been assumed to be correct records of the actual temperatures.) Test 5 steel temperatures at $50 \mathrm{~min}$ were approximately half of the steel temperatures in Test 6 , reflecting the increased nominal thickness of SFRM from $1.91 \mathrm{~cm}$ to $3.81 \mathrm{~cm}$ ( $0.75 \mathrm{in}$. to $1.5 \mathrm{in}$.). The upper portion of the columns near the ceiling heated more quickly than the rest of the column, due to the continual presence of a hot gas layer near the ceiling.

As in the bare steel tests, both truss A and truss B were located over the fire pan, but the fire primarily immersed truss B in flames. The trusses with $1.91 \mathrm{~cm}\left(0.75 \mathrm{in}\right.$.) of SFRM reached $100{ }^{\circ} \mathrm{C}$ in approximately $10 \mathrm{~min}$ (Figs. G-18, G-22, and G-23), and truss B in Test 5 with $3.81 \mathrm{~cm}(1.5 \mathrm{in}$.) of SFRM in Test 5 reached $100^{\circ} \mathrm{C}$ steel temperatures in $25 \mathrm{~min}$ (Fig. G-19), reflecting the effects of increased SFRM thickness. Thermocouples TM3IB and TL3IB became erratic approximately 35 min into Test 5 (these thermocouples are on the SFRM surface and subject to flame immersion during the test). Some of the other SFRM surface thermocouples also recorded abrupt jumps in their temperatures around 
this time, but the steel temperatures appear to be unaffected. Thermocouple TM3SA for truss A in Test 5 was damaged during the SFRM application process.

The thermocouple naming convention used in the figures is as follows:

For bars (i.e., TB4SB or TB3I):

TB
$1,2,3,4$
S
I

A, B
Bars

Location of thermocouple along length

Steel surface

Insulation (SFRM) surface

Bar number (for bare steel tests)

For columns (i.e., TCU3S or TCU2I):

TC

\section{$\mathrm{U}, \mathrm{M}, \mathrm{L}$}

$1,2,3,4$

$\mathrm{S}$

Columns

I

Upper, middle, or lower location with respect to elevation

Location of thermocouple along length

Steel surface

Insulation (SFRM) surface

For trusses (i.e., TL2SA or TM3IB):

$\mathrm{T}$

$\mathrm{U}, \mathrm{M}, \mathrm{L}$

$1,2,3,4$

$\mathrm{S}$

Truss

I

Upper, middle, or lower location with respect to elevation

Location of thermocouple along length

Steel surface

A, B

Insulation (SFRM) surface

Bar or truss number

\section{G.2.1 Insulated Steel Components Exposed to a 3 MW Fire for 50 Min in Test 5}

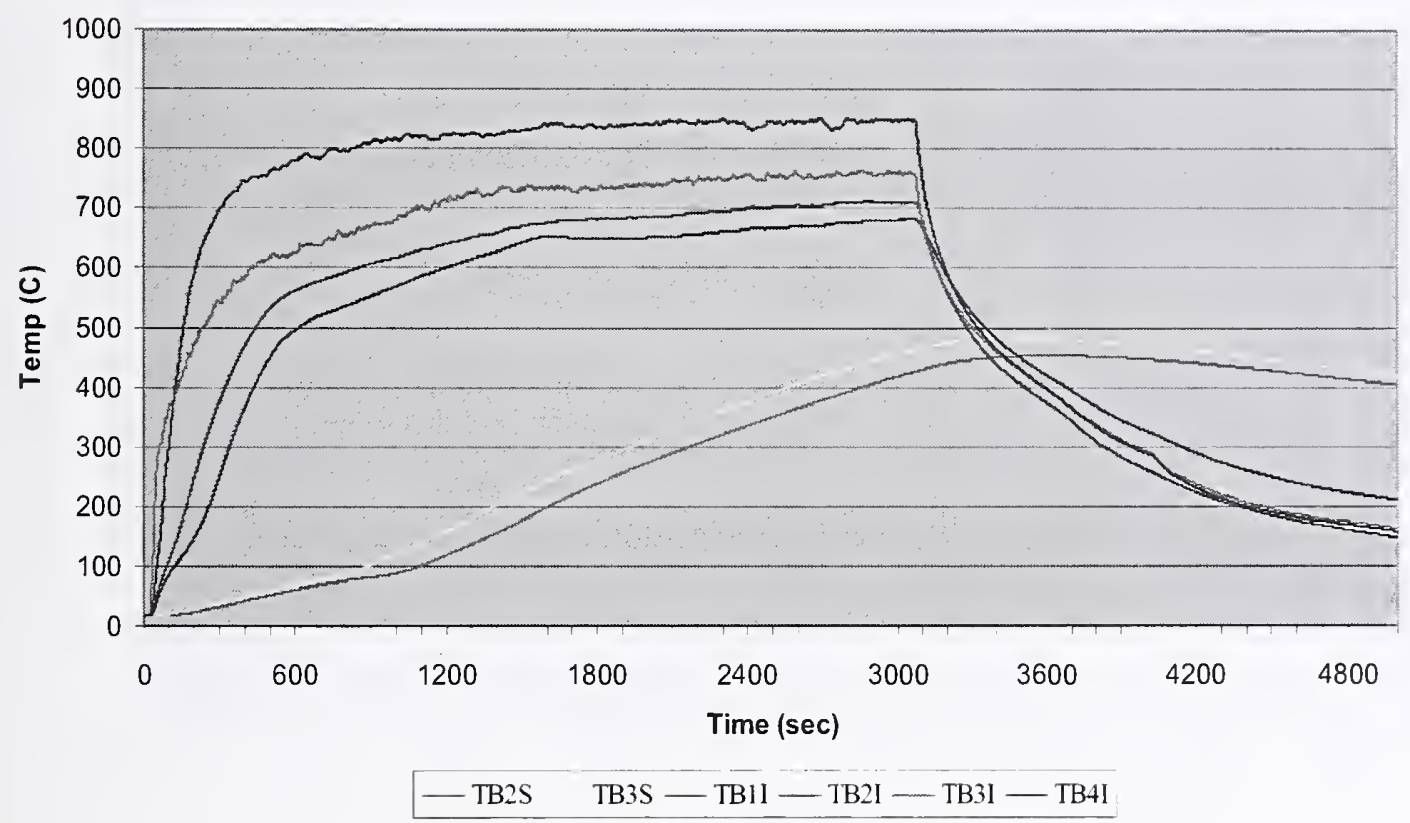

Figure G-16. Insulated (1.91 cm SFRM) steel bar in Test 5. 


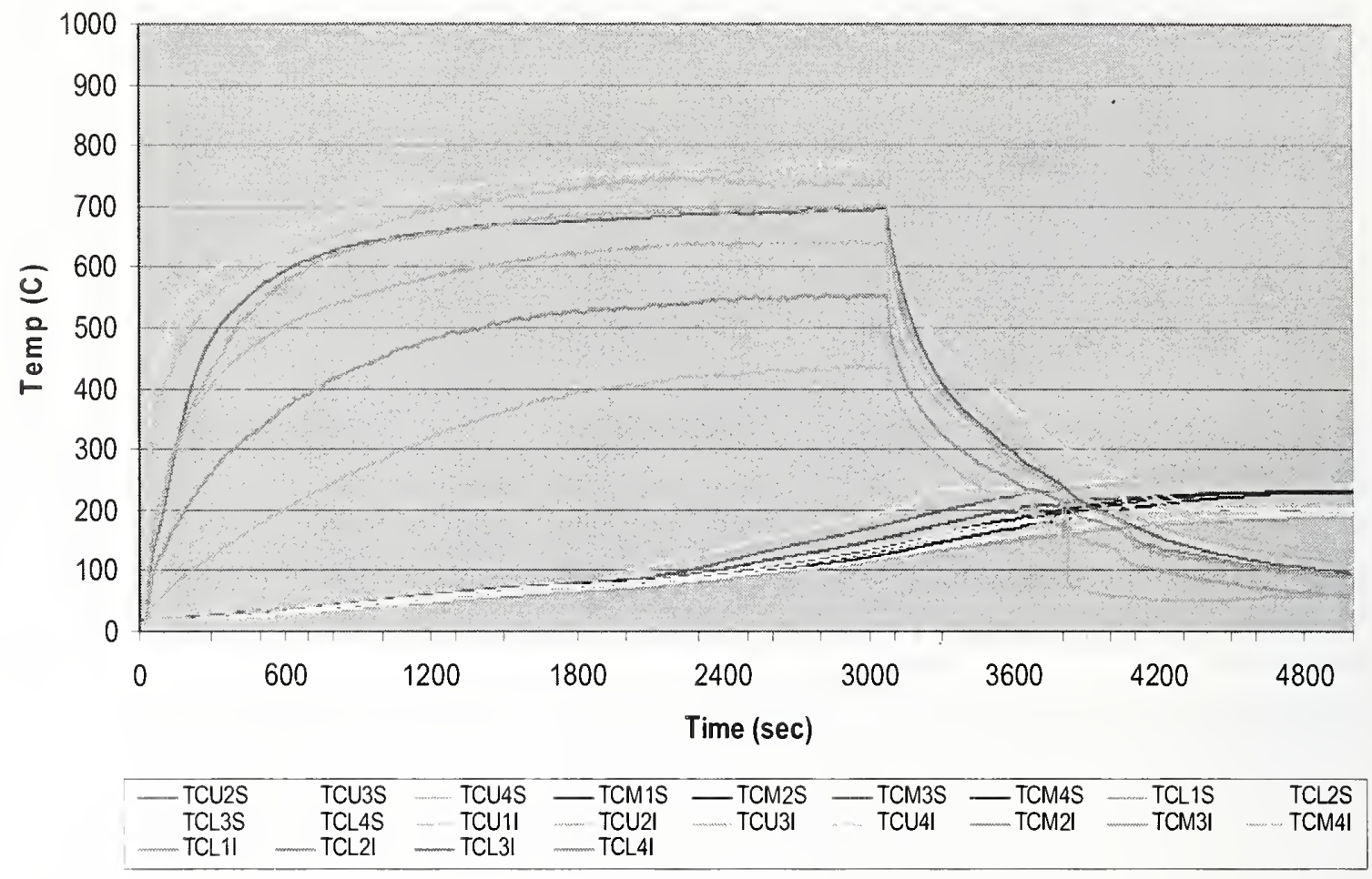

Figure G-17. Insulated (3.81 cm SFRM) steel column in Test 5.

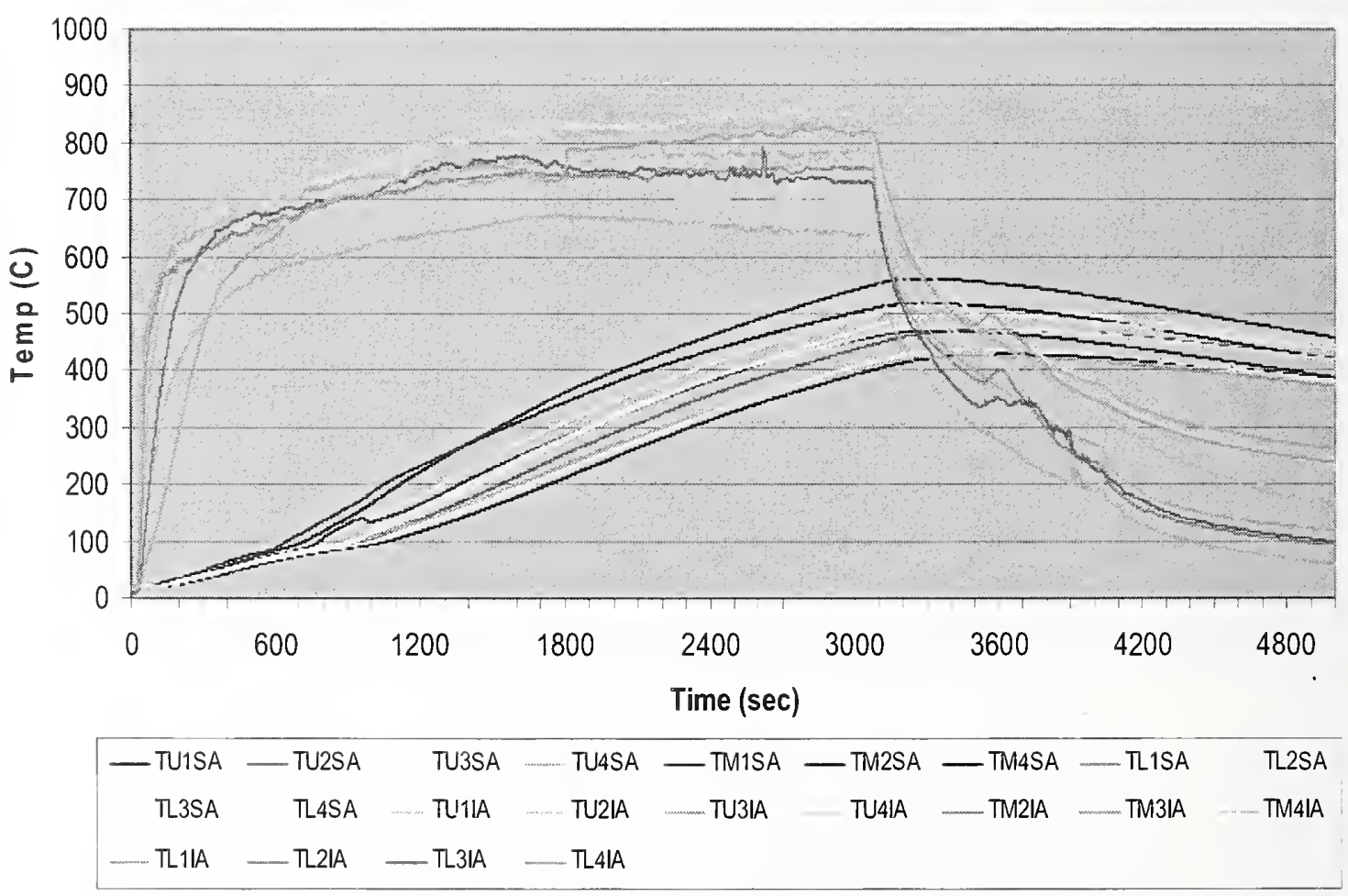

Figure G-18. Insulated (1.91 cm SFRM) steel truss A in Test 5. 


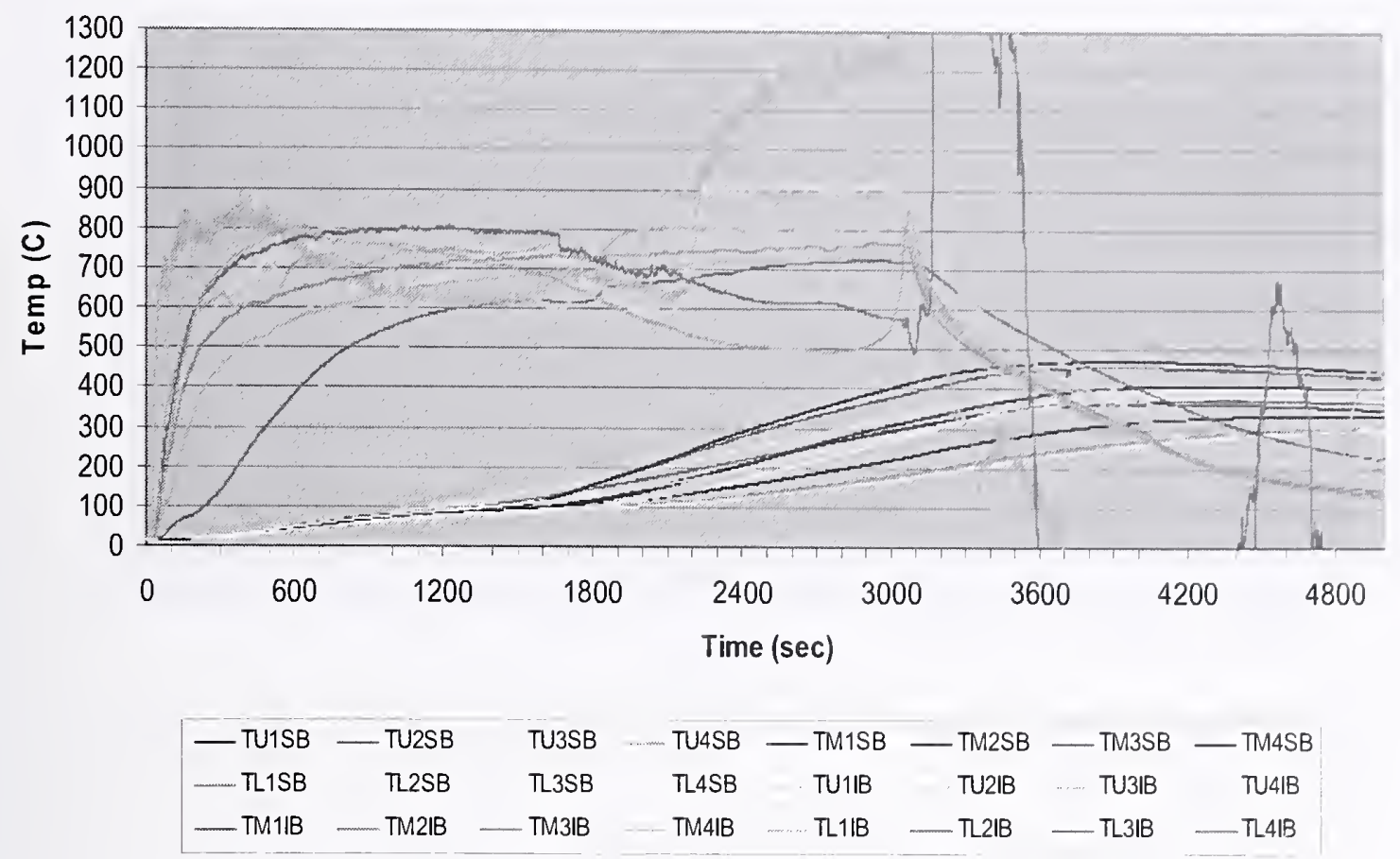

Figure G-19. Insulated (3.81 cm SFRM) steel truss B in Test 5.

\section{G.2.2 Insulated Steel Components Exposed to a 3 MW Fire for 50 Min in Test 6}

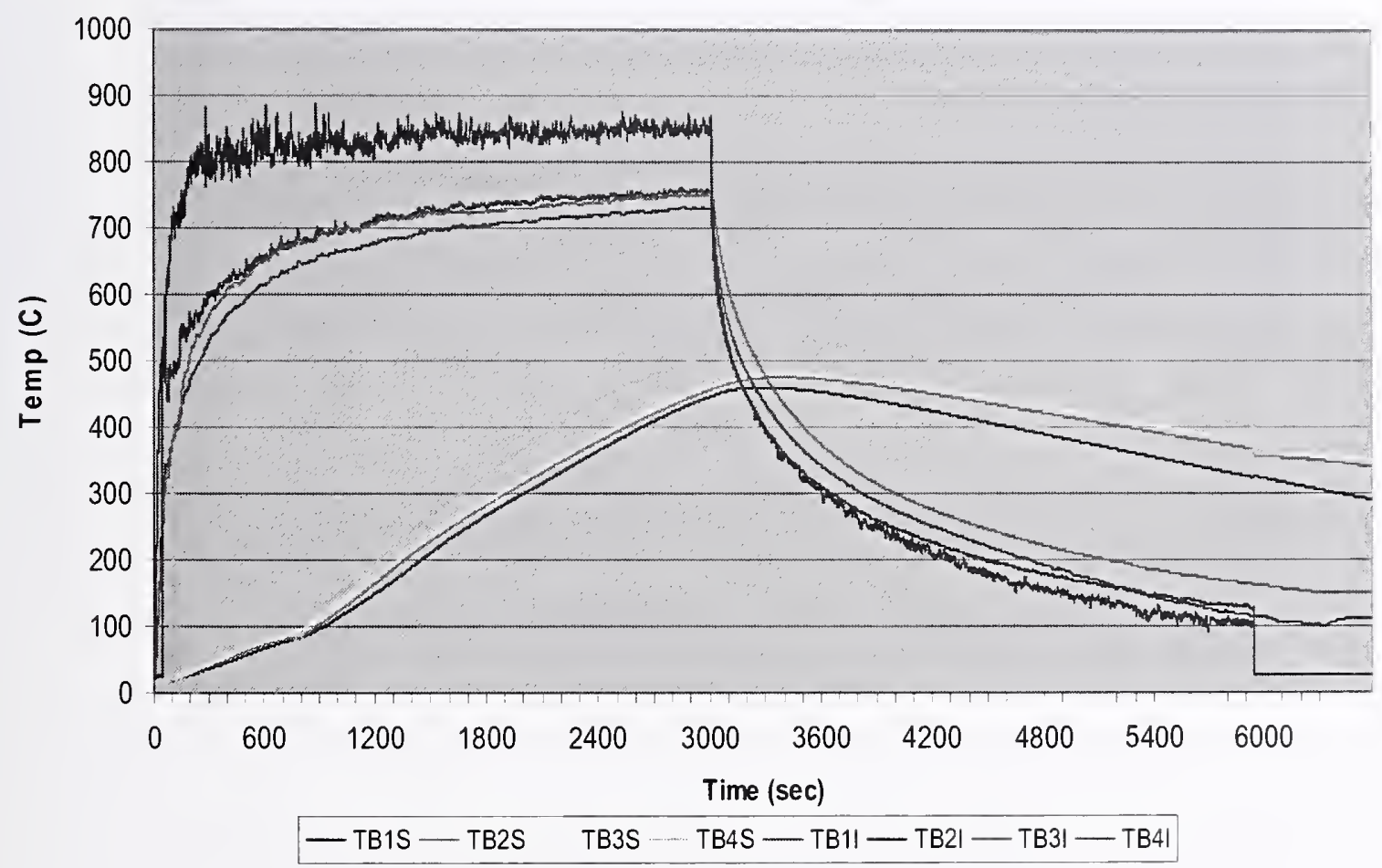

Figure G-20. Insulated (1.91 cm SFRM) steel bar in Test 6. 


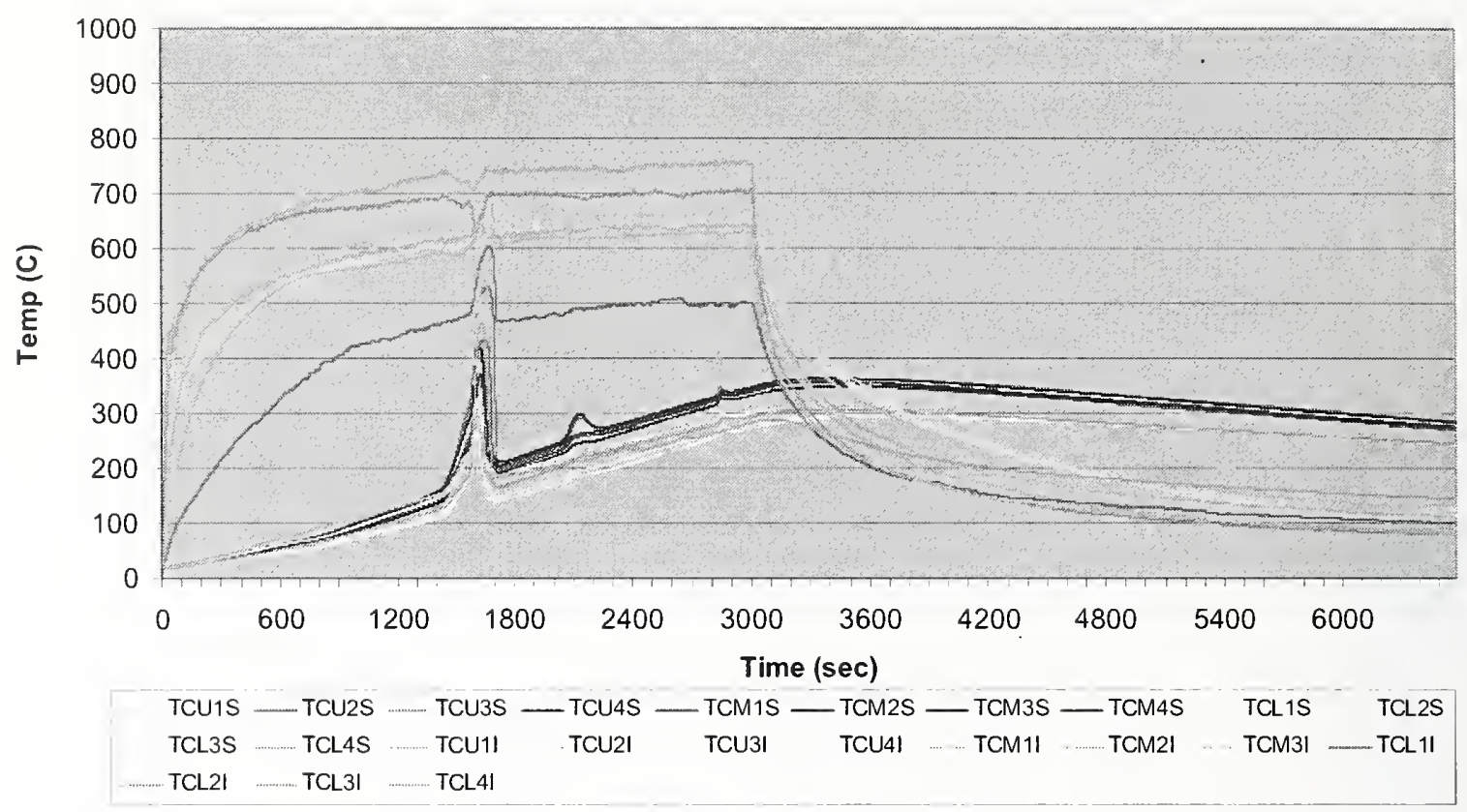

Figure G-21. Insulated (1.91 cm SFRM) steel column in Test 6.

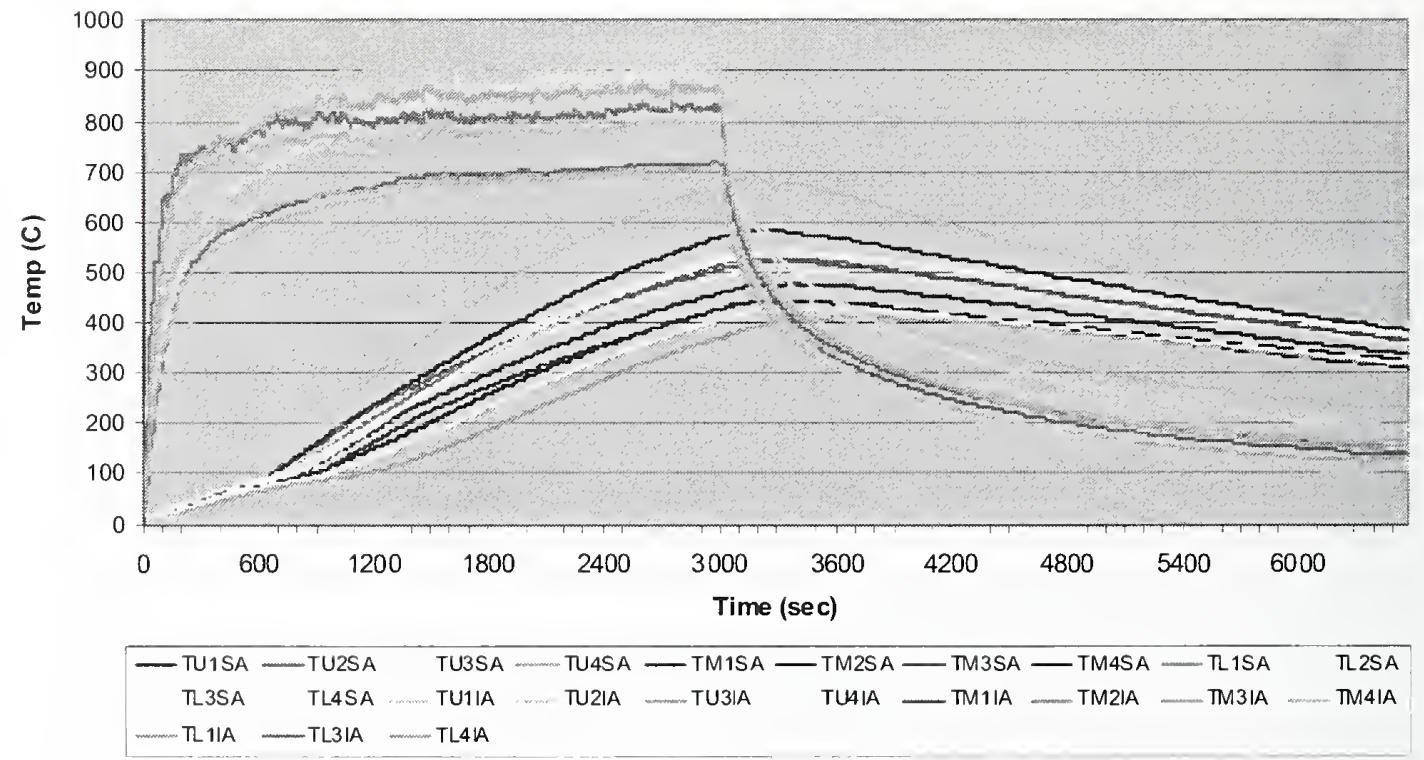

Figure G-22. Insulated (1.91 cm SFRM) steel truss A in Test 6. 


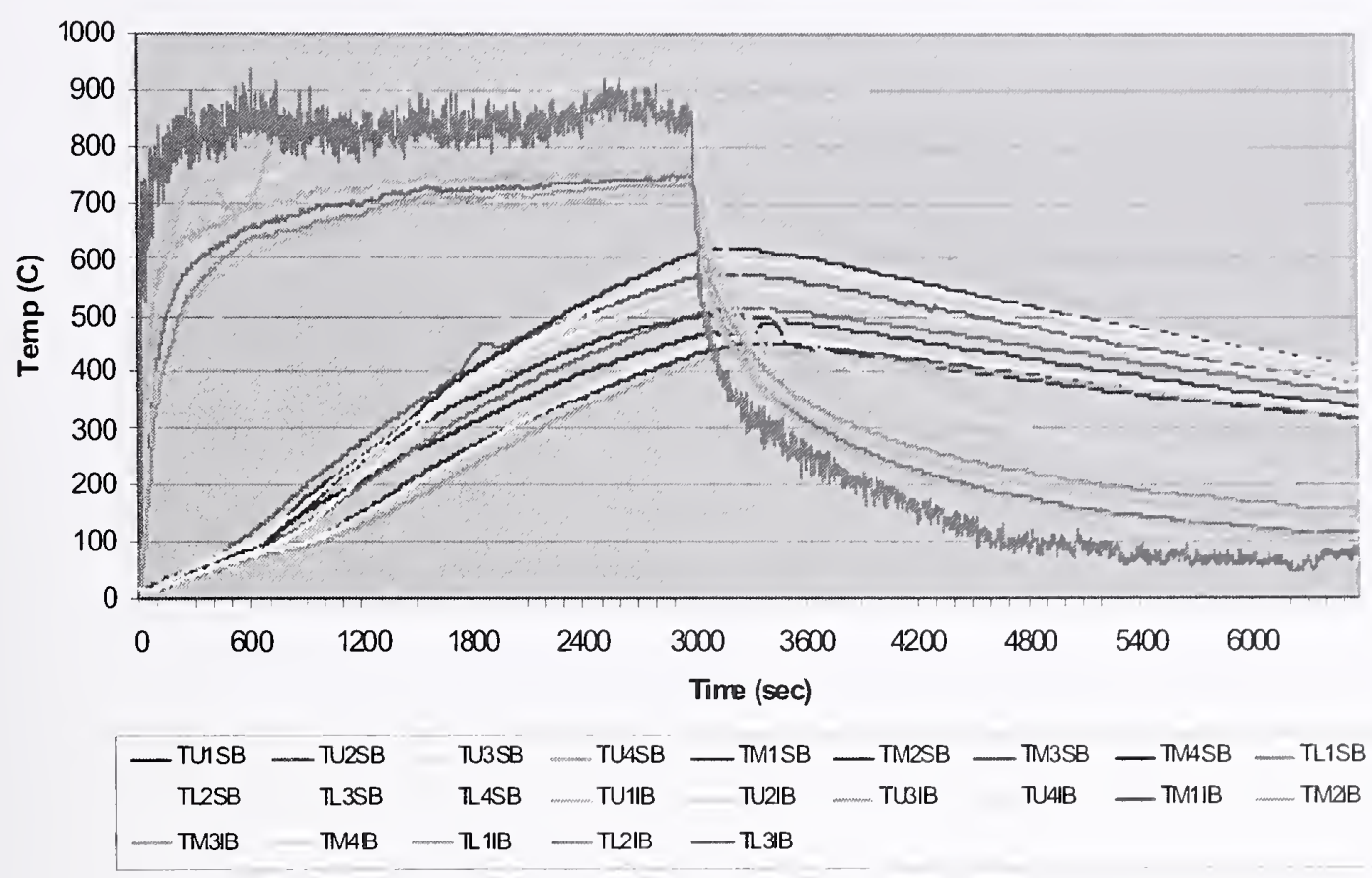

Figure G-23. Insulated (1.91 cm SFRM) steel truss B in Test 6. 
This page intentionally left blank. 
